REMOVING OIL FROM FRIED FOODS VIA MECHANICAL PROCESS

\author{
A Thesis \\ presented to \\ the Faculty of California Polytechnic State University, \\ San Luis Obispo \\ In Partial Fulfillment \\ of the Requirements for the Degree \\ Master of Science in Mechanical Engineering \\ by \\ Yufay Chow-Yee \\ June 2016
}


(C) 2016

Yufay Chow-Yee

ALL RIGHTS RESERVED 


\section{COMMITTEE MEMBERSHIP}

TITLE:

Removing Oil from Fried Foods Via Mechanical Process
AUTHOR:
Yufay Chow-Yee
DATE SUBMITTED: June 2016

COMMITTEE CHAIR: $\quad$ Mohammad Noori, Ph.D.

Professor of Mechanical Engineering

COMMITTEE MEMBER: Peter Schuster, Ph.D.

Professor of Mechanical Engineering

COMMITTEE MEMBER: Jesse Maddren, Ph.D.

Associate Professor of Mechanical Engineering

COMMITTEE MEMBER: Harish Bhutani

CEO of Monaero 


\title{
ABSTRACT \\ Removing Oil from Fried Foods Via Mechanical Process
}

\author{
Yufay Chow-Yee
}

Fried foods are delicious and enjoyed by almost everyone. However, they are not the healthiest foods to eat because of the amount of oil they contain. This thesis, sponsored by Moaero Company founder, Mr. Harrish Bhutani, intends to determine whether a simply designed centrifuge system can remove a reasonable amount of oil from fried foods after it has been deep fried without adversely affecting the texture of the fried food. Due to a large variety in the texture as well as the type of fried foods, and in order to keep the scope of this thesis more focused and feasible, the focus of this investigation will be French fries. Three variables are tested: the type of fry, the angular velocity of the centrifuge, and the time spent in the centrifuge. Multiple designs for the centrifuge system were made on SolidWorks. Engineer Equation Solver (EES) was used to aid steady state and transient heat transfer calculations. Minitab was used for statistical analysis. The impact of various parameters on the change in mass of the French fries, as a measure for evaluating the oil content, were studied. The results indicate whether a centrifuge will remove a reasonable amount of oil while also considering the integrity of the fries. The study concludes that centrifugation is be a cost-effective method for removing oil from fried foods. 


\section{ACKNOWLEDGMENTS}

First and foremost, I want to thank Mr. Harrish Bhutnai for providing the opportunity to work on this project. This project would not have been possible without the guidance of my committee members and other faculty members at Cal Poly. I owe a special thanks to Dr. Noori for his constant support in overcoming all the challenging aspects of this study. I would like to thank Dr. Schuster for helping me stay on track with my project and providing feedback whenever I needed it. I would also like to thank Dr. Maddren for helping me solve all the heat transfer challenges any time of the week. Thanks to Dr. Stephanie Jung for supporting me with the food science aspect of this study. I am also grateful to Professor Heather Smith for guiding me through the statistics analysis and introducing me to Minitab. Thanks to Professor Glen Thorncroft for allowing me to crash your lab in order to allow me to use the bomb calorimeter. I would also like to thank Michelle Zaludek for proofreading my paper within a moment's notice.

Additionally, I would like to thank my friends and family for their support. Thank you mom and dad for providing me with this amazing opportunity. I could not have done it without your support and unconditional love. Lastly, I would like to express my gratitude to Jenny Lee for constantly cheering me on when I needed it most. I could not have gotten this far without the support of everyone and I am extremely thankful to have made it this far. 


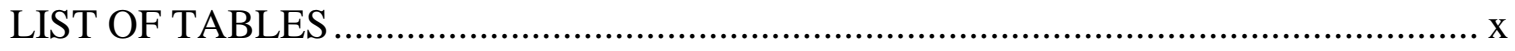

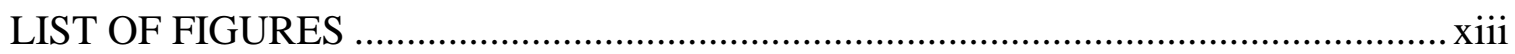

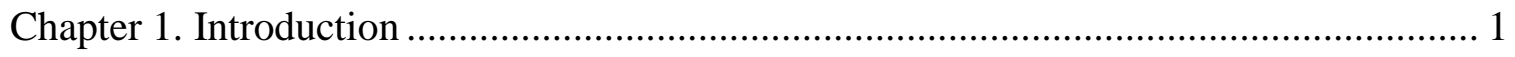

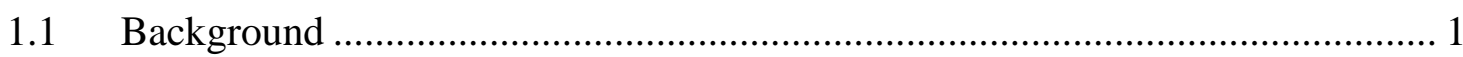

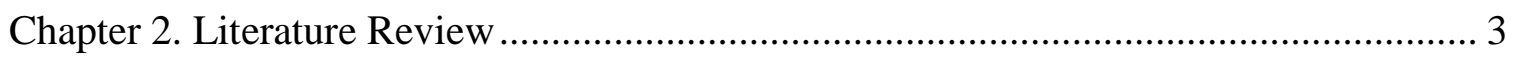

2.1 Deep Fried French Fry Microstructure ……........................................................ 3

2.1.1 Structural Oil (STO) ………......................................................... 3

2.1.2 Penetrated Surface Oil (PSO) ……………........................................ 5

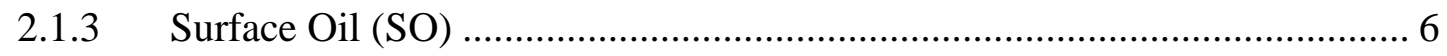

2.2 Heat and Mass Transfer During Deep Fat Frying ............................................. 6

2.2.1 Conduction and Convection ..................................................................... 6

2.2.2 Oil and Steam Mass Transfer............................................................... 9

2.3 Oil Removal Study with Paper Towels and Centrifugation ................................ 9

2.4 Current Oil Reduction Products and Ideas .................................................... 10

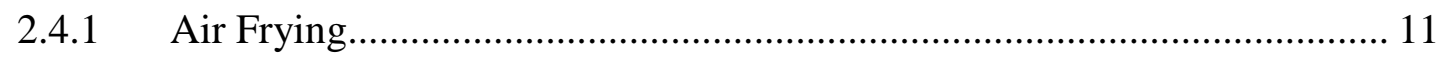

2.4.2 Low Pressure Frying .......................................................................... 11

2.5 Existing Fluid Removal Mechanism .............................................................. 12 
2.5.1 Oil Separating Machines .................................................................... 12

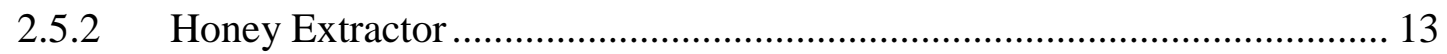

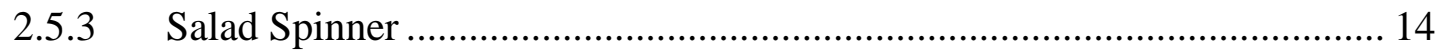

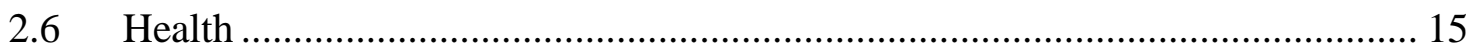

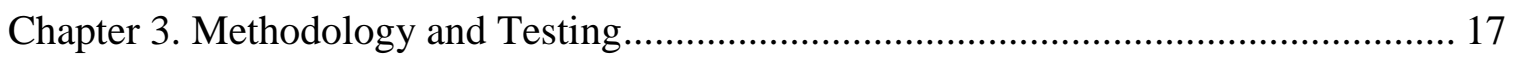

3.1 Preliminary Proof of Concept Testing …………......................................... 17

3.2 Equipment for Experimentation ............................................................... 19

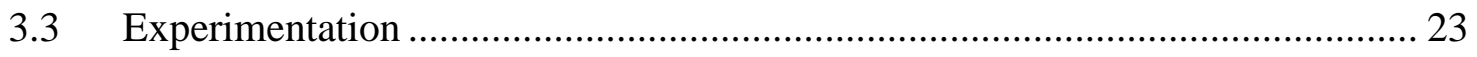

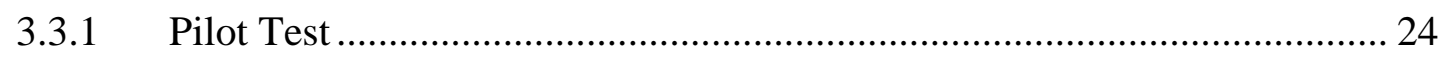

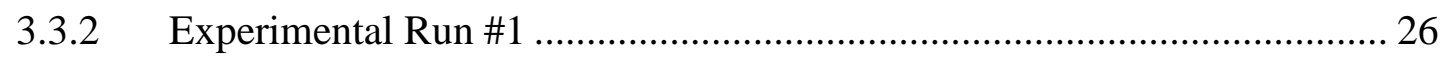

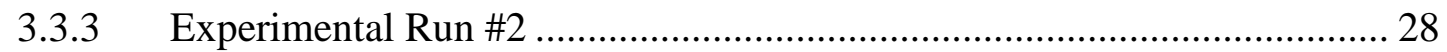

3.3.4 Experimental Run \#3 ..................................................................... 29

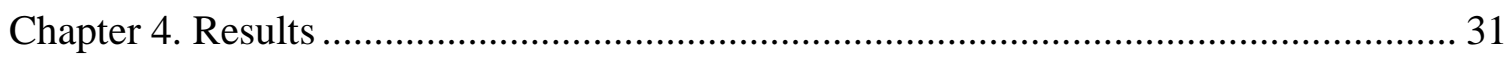

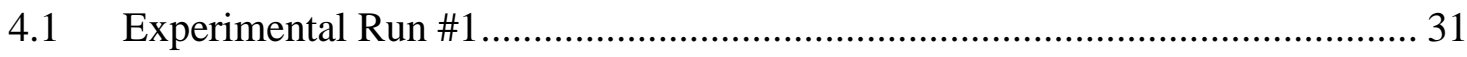

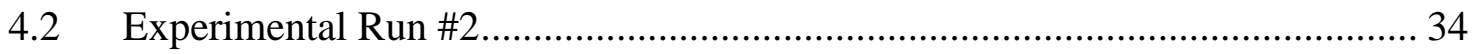

$4.3 \quad$ Experimental Run \#3.................................................................................. 37

4.4 Combined Data for all Three Experiments ..................................................... 40

Chapter 5. Additional Testing and Calculations ............................................................. 49

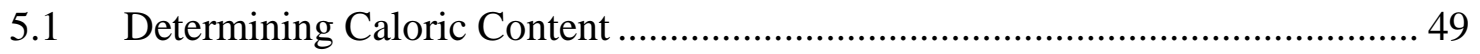

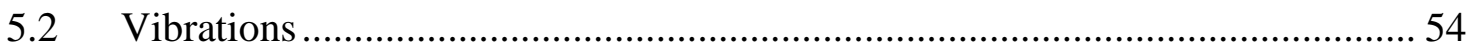




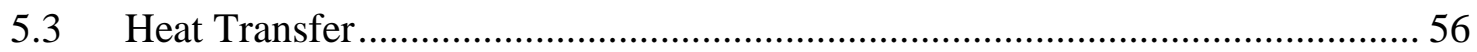

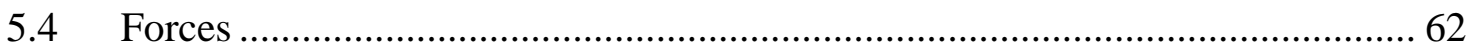

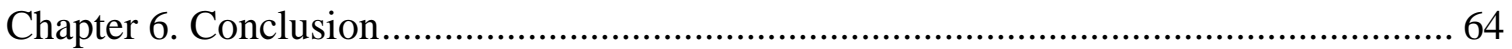

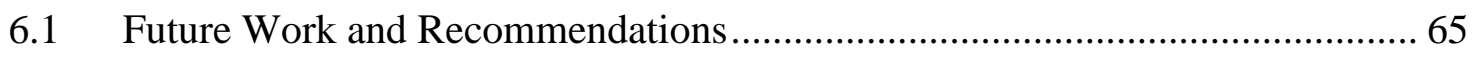

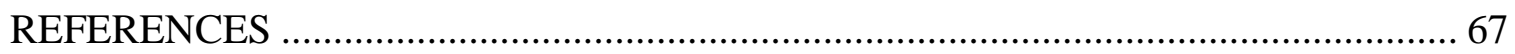

\section{APPENDICES}

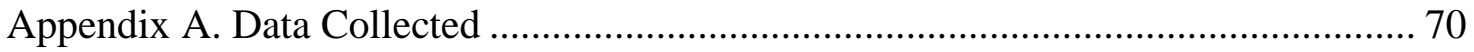

Appendix A1. Motor Calibration Curve Data ................................................... 70

Appendix A2. Motor Mount Drawing ......................................................... 71

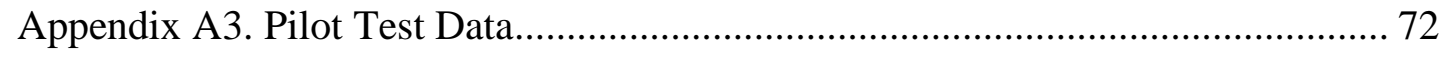

Appendix A4. Experimental Run \#1 Data ........................................................... 75

Appendix A5. Experimental Run \#2 Data .......................................................... 79

Appendix A6. Experimental Run \#3 Data ....................................................... 83

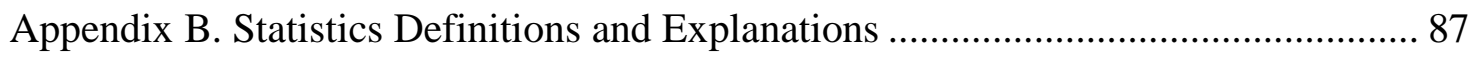

Appendix C. Minitab - Statistical Analysis ..................................................... 89

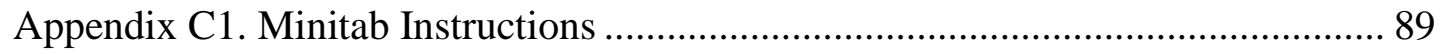

Appendix C2. Results for Experimental Run \#1 ................................................. 94

Appendix C3. Results for Experimental Run \#2 ….......................................... 96

Appendix C4. Results for Experimental Run \#3 ................................................. 99

Appendix C5. Results for Combined Experimental Runs ................................... 102 
Appendix D. Oxygen Bomb Calorimeter.

Appendix D1. Oxygen Bomb Calorimeter Procedures and Equations ................... 107

Appendix D2. Oxygen Bomb Calorimeter Data .................................................. 110

Appendix E. Additional Calculations.................................................................. 113

Appendix E1. Steady State Heat Transfer Calculations Using EES ..................... 113

Appendix E2. Transient Heat Transfer Calculations Using Matlab ....................... 114

Appendix E3. Experimental Raw Data for Transient Heat Transfer...................... 116 


\section{LIST OF TABLES}

Table

Page

Table 1 - Amount of Trials per Treatment for the Pilot Test........................................ 24

Table 2 - Amount of Trials per Treatment for Experimental Run \#1 ........................... 27

Table 3 - p-Values from Experimental Run \#1 Obtained via ANOVA.......................... 33

Table 4 - Grouping Information Using Tukey Comparison for Angular Velocity........... 33

Table 5 - Difference of Means using Tukey Pairwise Comparison................................ 33

Table 6 - Grouping Information Using Tukey Comparison for Angular Velocity.......... 34

Table 7 - p-Values from Experimental Run \#2 Obtained via ANOVA........................... 36

Table 8 - Grouping Information Using Tukey Comparison for Angular Velocity........... 36

Table 9 - Difference of Means using Tukey Pairwise Comparison ............................... 36

Table 10 - p-Values from Experimental Run \#3 Obtained via ANOVA.......................... 39

Table 11 - Grouping Information Using Tukey Comparison for Angular Velocity......... 39

Table 12 - Difference of Means using Tukey Pairwise Comparison.............................. 39

Table 13 - Grouping Information Using Tukey Comparison for Angular Velocity......... 40

Table 14 - p-Values from Experimental Run \#1-3 Obtained via ANOVA ..................... 42

Table 15 - Grouping Information Using Tukey Comparison for Type of Fry................. 43

Table 16 - Difference of Means using Tukey Comparison for Type of Fry .................... 43

Table 17 - Grouping Information Using Tukey Comparison for Angular Velocity......... 44

Table 18 - Difference of Means using Tukey Comparison for Angular Velocity ........... 44

Table 19 - Grouping Information Using Tukey Comparison for Time ......................... 45

Table 20 - Grouping Information Using Tukey Comparison for Type of Fry................. 48 
Table 21 - Mass of Samples used for the Bomb Calorimeter ....................................... 51

Table 22 - Calorie Comparison Between Raw and Cooked Fries .................................. 53

Table 23 - Nutrition Facts for $0.7 \mathrm{~g}$ of Vegetable Oil [20] ......................................... 54

Table 24 - Values for Calculating Natural Frequency of the Motor Mount ..................... 56

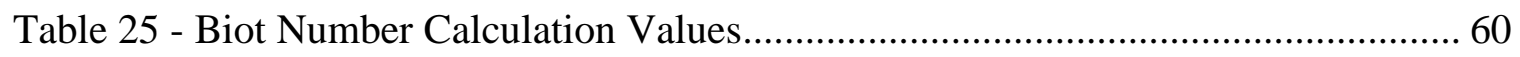

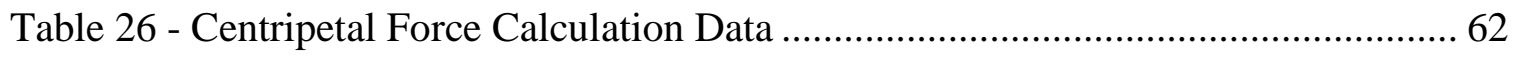

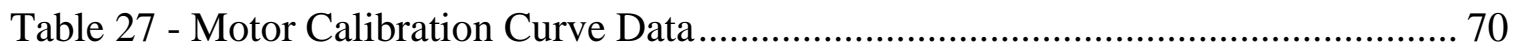

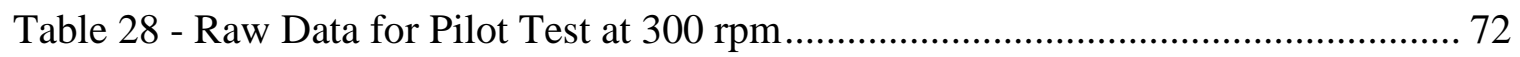

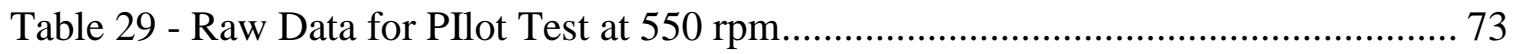

Table 30 - Data Obtained From Pilot Test .................................................................. 74

Table 31 - Raw Data From Experimental Run \#1 at 200 rpm ..................................... 75

Table 32 - Raw Data From Experimental Run \#1 at 450 rpm .................................... 76

Table 33 - Raw Data From Experimental Run \#1 at 700 rpm ..................................... 77

Table 34 - Combined Data for Experimental Run \#1 .............................................. 78

Table 35 - Raw Data From Experimental Run \#2 at 200 rpm ..................................... 79

Table 36 - Raw Data From Experimental Run \#2 at $450 \mathrm{rpm}$..................................... 80

Table 37 - Raw Data From Experimental Run \#2 at 700 rpm .................................... 81

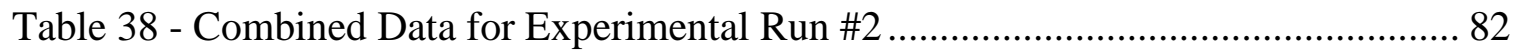

Table 39 - Raw Data From Experimental Run \#3 at 200 rpm ................................... 83

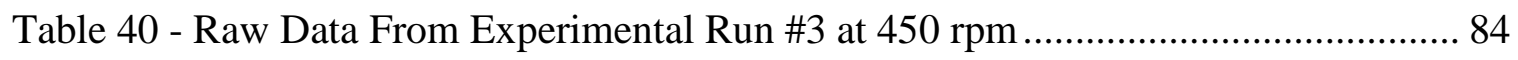

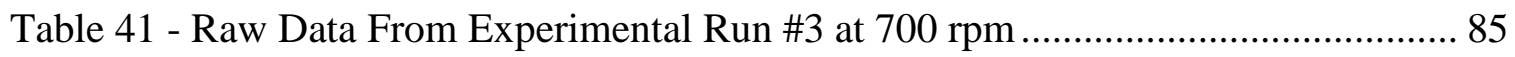

Table 42 - Combined Data for Experimental Run \#3 ............................................ 86

Table 43 - Oxygen Bomb Calorimeter Temperature Data for Raw Fries..................... 110 
Table 44 - Caloric Value (E) Calculation for Raw Fries .......................................... 110

Table 45 - Caloric Value (E) with Corrected Temperature for Raw Fries .................... 111

Table 46 - Oxygen Bomb Calorimeter Temperature Data for Cooked Fries ................ 111

Table 47 - Caloric Value (E) Calculation for Cooked Fries ....................................... 112

Table 48 - Caloric Value (E) with Corrected Temperature for Cooked Fries ................ 112

Table 49 - Experimental Temperature Profile of French Fry ................................... 116 


\section{LIST OF FIGURES}

Figure

Page

Figure 1 - Location of Oil in the Microstructure After Frying [1] ................................. 3

Figure 2 - Percentages of Total Oil Content [2] ....................................................... 5

Figure 3 - Heat and Mass Transfer Between Oil and Fried Food [3] ............................. 7

Figure 4 - Fried Chicken Centrifugation Study [6] ............................................... 10

Figure 5 - Tefal ActiFry Air Fryer Found on Amazon.com [8] ................................. 11

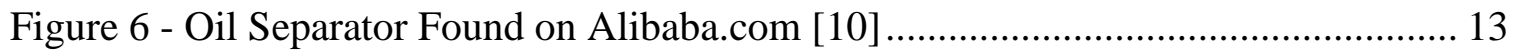

Figure 7 - Example of a Motorized Centrifugal Honey Extractor [11] .......................... 14

Figure 8 - Example of a Salad Spinner Found on Amazon.com [12] ............................ 15

Figure 9 - Fries Dumped into Salad Spinner After Frying ....................................... 18

Figure 10 - Excess Oil from French Fries............................................................. 19

Figure 11 - Motor with Gearbox and Chuck from Black and Decker Power Drill ......... 20

Figure 12 - 30V, 5A Precision Adjustable Power Supply QW-MS305D [16] ............... 20

Figure 13 - Motor Calibration Curve for Geared Motor at No Load............................. 21

Figure 14 - Testing Apparatus Assembled............................................................. 22

Figure 15 - Exploded View of Testing Apparatus with Labels ................................... 22

Figure 16 - Average Amount of Oil Extracted for Each Treatment ............................ 25

Figure 17 - Power Curves Generated from the Pilot Test.......................................... 26

Figure 18 - Individual Value Plot Obtained from Experimental Run \#1 ....................... 31

Figure 19 - Individual Value Plot for Experimental Run \#2 …................................. 35

Figure 20 - Individual Value Plot for Experimental Run \#3 ...................................... 38 
Figure 21 - Individual Value Plot for Experimental Run \#1-3 .................................. 41

Figure 22 - Main Effects Plot for Experimental Run \#1-3 ....................................... 46

Figure 23 - Interaction Plot for Type of Fry and Angular Velocity ............................. 47

Figure 24 - 1341 Plain Jacket Bomb Calorimeter.................................................. 49

Figure 25 - Temperature Profile of the Raw Fry Bomb Calorimeter Run...................... 52

Figure 26 - Temperature Profile of the Cooked Fry Bomb Calorimeter Run................... 53

Figure 27 - Isometric View of Motor Mount ......................................................... 55

Figure 28 - Side View of Motor Mount with Fixed Supports....................................... 55

Figure 29 - Heat Transfer Process for Steady State Problem ...................................... 57

Figure 30 - Temperature Profile of French Fry Experimental vs. Theoretical ................ 61

Figure 31 - Prototype Motor Mount Drawing...................................................... 71

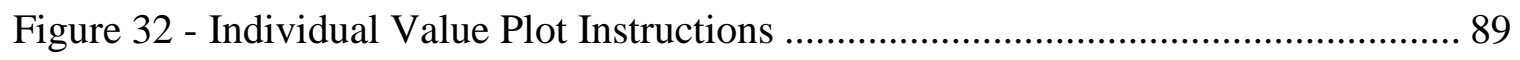

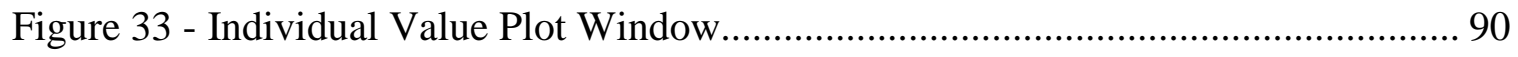

Figure 34 -ANOVA General Linear Model Instructions ....................................... 90

Figure 35 - ANOVA General Linear Model Preview............................................... 91

Figure 36 - Tukey Comparisons Instructions.................................................... 91

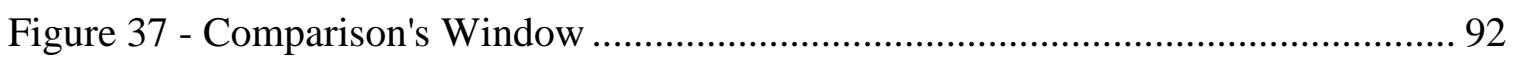

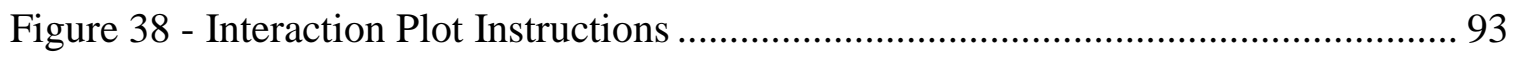

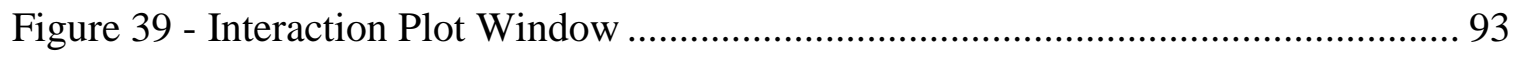

Figure 40 - Experimental Run \#1, Tukey Comparison for Angular Velocity ................. 95

Figure 41 - Experimental Run \#1, Tukey Comparison for Time ................................ 96

Figure 42 - Experimental Run \#2, Tukey Comparison for Angular Velocity .................. 98

Figure 43 - Experimental Run \#2, Tukey Comparison for Time ................................. 99 
Figure 44 - Experimental Run \#3, Tukey Comparison for Angular Velocity ................ 101

Figure 45 - Experimental Run \#3, Tukey Comparison for Time................................. 101

Figure 46 - Experimental Run \#1-3, Tukey Comparison for Type of Fry ..................... 105

Figure 47 - Experimental Run \#1-3, Tukey Comparison for Angular Velocity ............. 105

Figure 48 - Experimental Run \#1-3, Tukey Comparison for Time ............................. 106 


\section{Chapter 1. Introduction}

\subsection{Background}

Deep frying food has been around for decades because it enhances the flavor of the food while creating a crisp outer layer during the cooking process. Throughout the deep frying process, food experiences mass and heat transfer. Mass is transferred into the food via the medium it is fried in; generally oil or lard. Heat is transferred to the fried food by way of convection and into the core by conduction. Unfortunately, consistently consuming oil or lard from deep fried foods may cause health issues in the long run. Thus, the purpose of this paper is to identify if a centrifuge can remove a reasonable amount of oil from fried foods. This study will focus on the popular French Fries. The reason for narrowing down the study to one type of fried food is because every food that is fried generates a different type of crust which can make it easier or more difficult to extract oil. The method that was studied consisted of a centrifuge (rapidly spinning container). This way, one can enjoy the tasty French Fries while worrying less about consuming excessive oil or lard.

In order to prove how much oil can be removed, many trials of fries were processed through a centrifuge. The centrifuge was manufactured and the design process was documented in Chapter 3 along with the methodology. The variables that were independently varied are: duration in the centrifuge, angular velocity of the centrifuge, and type of fry. The data was processed using Minitab, a statistical analysis software, with results explained in Chapter 4. The data recorded was the change in mass before and after the fries are processed in the centrifuge. The data obtained was used to identify 
trends from the statistical analysis. Additionally, the manufacturing required some analysis such as vibrations, heat transfer, and motor torque calculations. These calculations will be in Chapter 5. Lastly, the conclusions and suggested future work will be discussed in Chapter 6 . 


\section{Chapter 2. Literature Review}

\subsection{Deep Fried French Fry Microstructure}

When food is deep fried, a crust is generated. The microstructure of the crust is discussed in this section. At any time during the deep frying process, the oil takes the lowest resistance path into the food being fried. Similar to an electric circuit or water flowing through pipes, current and water will take the lowest resistance path. What this means is that oil will find the easiest path into the food during and after the frying process. The microstructure of a fried potato slice is broken down into three sections: structural oil, penetrated surface oil, and surface oil [1]. See Figure 1 for an illustration of these locations.

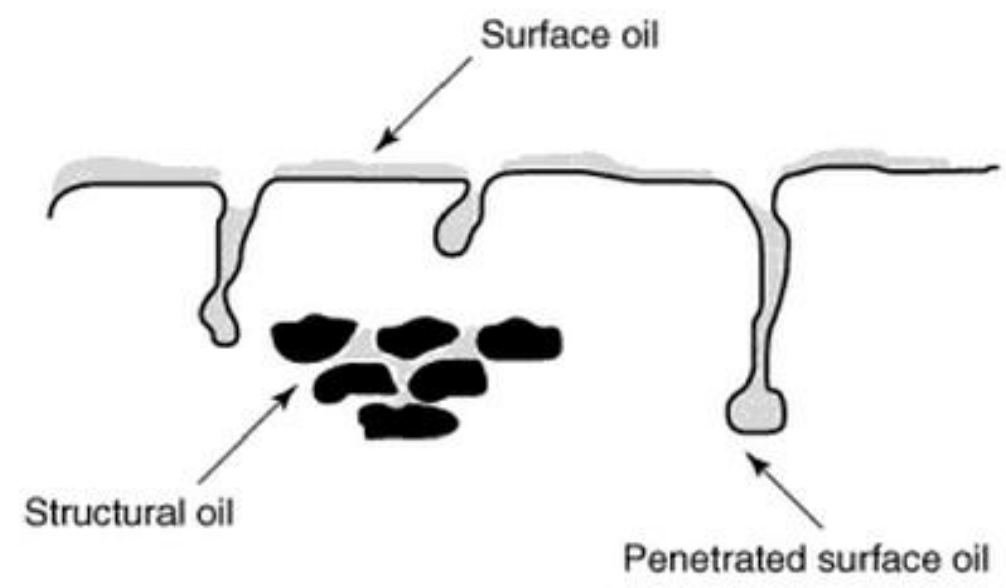

Figure 1 - Location of Oil in the Microstructure After Frying [1]

\subsubsection{Structural Oil (STO)}

When food is initially submerged in the fryer, the hot oil begins to bubble violently and contact between food and oil ensues. This means that heat and mass transfer are now 
occurring simultaneously. The oil absorbed into food during the frying process is known as structural oil [1]. As shown in Figure 2 below, structural oil is a small percentage of the whole regardless of frying temperature. Out of all the regions that oil can be found, structural oil contains the second least amount of oil [2]. This data was obtained experimentally for potato slices fried at various temperatures until the potatoes reached a specified moisture content [2]. When the potatoes reached this moisture content, the potatoes were deemed cooked [2]. Since this oil is absorbed into the potato slices, it is difficult to remove via mechanical process. It is assumed that structural oil is very difficult to remove oil via centrifuge because oil in this section is inside the food; past the outer crust. This means that the path for the oil to be extracted has a high resistance path compared to other locations that oil can be removed. There are two other locations where oil rests that can be removed more easily. These locations are discussed in the following sections.

The experiments that produced the data for the chart in Figure 1 are for potato slices. This provides a general guideline to where oil can be found on French fries, along with the corresponding percentage. They are very similar in that they are cooked the same way, but the cuts made on the potato are not similar. 


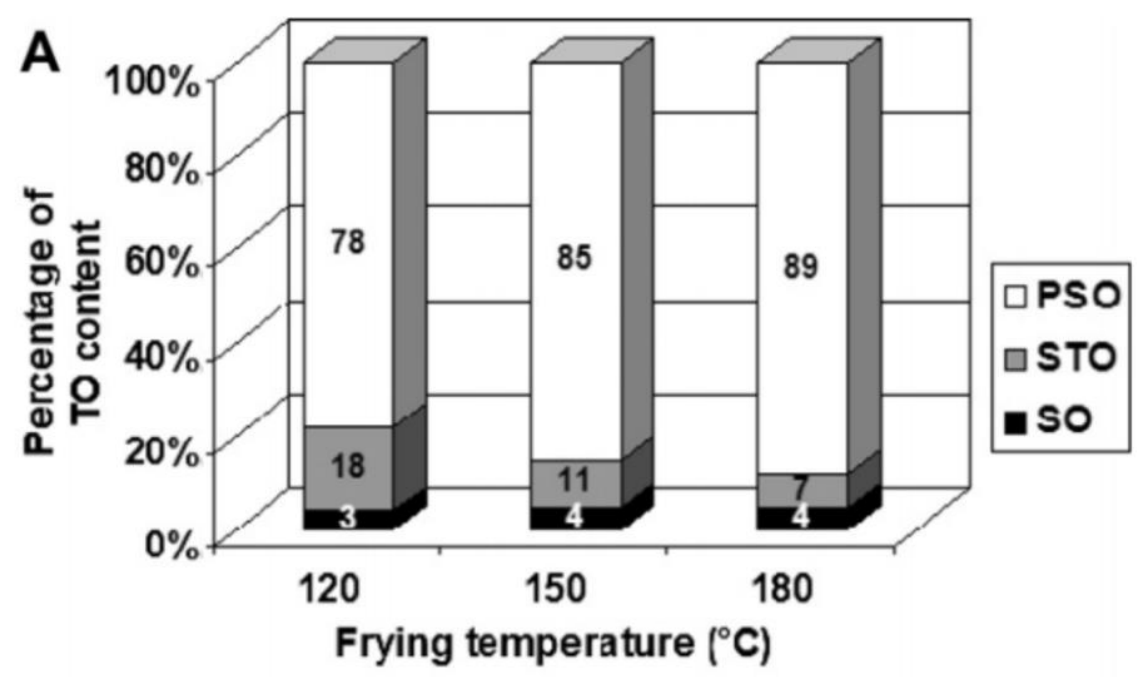

Figure 2 - Percentages of Total Oil Content [2]

\subsubsection{Penetrated Surface Oil (PSO)}

Oil on the surface that is slowly suctioned into the food after it is removed from the fryer is known as penetrated surface oil [2]. According to Figure 1, this is where a majority of the oil is located. Oil is suctioned into the food because of capillary forces [2]. These capillary forces are caused by the change in temperature when the fried food is exposed to the atmosphere after being removed from the hot oil. Capillary forces are generated from the change in pressure causing fluid to flow into the fried food without any input [2]. The penetrated surface oil is where the most oil can be extracted from if it is caught before it has been suctioned into the food. The oil must be extracted immediately after frying in order to remove the most amount of oil. Figure 2 shows the location of the PSO in the food microstructure after it has been suctioned into the crust. 


\subsubsection{Surface Oil (SO)}

When fried food comes out of the fryer and onto the dinner plate, there is a small amount of oil on the surface of the fried food. The oil that remains on the outside of the crust after frying is known as surface oil [2]. For instance, when you eat French fries and touch the fries with your hands, there is a small amount of oil residue that stays on your finger. Surface oil is where the least amount of oil is located, see Figure 1 above [2]. Although this area has the smallest concentration of oil, it is the easiest to remove due to the nature of its location. See Figure 2 above for the location of surface oil in the microstructure.

\subsection{Heat and Mass Transfer During Deep Fat Frying}

When food is cooked, regardless of the method of cooking, food undergoes heat and mass transfer. This section will briefly discuss the processes of heat and mass transfer that occur during and immediately after deep frying.

\subsubsection{Conduction and Convection}

As freshly cut potatoes are submerged under $375^{\circ} \mathrm{F}$ oil, heat transfer occurs between the two. Convection occurs between the oil and the fries, while conduction heats the core from the crust [3]. Figure 3 illustrates the heat and mass transfer taking place during deep frying. 


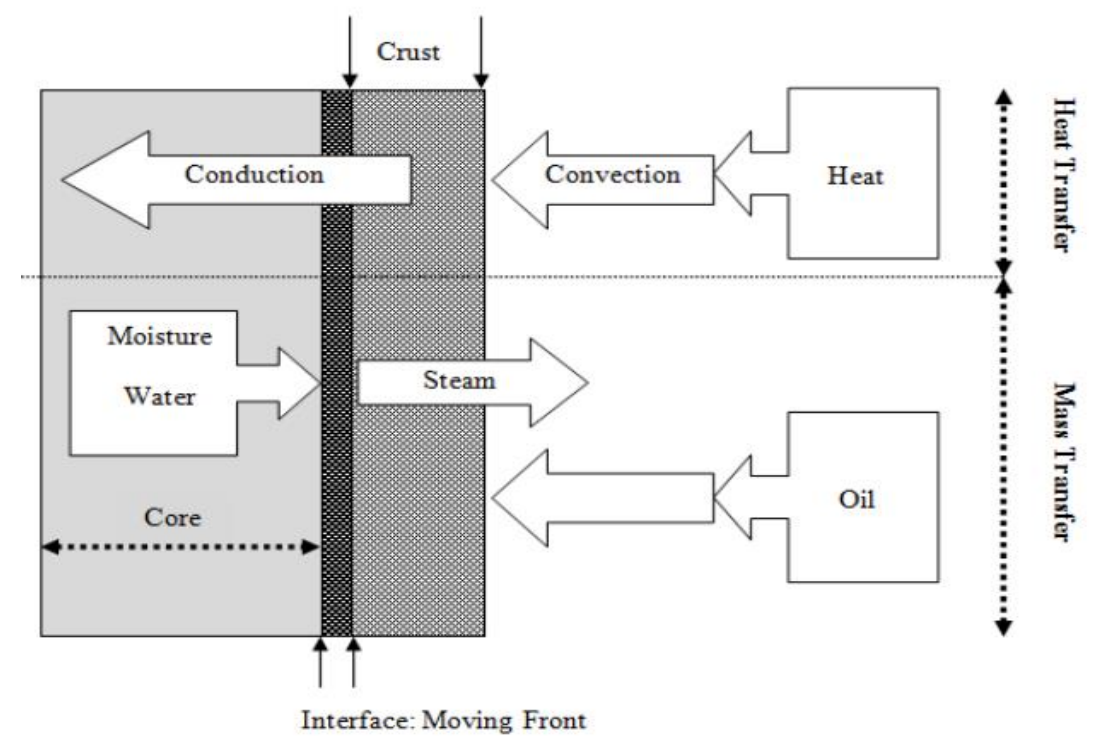

Figure 3 - Heat and Mass Transfer Between Oil and Fried Food [3]

Convection between the food and the oil is extremely hard to model because of the behavior of hot oil. When food is submerged in the hot oil, the oil begins to bubble which generates turbulent convective heat transfer and varies as the food cooks [3]. The bubbling is random and violent, this makes it difficult to be able to predict or model the food in hot oil. The difficult part about modeling deep frying is the heat transfer coefficient. The flow of oil caused by bubbling is unpredictable. Not only is it difficult to predict the heat transfer coefficient, it is not constant throughout the cooking process. The bubbling occurs because steam given off from the fried food. Over time, less moisture exist in the fried food, thus the violent bubbling subsides. An equation for heat transfer was modeled, but is only valid after the internal temperature is high enough to evaporate water, $212^{\circ} \mathrm{F}$ [3]. See equation 1 below. Using this equation assumes that all the heat is used to convert water to steam. This will provide an under-estimate because heat is also lost in the deep fryer due to convection with the air and conduction with the fryer itself. 


$$
\begin{aligned}
& \qquad q=h_{c} A\left(T_{\infty}-\mathrm{T}_{\mathrm{L}}\right)=\lambda \rho_{w} \varepsilon A \frac{d(L-\delta)}{d t} \\
& q=\text { heat flow }(\mathrm{W}) \\
& h_{c}=\text { convective heat transfer coefficient }\left(\mathrm{W} / \mathrm{m}^{2} \mathrm{~K}\right) \\
& A=\text { surface area }\left(\mathrm{m}^{2}\right) \\
& T_{\infty}=\text { oil temperature }(C) \\
& T_{L}=\text { surface temperature }(C) \\
& \lambda=\text { latent heat of vaporization }(\mathrm{J} / \mathrm{kgC}) \\
& \rho_{w}=\text { water density }\left(\mathrm{kg} / \mathrm{m}^{3}\right) \\
& \varepsilon=\text { water volume fraction } \\
& (L-\delta)=\text { crust thickness }(\mathrm{m})
\end{aligned}
$$

While heat transfer via conduction for fried food between the crust and the core is defined as:

$$
\frac{\partial T}{\partial t}=\alpha \frac{\partial^{2} T}{\partial x^{2}}
$$

$$
\begin{aligned}
& T=\text { temperature }(C) \\
& t=\operatorname{time}(\mathrm{s}) \\
& \alpha=\text { heat diffusivity }\left(\mathrm{m}^{2} / \mathrm{s}\right) \\
& x=\text { position }(\mathrm{m})
\end{aligned}
$$

Equation 2 uses the assumption that the item being deep fried is one-dimensional [3]. Using this assumption, calculations can be simplified, but will provide a temperature lower than the actual temperature. This is because fried food will have heat coming into it from all sides while the equation above uses the assumption of an infinitely long piece 
which eliminates conduction from two sides at the end of the fries. While heat transfer occurs, mass transfer occurs simultaneously.

\subsubsection{Oil and Steam Mass Transfer}

There are two different ways mass transfer occurs during deep frying: oil into the food, and steam out of the food. Figure 3 depicts the mass transfer in and out of the food. As food is dunked into the deep fryer, bubbles will stir the deep fryer and create movement similar to that of a Jacuzzi [4]. During the deep frying process, the moisture inside the food will turn to steam when the water molecules reach $212^{\circ} \mathrm{F}$. The rise in pressure will cause the steam to escape from the inside of the fried food. Meanwhile, small amounts of

oil will make it into the fried food, known as structural oil [5]. In addition, surface oil and penetrated surface oil are also prominent after food is removed from the hot oil. It is difficult for oil to reach the inside of the food during frying because of the steam exiting rapidly from the fried food. This causes oil to be pushed away from the food, nonetheless the fried food is still submerged in hot oil and constantly surrounded by hot oil molecules.

\subsection{Oil Removal Study with Paper Towels and Centrifugation}

There was a short paper that was found related to oil removal on schnitzel, a fried chicken dish. The purpose of that paper was to determine if using a centrifuge was an effective method for removing fat from pieces of schnitzel [6]. Pieces of fried chicken were spun with a paper towel underneath the chicken. The paper towel would absorb the oil removed during centrifugation and was later placed on a microscope to analyze the 
transparency [6]. The amount of oil was estimated from the transparency of the paper towel [6]. An image of the paper towels are in Figure 4. The study concluded that a piece of fried chicken could be spun at 1,000 rpm which produced a piece of chicken that was visually appetizing [6]. On the other hand, processing fried chicken at 4,000 rpm produced an edible, but visually unappealing piece of fried chicken [6]. Thus, according to this study, centrifugation is an inexpensive and efficient way to make fried chicken healthier [6]. These results are promising, but fries may pose different results because they are more fragile.

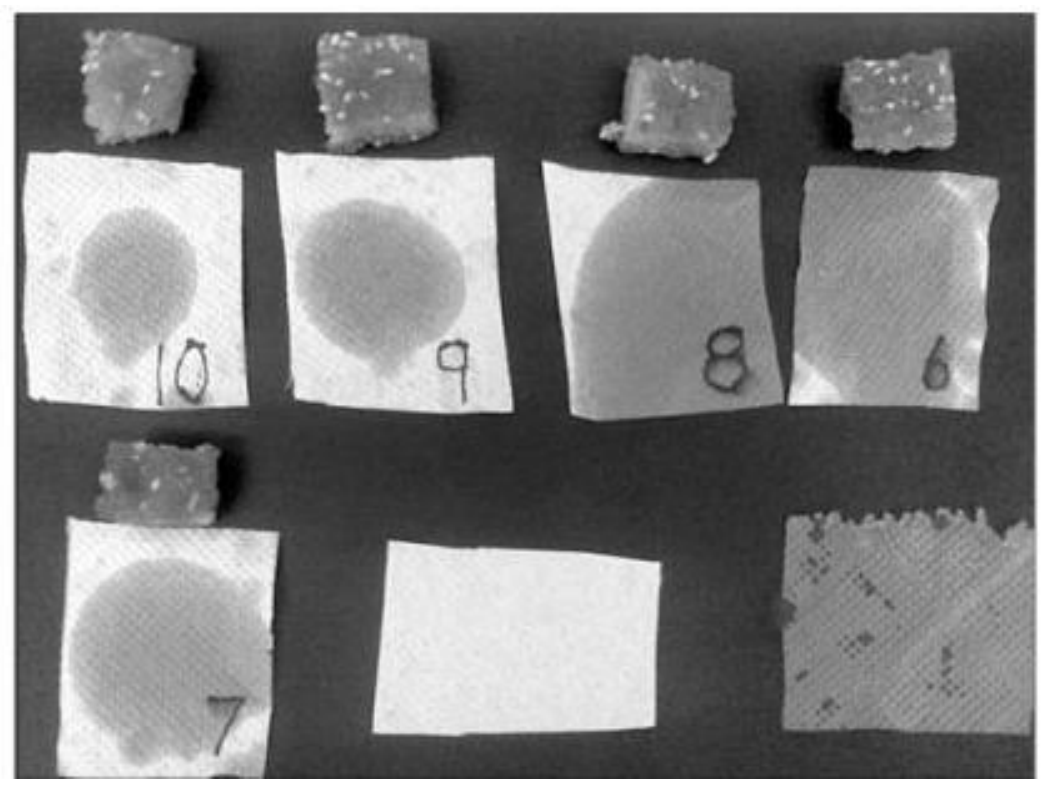

Figure 4 - Fried Chicken Centrifugation Study [6]

\subsection{Current Oil Reduction Products and Ideas}

Processing fried foods after they have been fried is one way to attack the problem of excess oil on foods. Alternative cooking methods can also can also provide information on other ways of attacking this problem. This section discusses existing products or method that relate to reducing the amount of oil in fried foods. 


\subsubsection{Air Frying}

Air frying is a new method that allows consumers to enjoy foods with much less fat content. Tefal has come up with a contraption called the ActiFry which is advertised to for "guilt free pleasure" according to their marketing slogan. It is essentially a small enclosure that circulates hot air while a spindle constantly moves all of the food to allow all surfaces to be cooked evenly. The frying part comes from throwing in a splash of oil into the machine prior to starting the cooking phase. According to experimentation, air frying $(0.0025 \%$ oil $)$ produces lower oil uptake compared to deep frying ( $14.81 \%$ oil $)$ potato slices [7]. Figure 5 is an image of one of Tefal's air fryers. This is one of many types of air fryers currently on the market.

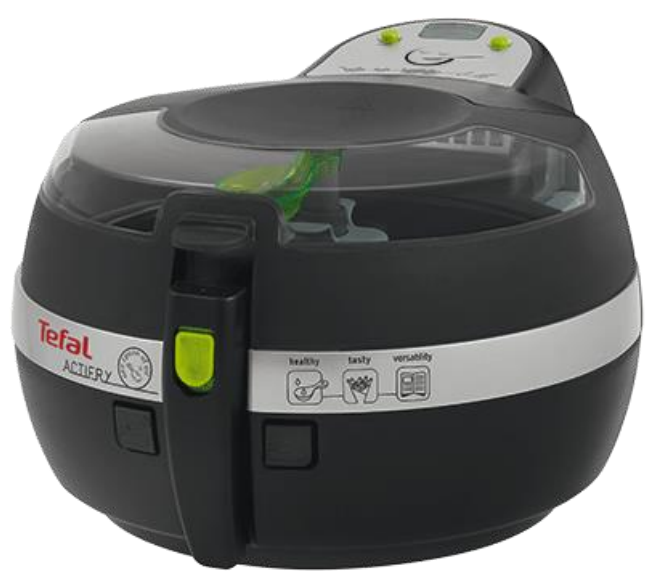

Figure 5 - Tefal ActiFry Air Fryer Found on Amazon.com [8]

\subsubsection{Low Pressure Frying}

Other attempts to enjoy fried food is by deep frying in a low pressure chamber. Cooking in a vacuumed chamber allows the oil to cook food at a lower temperature. Cooking in lower temperatures correlates to food being deemed cooked at a lower temperature [4]. Due to the varying temperatures of frying, the frying behavior is different in a pressure 
chamber versus atmospheric temperature. Overall, frying in vacuum conditions results in lower oil content in food after frying [9].

\subsection{Existing Fluid Removal Mechanism}

Researching any existing methods used for removing fluids can contribute to the ideation of the design aspect. The focus of this paper is a centrifuge, and they can come in many different shapes or sizes.

\subsubsection{Oil Separating Machines}

Although uncommon, there are few machines that are specifically made to remove oil from fried foods. They are giant centrifuges made of stainless steel that can be purchased from Alibaba. Alibaba is a platform for global wholesale trade. This machine shown Figure 6 is marketed to extract oil from fried foods where the oil can be drained from the larger container and re-used. Some unique features about this centrifuge is that is can spin up to $1500 \mathrm{rpm}$ and have a capacity of up to $7 \mathrm{~kg}$ as advertised on Alibaba. Even though these exist, they may not work well to produce visually appetizing final products for all types of fried foods. For instance, from the study mentioned in section 2.3, at higher angular velocities, fried chicken did not look appetizing. This may be the case for various types of fried foods. As for fries, the conclusion will be determined as a result of this thesis. 


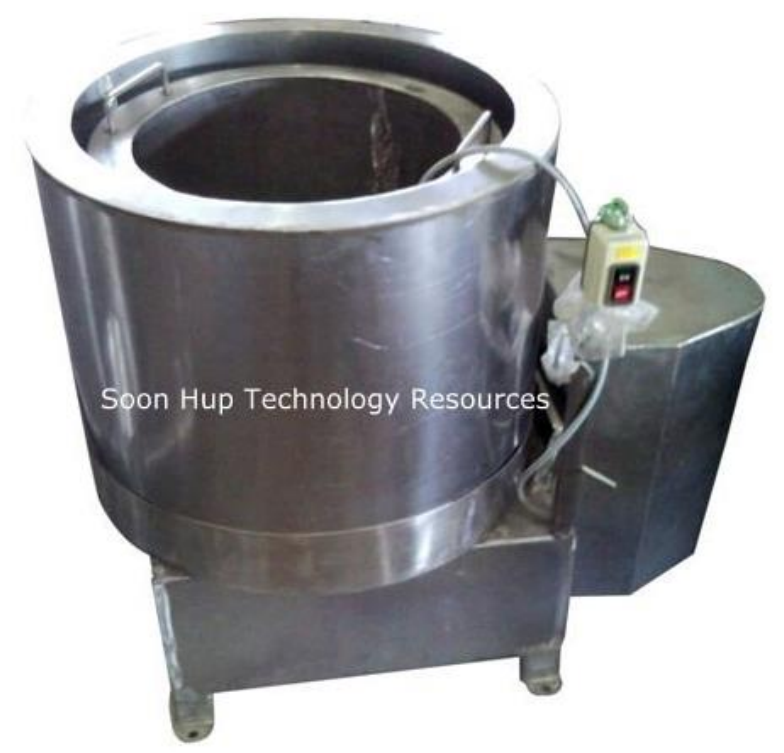

Figure 6 - Oil Separator Found on Alibaba.com [10]

\subsubsection{Honey Extractor}

One of many products that removes fluids from a solid via centrifuge is a honey extractor. A honey extractor is a barrel with a carriage in the center that holds the honeycomb panels. The carriage is spun at around $80-120$ RPMs to remove honey from the honeycombs. Honey is a fairly dense fluid, but since it is loosely held in its honeycomb, it is not necessary to have high amounts of centripetal force. Additionally, the reason these centrifuges do not spin at higher angular velocities is because the panels are fragile and can easily be damaged from the high viscosity honey. Figure 7 below depicts a commercial honey extractor. 


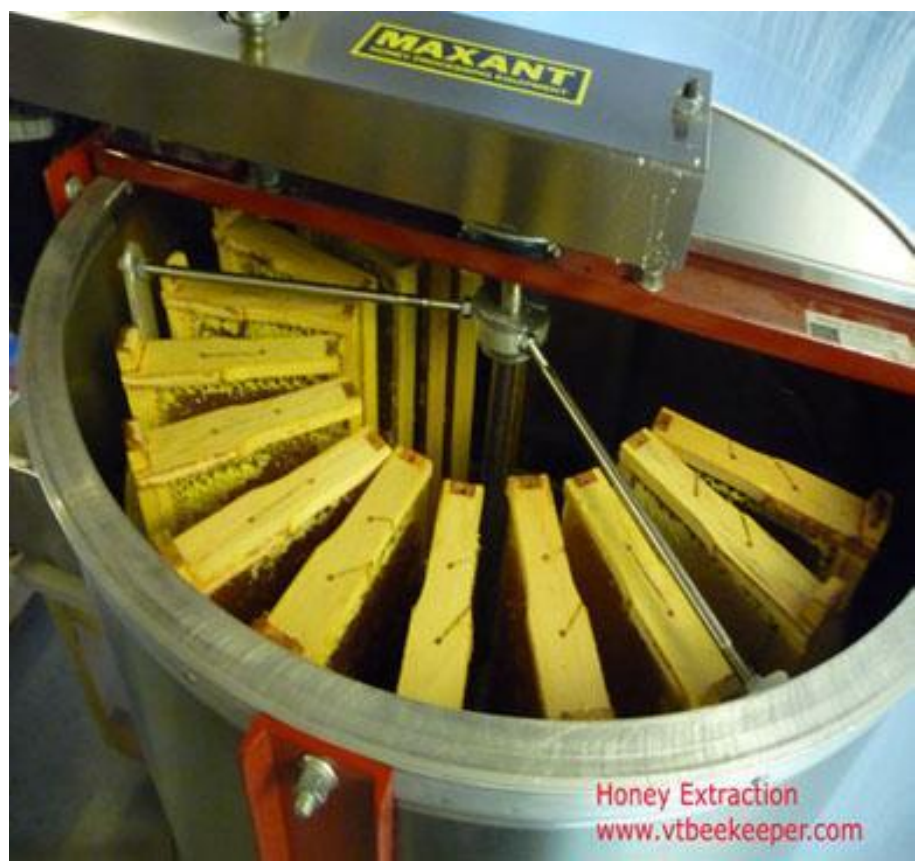

Figure 7 - Example of a Motorized Centrifugal Honey Extractor [11]

\subsubsection{Salad Spinner}

Another neat device that uses centrifugal force to remove fluid is a salad spinner. An image of a common salad spinner is shown in Figure 8 below. It is as simple as a centrifuge can get. This container has a basket inside which holds your greens and the basket will spin with human input. Water will then collect at the bottom of the container as it drips down from the side walls. Simple, yet very effective and inexpensive. This can also be easily modified to work as a test centrifuge for French Fries. If an electric motor was mounted, the angular velocity could then easily be controlled by the input voltage. 


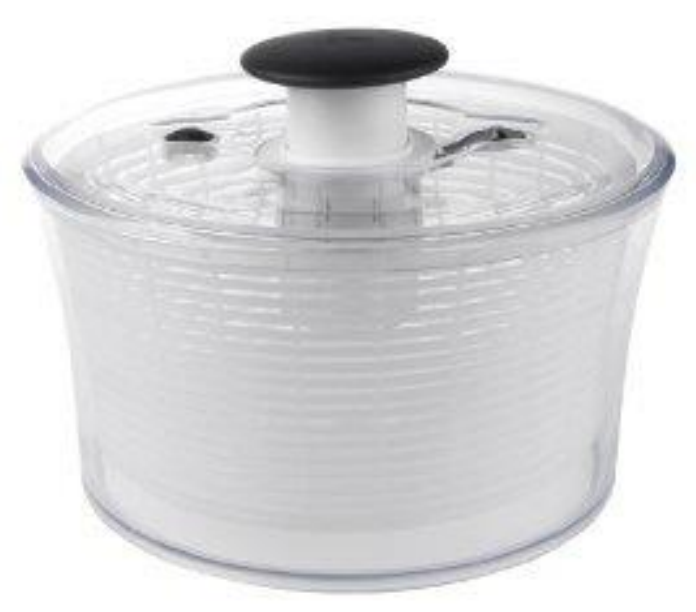

Figure 8 - Example of a Salad Spinner Found on Amazon.com [12]

\subsection{Health}

Overindulging on fried foods may have negative side effects. French Fries fried in oil or lard consumed frequently can cause health issues [13]. The American Heart Association concluded after a study that people who consumed fried food frequently are at a higher risk of becoming overweight or obese [13]. Generally, people who consumed fried foods four times or more a week have a higher body mass index than people who consume fried foods less often [14]. According to studies, kids and adolescents who have high body mass indices, or are overweight, have a higher chance of remaining that way when they become adults [15]. Fried foods contain oil or lard which are known to have high amounts of trans-fat and saturated fat [14]. Frequent consumption of trans-fat generally leads to weight gain, while frequent consumption of saturated fats can lead to the risk of various chronic diseases [14]. Although fried foods have negative side effects in the long run, it is easy to ignore them because it is so palatable. Who wouldn't want to continue 
eating something that is tasty and delicious to them? These are some of the effects of eating excessive fried foods, while there are more side effects, these are the main ones. Another lengthy paper can be written about the adverse effects of consistently consuming fried foods. These reasons fueled the motivation of this paper. The idea is to be able to consume delicious fried foods with less oil or lard in it. 


\section{Chapter 3. Methodology and Testing}

The methodology undertaken in this work was testing French fries under various treatments with different types of fries. The reason for testing different treatments and types of fries was to obtain data on the amount of oil that was extracted using a centrifuge. The variables that are considered are angular velocity and time. Having the fries exposed to various treatments leads to identifying what angular velocity and time can provide maximum oil removal. By processing the raw data through statistical analysis software, trends can be identified. Fries were examined via visual inspection, feeling, and a few taste tests. One of the more important visual items to consider was if the fries broke in half or cracked. This is critical because the fries should maintain most of its texture and aesthetics so it can be visually appetizing.

The testing consisted of measuring the amount of oil removed from various treatments of fries. This determined the amount of oil removed and can then be processed using Minitab, the statistical analysis software. This analysis makes it possible to depict trends and interactions between data sets. The following sections will explain the procedures required in order to obtain all the data necessary to conclude this study.

\subsection{Preliminary Proof of Concept Testing}

In order to identify if it was even possible to remove oil via centrifuge, a preliminary testing was carried out with a salad spinner, similar to the one in Figure 8. Potatoes were 
cut and placed in hot oil for about five minutes. As shown below in Figure 9, the fries were placed in the salad spinner and spun for approximately one minute.

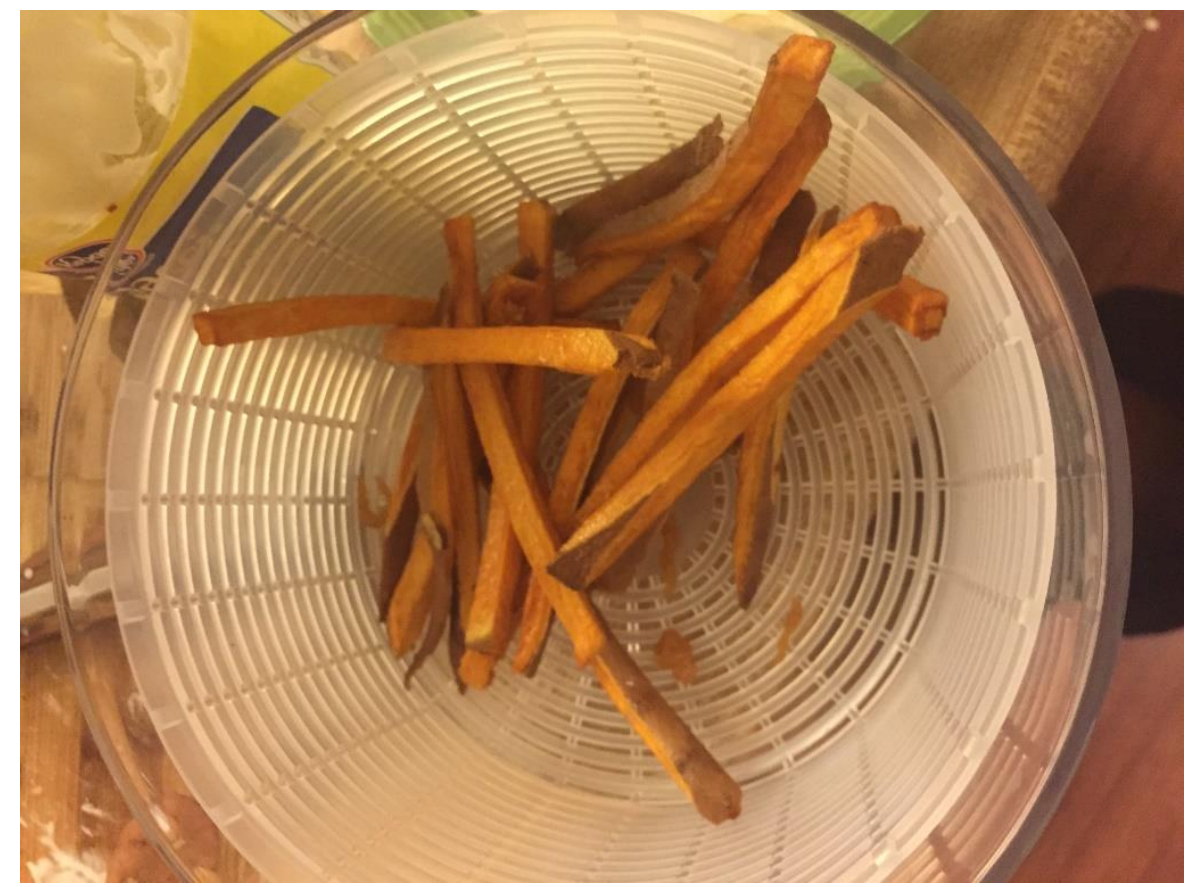

Figure 9 - Fries Dumped into Salad Spinner After Frying

After the fries were spun in the salad spinner, there was sufficient evidence that oil had been removed from the fries through this process. Figure 10 is an image proving that the oil from the fries have been spun off and transferred over to the walls of the container. The preliminary test proved that it was possible to remove oil from fries using a centrifuge-like mechanism. Further experimentation determines how much oil can be removed via centrifuge. 


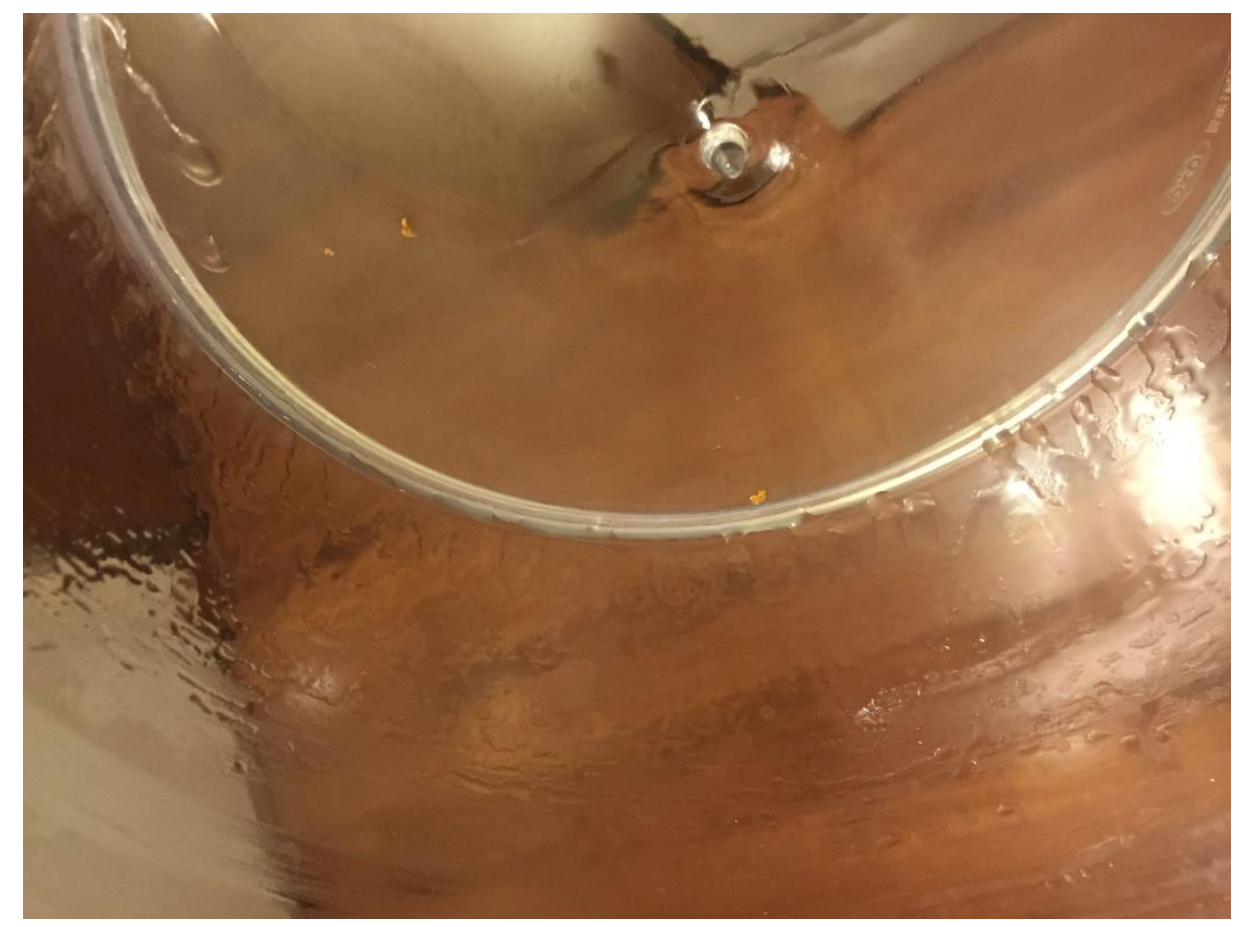

Figure 10 - Excess Oil from French Fries

\subsection{Equipment for Experimentation}

In order to control the angular velocity of the centrifuge, certain equipment were used for testing. Below is a short list of the items that were needed for testing.

- Salad Spinner

- Electric Motor

- Adjustable Power Supply

- Tachometer

The first item that was needed was a salad spinner; it was physically modified in order to accommodate an electric motor. The salad spinner that was used is shown in Figure 8. The electric motor used for experimentation was taken from a Black and Decker 20V cordless power drill. The reason for using the motor from a power drill was that it was 
already an assembled system with a gearbox and a chuck. The motor, gearbox, and the chuck are shown below in Figure 11. The manufacturer had indicated that the maximum speed of the motor was $19,300 \mathrm{rpm}$ with no load. With the $28: 1$ gear ratio, this provides an output angular velocity of over $690 \mathrm{rpm}$. The stall torque occurred at $0.49 \mathrm{Nm}$, with the gear reduction, the output torque was $14 \mathrm{Nm}$. The output torque is very high and will easily power this system to the needed angular velocity. The values provided by the manufacturer that do not account for losses. Nonetheless, the motor should provide more than enough power for this application. Additionally, if the there was a need to increase

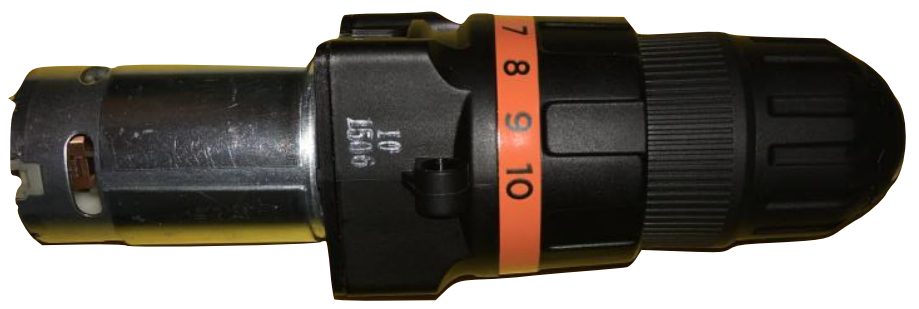

Figure 11 - Motor with Gearbox and Chuck from Black and Decker Power Drill

The motor is powered by an adjustable power supply that allows to vary the angular velocity. The power supply used is shown below in Figure 12.

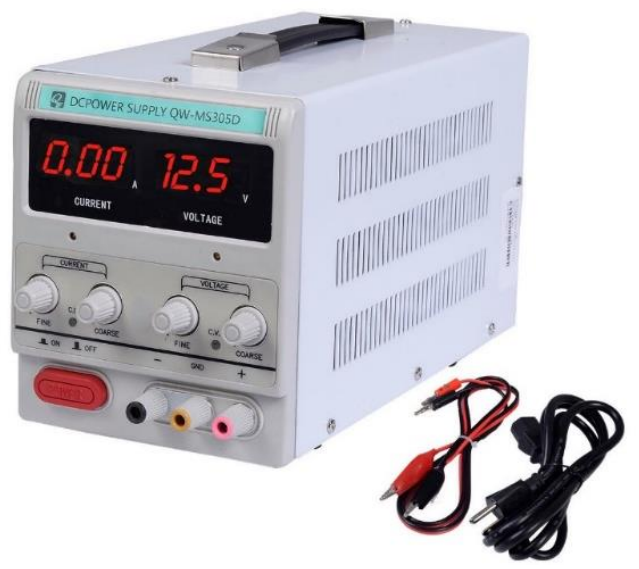

Figure 12 - 30V, 5A Precision Adjustable Power Supply QW-MS305D [16] 
To identify what voltage was needed for a specified angular velocity output on the motor, a calibration curve was generated. Data was collected from a tachometer that measured the angular velocity at various input voltages to compile a calibration curve. With the calibration curve shown below in Figure 13. From the calibration curve, output angular velocity was determined by using the equation generated for a line. See Appendix A1 for data regarding this plot. The calibration curve was generated with no load on the motor. The basket and fries that were attached the motor do not weigh much, thus nearly negligible angular velocity different with the load.

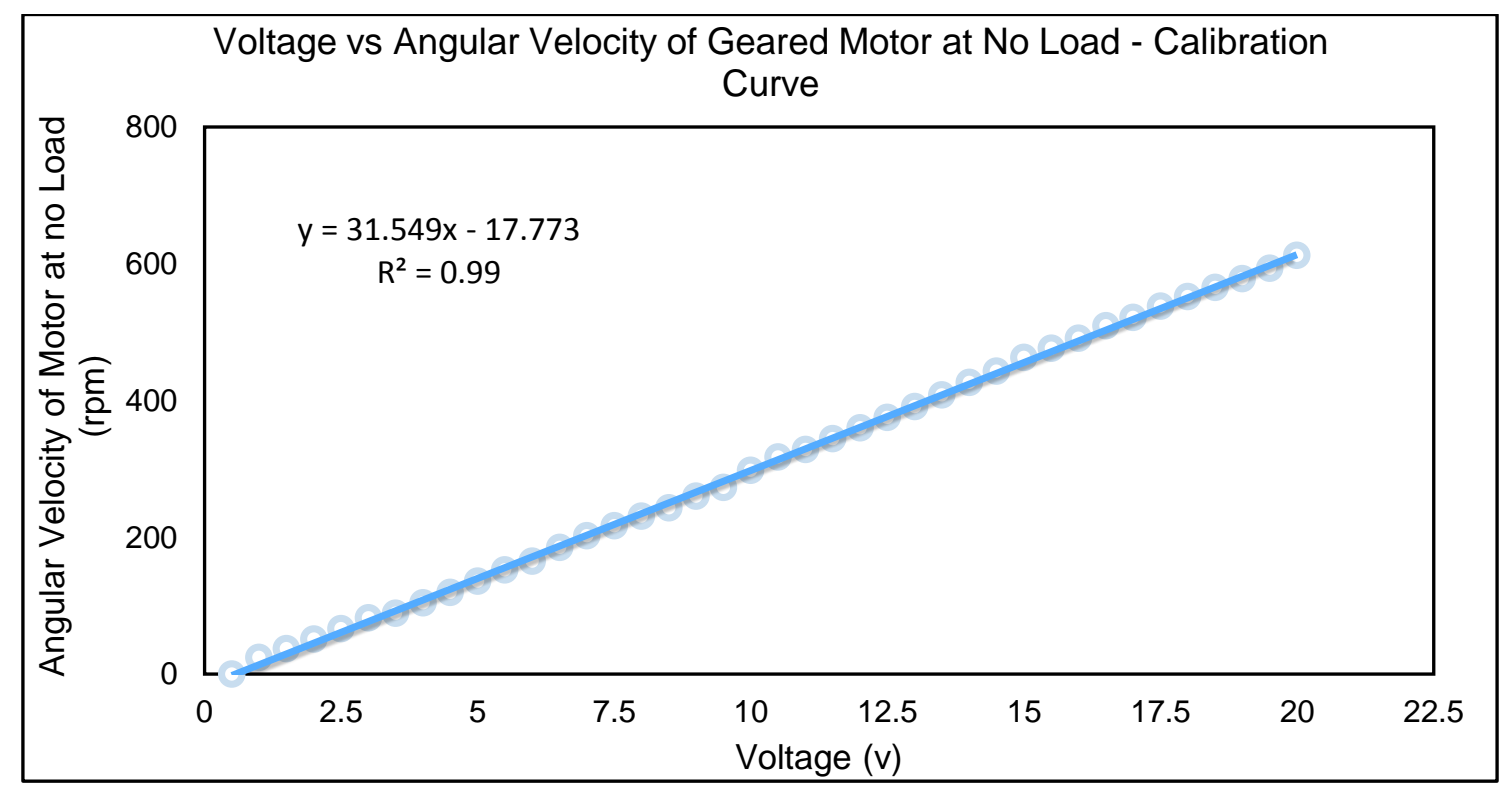

Figure 13 - Motor Calibration Curve for Geared Motor at No Load

The assembled testing apparatus is shown below in Figure 14. While Figure 15 below shows the exploded view of the testing apparatus. 


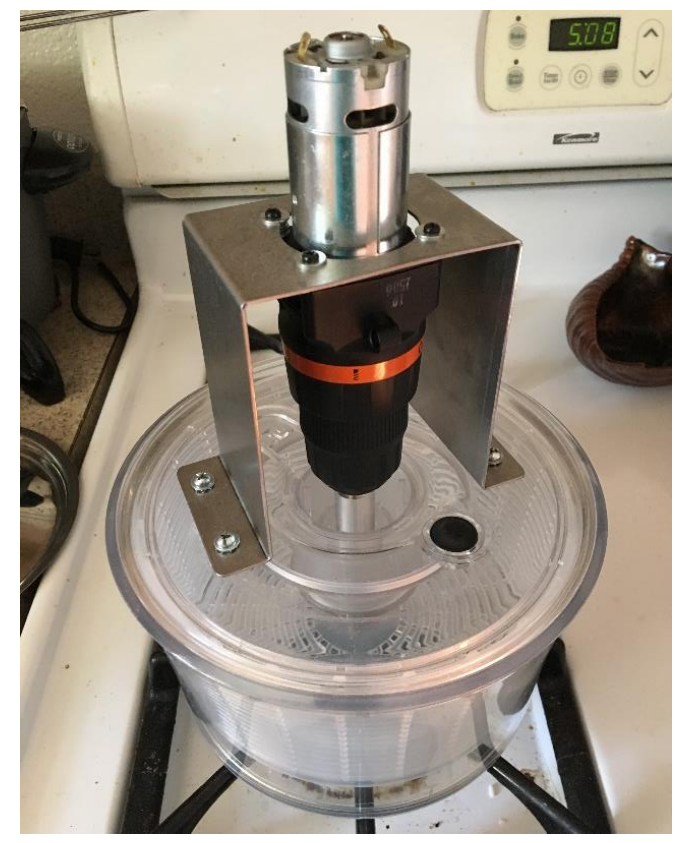

Figure 14 - Testing Apparatus Assembled

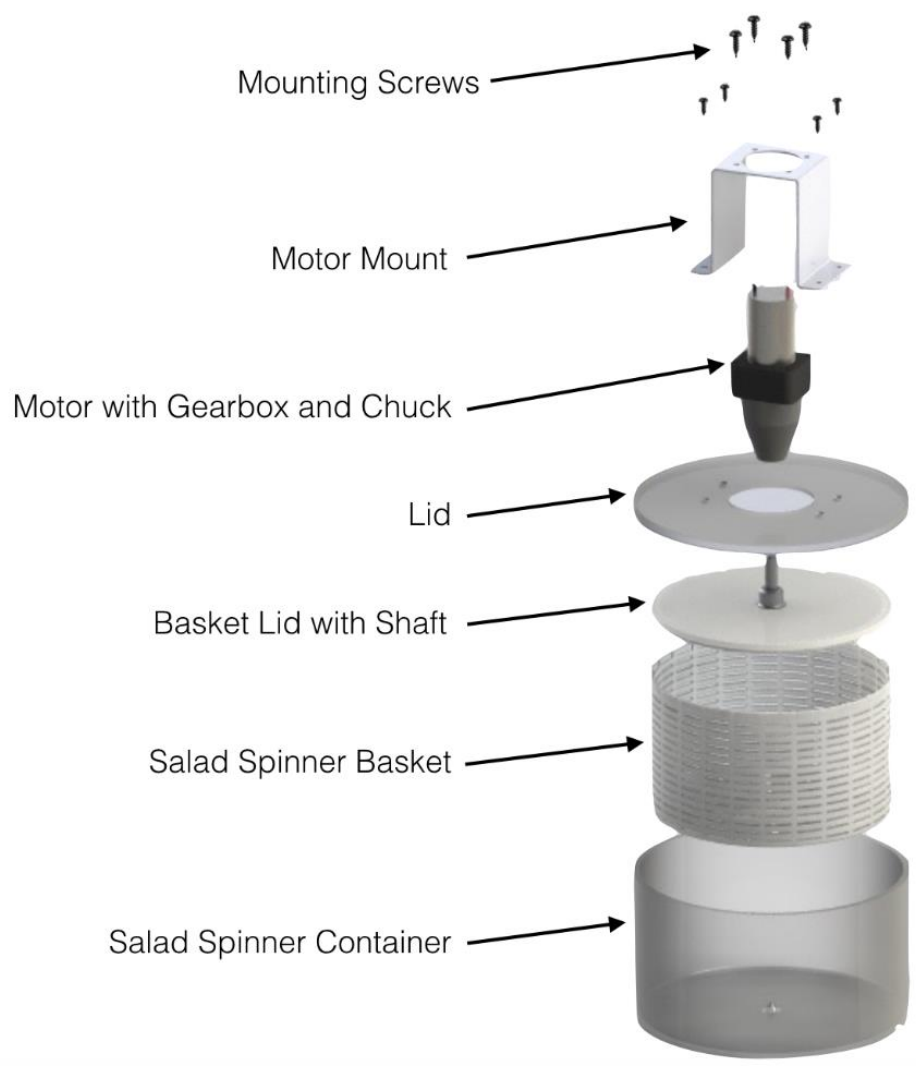

Figure 15 - Exploded View of Testing Apparatus with Labels 
The testing apparatus mainly consists of salad spinner components - most of which have been modified to work for this project. The most challenging part about the design portion was identifying a method to mount the motor onto the salad spinner. This mount had to be sturdy enough to withstand the vibrations of the motor while not interfering with the magnets of the electric DC motor; this is only an issue if carbon steel is used for the motor mount. The motor mount was then made with steel because of its availability and reasonable cost. In order to avoid magnetic interference, the mount was designed with sufficient clearance between the mount and the DC motor. This part was made at the hanger, one of Cal Poly's fully equipped machine shops. A 1/16" sheet of carbon steel was purchased and manufactured into the motor mount. At the machine shop, holes were drilled and the sheet metal was cut to size and bent accordingly. See Appendix A2 for a drawing of this component.

\subsection{Experimentation}

The purpose of the experimentation was to identify how much oil could be removed from French Fries by processing them through a centrifuge. Removing the oil would reduce the fat and the calorie content and hence would make the French Fries slightly healthier. The question to be addressed was how much oil could be removed without adversely affecting the texture.

During the experiment, the general process followed was identical to that of the preliminary pilot test, however, certain variables were controlled. Some of these variables included the type of fry, the speed of the centrifuge, and the time the fries spent 
in the centrifuge. The variables were independently manipulated. This approach resulted in identifying the combination that would yield fries with the most oil removed, while maintaining the taste and the texture of the fries.

\subsubsection{Pilot Test}

In order to determine the number of trials per treatment for this experiment, a pilot test was conducted. Since this was a pilot test, it was not possible to determine a clear trend in this data. The data obtained from the pilot test was used to determine the number of trials required to obtain statistically significant data. During the pilot test, there were four different treatments with at least four trials of each. Each trial in each treatment consisted of four fries. The amount of fries per treatment was small to avoid wasting large amounts of fries. The key factor in conducting the test was the number of trials carried out rather than the quantity per trial. The number of trials per treatment for the pilot test is shown below on Table 1 .

Table 1 - Amount of Trials per Treatment for the Pilot Test

\begin{tabular}{|l|c|c|c|}
\cline { 3 - 4 } \multicolumn{2}{c|}{} & \multicolumn{2}{c|}{ Time } \\
\cline { 3 - 4 } \multicolumn{2}{c|}{} & 60 seconds & 120 seconds \\
\hline Angular & 350 RPM & 4 & 4 \\
\cline { 2 - 4 } Velocity & 550 RPM & 4 & 8 \\
\hline
\end{tabular}

The procedures for the pilot test were as follows:

1) Cut Russet potatoes with French fry cutter and make fries all approximately the same size (9.5 grams)

2) Place four fries in $350-375 \mathrm{~F}$ vegetable oil for approximately four minutes

3) Rapidly measure the mass of each French fry 
4) Transfer to salad spinner and spin for 60 seconds to 120 seconds

5) Measure mass of fries in order to determine amount of oil lost

The treatment at $550 \mathrm{rpm}$ for 120 seconds included twice the number of trials compared with the other treatments. The purpose of doubling the trials for that treatment was to check if that would produce any difference after running more trials. It was assumed that the treatment could possibly produce the largest amount of oil extracted. After running these trials for the pilot test, the results were plotted in a scattered plot on Figure 16. The blue dots depict the average for each treatment, while the grey dots depict the average for a specific trial. The response is shown on the y-axis as change in mass, which was the amount of oil removed from the fries after centrifugation.

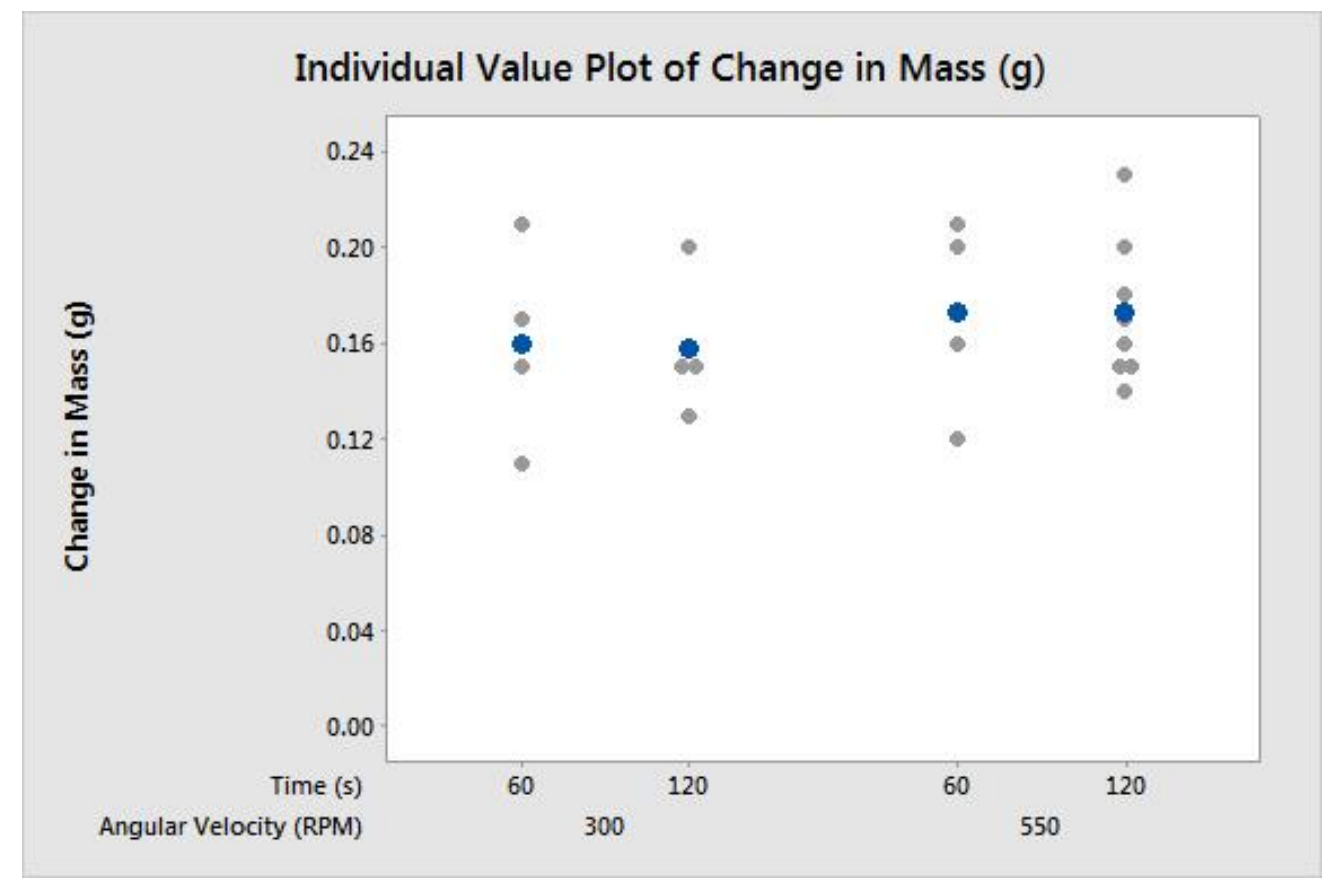

Figure 16 - Average Amount of Oil Extracted for Each Treatment 


\subsubsection{Experimental Run \#1}

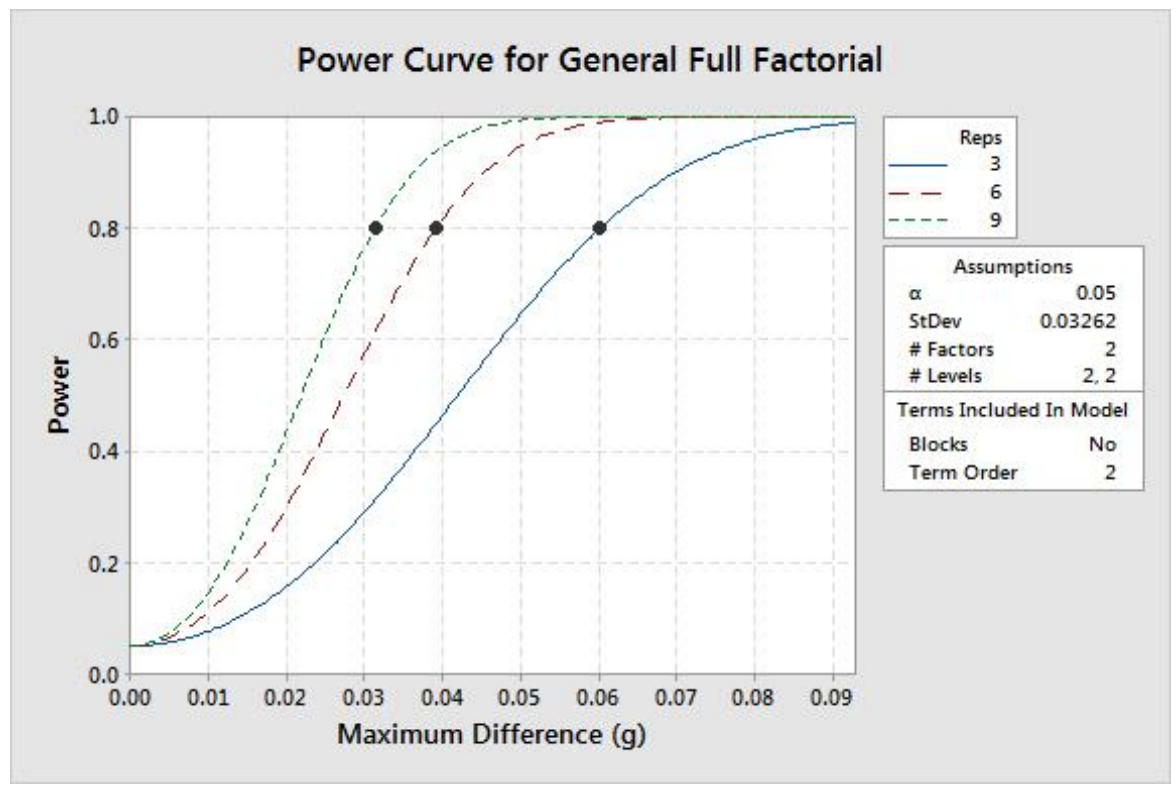

Figure 17 - Power Curves Generated from the Pilot Test

Using Minitab 17, statistical analysis software, the pilot test data was processed in order to determine how many repetitions the first experimental run would need [17]. Figure 17 depicts the power curves obtained from Minitab. The purpose of a power analysis is to determine the amount of trials required to have sufficient power to draw conclusions [17]. Each curve refers to the different amount of repetitions, the plot above includes three, six, and nine repetition curves. In this figure the black dots, on the red dashed line for six repetitions, represent an $80 \%$ probability that a maximum difference of $0.04 \mathrm{~g}$ can be obtained with only six repetitions. While with nine repetitions, there is an $80 \%$ probability that the max difference will be slightly over $0.03 \mathrm{~g}$. It was determined that six repetitions for each treatment would be best for experimental run \#1. This provided enough trials to draw conclusions because $0.04 \mathrm{~g}$ max different was an acceptable value and 36 trials did not take an excessive amount of time to run. Table 2 shown below describes each treatment and the amount of trials per treatment. 
Table 2 - Amount of Trials per Treatment for Experimental Run \#1

\begin{tabular}{|c|c|c|c|}
\cline { 3 - 4 } \multicolumn{2}{c|}{} & \multicolumn{2}{c|}{ Time } \\
\cline { 3 - 4 } \multicolumn{2}{c|}{} & 60 seconds & 120 seconds \\
\hline \multirow{3}{*}{$\begin{array}{c}\text { Angular } \\
\text { Velocity }\end{array}$} & 200 RPM & 6 & 6 \\
\cline { 2 - 4 } & 450 RPM & 6 & 6 \\
\cline { 2 - 4 } & 700 RPM & 6 & 6 \\
\hline
\end{tabular}

The recipe for this experimental run was a quick and easy one. The procedures for experimental run \#1 were very similar to that of the pilot test. The procedures were as follows:

1) Cut Russet potatoes with French fry cutter and obtain fries all approximately the same size (approx. 9.5 grams)

2) Place fries in $350-375 \mathrm{~F}$ vegetable oil for approximately four minutes

3) Rapidly take the mass of each French fry

4) Transfer to centrifuge and spin at a specified rpm for a specified time, depending on treatment

5) Obtain mass of fries again in order to obtain the change in mass

Assuming all the mass lost from the fries in the centrifuge was oil, the change in mass of the fries was obtained. This change indicated how much oil was removed from the fries. This value could then be compared to other treatments to identify which treatment would extract the most oil. Other factors considered while spinning fries was the texture and the flavor of the fries. Oil adds flavor to the food, thus removing oil removes some of the flavor. In addition, spinning at high angular velocities may cause the fries to bend or break in half, which was undesirable. 
The results of the 36 trials from this experimental run could provide data that determined whether angular velocity or time in the centrifuge affected the amount of oil extracted. The results could also determine if there was an interaction between the time and the angular velocity. An interaction between the two variables indicates that one variable depends on another.

\subsubsection{Experimental Run \#2}

Experimental run \#1 was done with home cooked fries starting with a potato, while in the $2^{\text {nd }}$ run used store-bought frozen fries were used. The fries were packaged and processed by NORPAC. Using these fries was an attempt to obtain fries similar to those used in commercial establishments. This experiment provided data that can compare home fries and commercially used fries. The number of trials and treatments were identical to experimental run \#1 as shown in Table 2 above. The procedure was as follows:

1) Place fries in $350-375 \mathrm{~F}$ vegetable oil for approximately five minutes

2) Rapidly take the mass of each French fry

3) Transfer to centrifuge and spin at a specified rpm for a specified time, depending on treatment

4) Obtain mass of fries in order to determine amount of oil lost

Since frozen pre-cut fries were used, the only difference was that there was no need to cut the fries. All the fries from experimental run \#2 were different in size and shape, therefore, the data was normalized in order to compare data across all types of fires. The 
percentage change in mass was calculated in order to properly compare the two different styles of fries.

The results from experimental run \#2 from frozen store-bought fries produced a different outcome from experimental run \#1. The results also revealed if the angular velocity and duration of centrifugation affected the amount of oil extracted.

\subsubsection{Experimental Run \#3}

The third experimental run was carried out with freshly cut Russet potatoes, but with a different recipe. The purpose of running another experiment similar to experimental run \#1 was to obtain home style fries that have a crunchier texture. The fries from the first experimental run were slightly soft and soggy. This was due to the fact that the recipe was the fastest and the easiest way to make home style French fries. The fries in this experimental run will use a recipe derived from Guy Fieri’s double fry technique. [18] An additional step prior to the second round of frying was added to generate a crispier crust. The procedures for this experimental run were as follows:

1) Cut Russet potatoes with French fry cutter and obtain fries all approximately the same size (approx. 9.5 grams)

2) Place fries in $350-375 \mathrm{~F}$ vegetable oil for approximately one minute

3) Remove fries from hot oil and place in ice cold water for a few minutes

4) Remove fries from cold water and dry with a paper towel

5) Place fries back in hot oil for approximately four minutes

6) Remove fries from hot oil and rapidly take the mass of each French fry 
7) Transfer to centrifuge and spin at a specified rpm for a specified time, depending on treatment

8) Obtain mass of fries again in order to obtain the change in mass

The purpose of this experimental run was to test a wider variety of fries. This experiment also generated more data that further revealed the effects of the angular velocity and the duration of centrifugation 


\section{Chapter 4. Results}

\subsection{Experimental Run \#1}

Experimental run \#1 was successfully accomplished with fresh cut Russet potatoes. The recipe used was simply frying the fries in hot oil for four minutes. There were six treatments with six trials of each treatment, totaling 36 trials. Each trial consisted of four fries. See Table 2 above for a brief description of each treatment. Figure 18 depicts a scatter plot of the data obtained from this experimental run. The blue dots mark the average amount for that specific treatment, while the grey dots are the average of each trial.

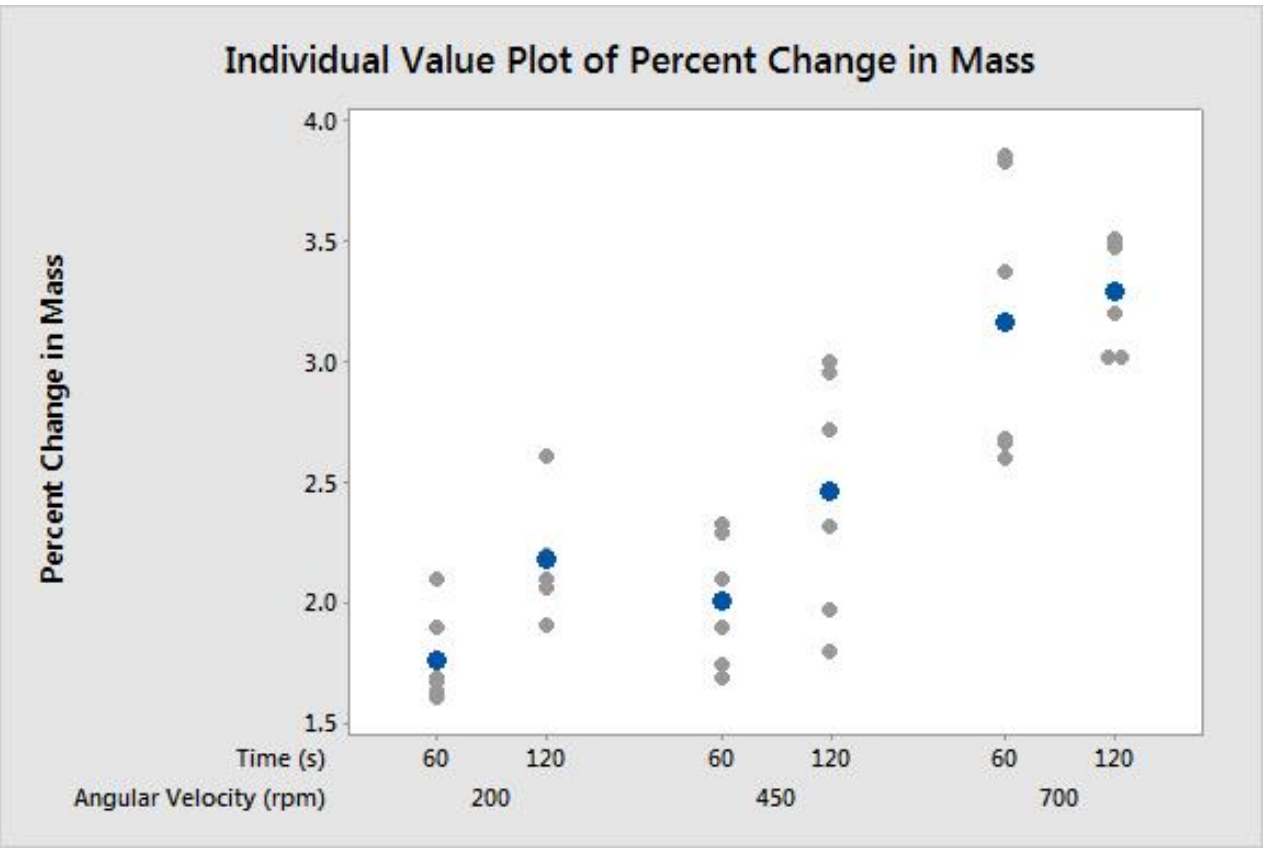

Figure 18 - Individual Value Plot Obtained from Experimental Run \#1 
In the following sections of Chapter 4, statistical analysis will be abundant. This paragraph will briefly review the statistics used for this paper. Starting with the analysis of variance, also known as ANOVA, it was used to determine if there exist a significant difference between data sets [19]. The ANOVA produced p-values which represents the probability of the occurrence of a given event [19]. For instance, at small p-values, the null hypothesis would be rejected [19]. This means it is unlikely that the data sets are different by chance. When a data set is deemed statistically significant - ANOVA produces a small p-value - Tukey comparisons were carried out. Tukey comparisons use data from the ANOVA and identifies means that are statistically different from each other. For example, the ANOVA can prove that angular velocity affects the amount of oil extraction from an experiment. While the Tukey comparisons can prove that $450 \mathrm{rpm}$ and $700 \mathrm{rpm}$ produces statistically different data. The two main comparisons used in this study are the difference of mean and grouping comparisons. The difference of mean compares two data sets and determines a p-value for them. The p-value will identify if the two data sets are different. On the other hand, the grouping comparison will place each data set in a group, therefore data sets labeled in the same group are not statistically different.

From the scatterplot shown on Figure 18, it seems that angular velocity does affect the amount of oil removed for these fries. After running the ANOVA model, the p-value indicated that the angular velocity was likely to affect the amount of oil extracted because the null hypothesis is rejected. It is possible to use the Tukey comparison since ANOVA verified that angular velocity was statistically significant. Table 4 shows grouping labels 
for each angular velocity used in the experiment. When there are angular velocities that do not share a letter, the two or more angular velocities are significantly different. Noticing that the average amount of oil extracted from $200 \mathrm{rpm}$ and $450 \mathrm{rpm}$ were not significantly different from each other, they were placed in the same group. While at 700 $\mathrm{rpm}$, there was a significant difference, this data was in a different group. The difference of means using the Tukey pairwise comparison also proves that assessing $200 \mathrm{rpm}$ and $450 \mathrm{rpm}$ is unlikely to produce a statistical difference due to the large p-value of 0.215 or $21.5 \%$. While on the other hand, comparing $700 \mathrm{rpm}$ to $200 \mathrm{rpm}$ or $450 \mathrm{rpm}$ produces a p-value of zero. This indicates that the null hypothesis is rejected and there is a statistical difference between these values for the resulting amount of oil extracted. Therefore, it can be concluded with confidence that the angular velocity affects the amount of oil extracted during the use of the centrifuge.

Table 3 - p-Values from Experimental Run \#1 Obtained via ANOVA

\begin{tabular}{|c|c|}
\hline Factor & p-Value \\
\hline Angular Velocity & 0.000 \\
\hline Time & 0.013 \\
\hline
\end{tabular}

Table 4 - Grouping Information Using Tukey Comparison for Angular Velocity

\begin{tabular}{|c|c|c|}
\hline Angular Velocity (rpm) & Mean Percent Change in Mass & Grouping \\
\hline 700 & 3.23 & $\mathrm{~A}$ \\
\hline 450 & 2.36 & $\mathrm{~B}$ \\
\hline 200 & 1.97 & $\mathrm{~B}$ \\
\hline
\end{tabular}

Table 5 - Difference of Means using Tukey Pairwise Comparison

\begin{tabular}{|c|c|c|}
\hline Difference of Angular Velocity Levels & Difference of Means & p - Value \\
\hline $450-200$ & 0.26 & 0.215 \\
\hline $700-200$ & 1.25 & 0.000 \\
\hline $700-450$ & 0.99 & 0.000 \\
\hline
\end{tabular}


See Appendix C for descriptions, tutorials, and raw data from the statistical analysis using Minitab 17.

The p-value obtained from the ANOVA for time is modeled to be 0.013 , which implies that the null hypothesis is rejected. Since the null hypothesis is rejected, it is likely that time spent in the centrifuge effects the amount of oil removed from the fries. Since ANOVA for time proved statistically significant, the Tukey pairwise comparison grouping information was obtained. When 120 seconds and 60 seconds have different grouping labels for the Tukey pairwise comparison, it indicates that the average amount of oil extracted is statistically different at these two times.

Table 6 - Grouping Information Using Tukey Comparison for Angular Velocity

\begin{tabular}{|c|c|c|}
\hline Time (s) & Mean Percent Change in Mass & Grouping \\
\hline 120 & 2.64 & $\mathrm{~A}$ \\
\hline 60 & 2.31 & $\mathrm{~B}$ \\
\hline
\end{tabular}

From experimental run \#1 it was concluded that angular velocity and time are likely to independently make a difference in the amount of oil extracted from fries when placed in a centrifuge. These results were obtained using Minitab's ANOVA and Tukey pairwise comparisons. See Appendix B and Appendix C for more details pertaining to the statistical analysis done using Minitab 17. These conclusions are for a simple and quick recipe of home-made fries from Russet potatoes.

\subsection{Experimental Run \#2}

The second experimental run was successfully accomplished with store-bought frozen fries. The fries bought were processed by NORPAC. These fries endured the same 
treatments as the home-cooked fries from the first experimental run. After obtaining data for 36 total trials for six different treatments, the data was plotted on an individual value plot shown below on Figure 19. The grey points are the average values of the four fries for each trial, while the blue dots depict the average value for that specific treatment of six trials. Assuming that only oil is being removed, the change in mass is calculated by weighing the fries before and after being placed in the centrifuge.

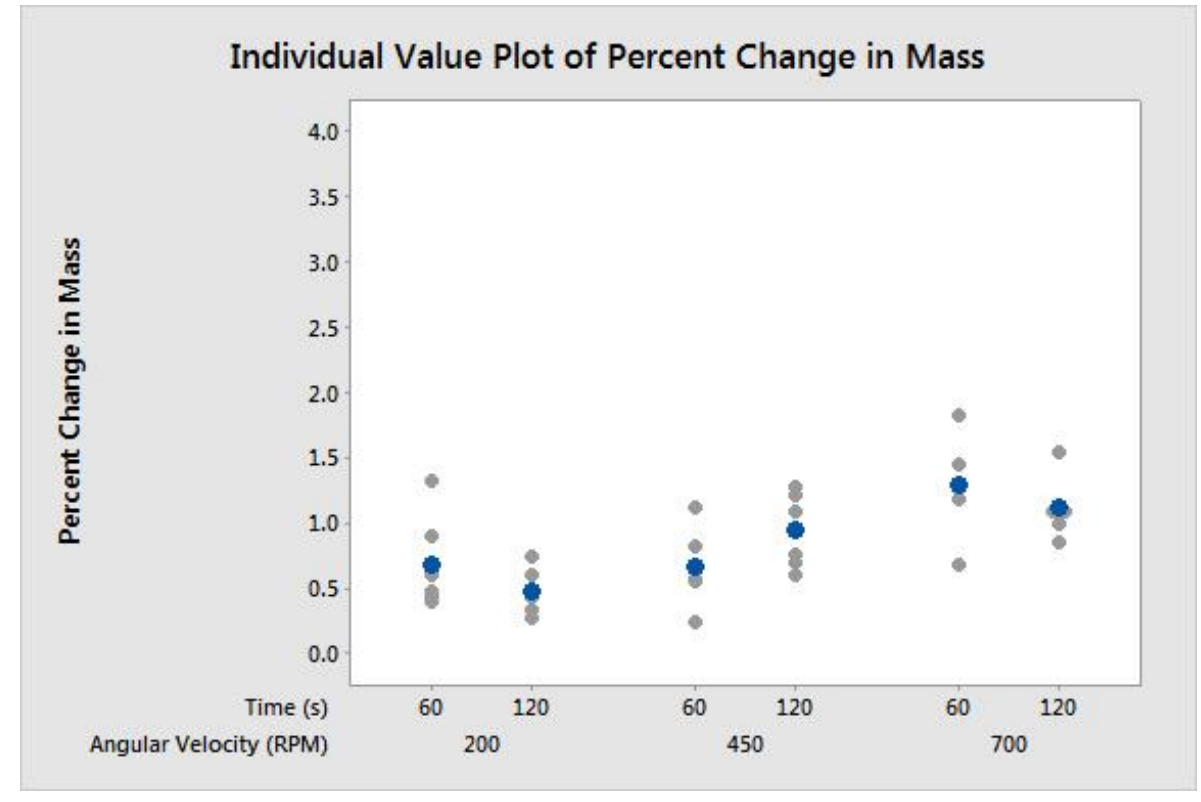

Figure 19 - Individual Value Plot for Experimental Run \#2

By simply viewing the individual value plot alone, the angular velocity seems to have an effect on the amount of oil extracted. In order to identify if the effects of time and angular velocity independently affect the amount of oil removed, an ANOVA was modeled in Minitab. This produced a p-value of zero for angular velocity, which implies that the null hypothesis is rejected. When the null hypothesis is rejected, for this case it signifies that it is very likely that the angular velocity would make a difference in the amount of oil removed from the fries. In order to validate the results from ANOVA, the Tukey pairwise 
comparison was utilized. The grouping information for the Tukey comparison is shown in Table 8 below. This table shows that $700 \mathrm{rpm}$ is statistically different from $450 \mathrm{rpm}$ and $200 \mathrm{rpm}$. Therefore, the two lower angular velocities are not statistically different. This is confirmed by the difference of means shown on Table 9 below. Between $450 \mathrm{rpm}$ and $200 \mathrm{rpm}$, a p-value of 0.185 is obtained via difference of means from the Tukey pairwise comparison model. This means that between $450 \mathrm{rpm}$ and $200 \mathrm{rpm}$ the null hypothesis is not rejected and it is likely that these two values do not make a statistical difference in the amount of oil removed. On the other hand, comparing $700 \mathrm{rpm}$ to either $450 \mathrm{rpm}$ or $200 \mathrm{rpm}$ produces a very low p-value meaning that it is very likely these two to have statistically different values.

Table 7 - p-Values from Experimental Run \#2 Obtained via ANOVA

\begin{tabular}{|c|c|}
\hline Factor & p-Value \\
\hline Angular Velocity & 0.000 \\
\hline Time & 0.736 \\
\hline
\end{tabular}

Table 8 - Grouping Information Using Tukey Comparison for Angular Velocity

\begin{tabular}{|c|c|c|}
\hline Angular Velocity (rpm) & Mean of Percent Change in Mass & Grouping \\
\hline 700 & 1.21 & $\mathrm{~A}$ \\
\hline 450 & 0.80 & $\mathrm{~B}$ \\
\hline 200 & 0.59 & $\mathrm{~B}$ \\
\hline
\end{tabular}

Table 9 - Difference of Means using Tukey Pairwise Comparison

\begin{tabular}{|c|c|c|}
\hline Difference of Angular Velocity Levels & $\begin{array}{c}\text { Difference of Means } \\
\text { (\% Change in Mass) }\end{array}$ & $\mathbf{p}$ - Value \\
\hline $450-200$ & 0.22 & 0.185 \\
\hline $700-200$ & 0.62 & 0.000 \\
\hline $700-450$ & 0.40 & 0.006 \\
\hline
\end{tabular}

To understand the effects that time has on the amount of oil removed, just from viewing the individual value plot, there does not seem to be a pattern and seems inconclusive. 
Noting that the p-value obtained from ANOVA was calculated to be 0.736 , or $73.6 \%$, the null hypothesis was not rejected and it was unlikely that time has an effect on the amount of oil removed. Since the time was not statistically significant, a Tukey comparison could not be successfully obtained.

Also, for this experimental run, it was important to note that $8.3 \%$ of the fries at $450 \mathrm{rpm}$ were damaged, while $16.7 \%$ of the fries at $700 \mathrm{rpm}$ were damaged. This can pose an issue because when fries are broken in half, they seem to look less appetizing.

From the data obtained after running experiment \#2 with store-bought frozen fries, angular velocity was very likely to affect the amount of oil removed, while time was unlikely to make a statistical difference. These conclusions were obtained after analyzing the data from 36 trials of fries that were processed in the centrifuge post-frying. ANOVA and Tukey comparisons were used in Minitab for the statistical analysis. See Appendix B and Appendix $\mathrm{C}$ for more details on the statistical analysis using Minitab.

\subsection{Experimental Run \#3}

This experimental run incorporated a new recipe for fries, starting with a Russet potato. This recipe was different in that it included a few additional steps in the cooking process that produced fries with a crispier crust. The data collected from this run is shown below on Figure 20. The grey points are the average values of the four fries for each trial, while the blue dots depict the average value for that specific treatment of six trials. 


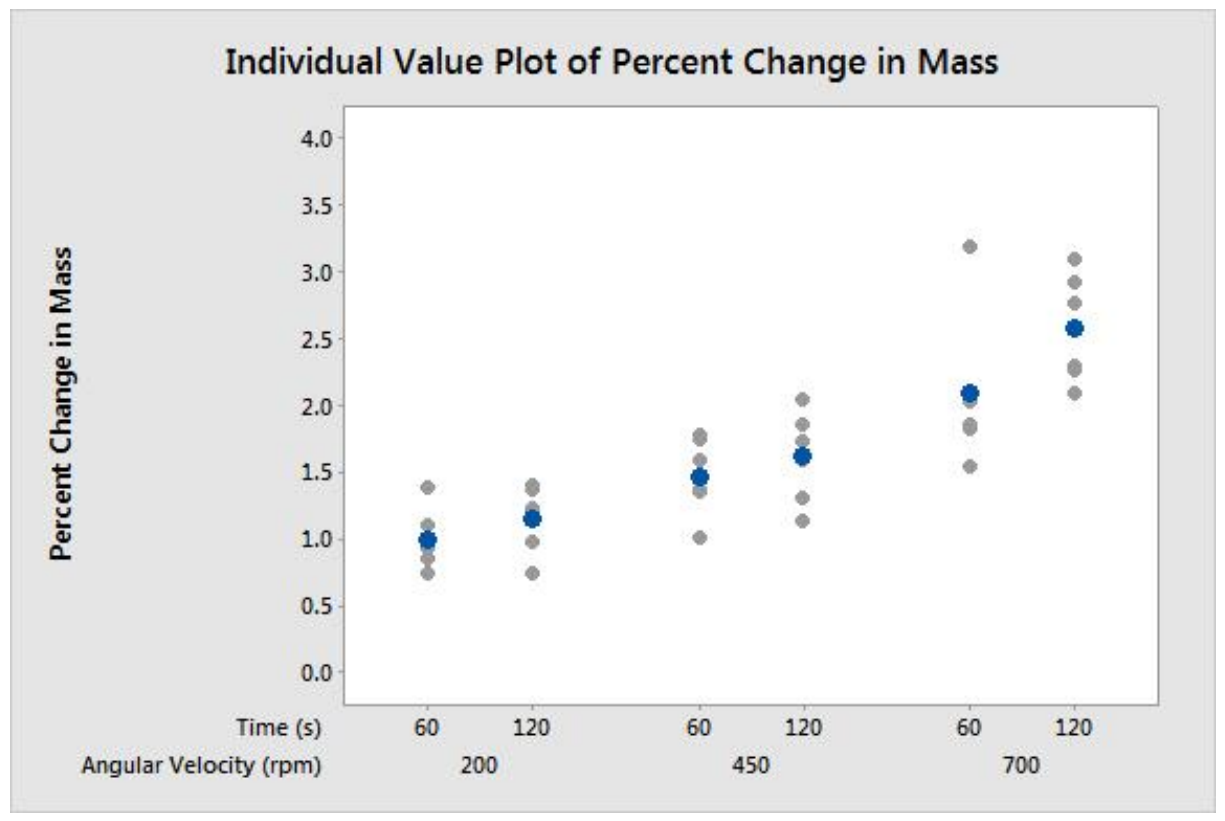

Figure 20 - Individual Value Plot for Experimental Run \#3

From the individual value plot alone, it seemed that angular velocity did in fact affect the amount of oil extracted from the fries. In order to confirm this, the p-value was obtained via ANOVA. Angular velocity had a p-value of zero which means the null hypothesis was rejected. Therefore, it was very likely that changing the angular velocity affected the amount of oil extracted. In addition, this means that the data was statistically significant for angular velocity. The grouping information was obtained via Tukey pairwise comparison, each angular velocity, $200 \mathrm{rpm}, 450 \mathrm{rpm}$, and $700 \mathrm{rpm}$ were statistically different from each other. In addition, the difference of means obtained from the Tukey pairwise comparison produced very small or zero p-values for all different angular velocities. This means that the null hypothesis was rejected and it is very likely these angular velocities produce statistically difference results. This case shows that as the angular velocity was increased from $200 \mathrm{rpm}$ to $700 \mathrm{rpm}$, the mean percent change in 
mass - or amount of oil extracted - increased. Table 11 and 12 show the Tukey pairwise comparison data below for angular velocity.

Table 10 - p-Values from Experimental Run \#3 Obtained via ANOVA

\begin{tabular}{|c|c|}
\hline Factor & p-Value \\
\hline Angular Velocity & 0.000 \\
\hline Time & 0.042 \\
\hline
\end{tabular}

Table 11 - Grouping Information Using Tukey Comparison for Angular Velocity

\begin{tabular}{|c|c|c|}
\hline Angular Velocity (rpm) & Mean of Percent Change in Mass & Grouping \\
\hline 700 & 2.33 & $\mathrm{~A}$ \\
\hline 450 & 1.55 & $\mathrm{~B}$ \\
\hline 200 & 1.07 & $\mathrm{C}$ \\
\hline
\end{tabular}

Table 12 - Difference of Means using Tukey Pairwise Comparison

\begin{tabular}{|c|c|c|}
\hline Difference of Angular Velocity Levels & $\begin{array}{c}\text { Difference of Means } \\
\text { (\% Change in Mass) }\end{array}$ & $\mathbf{p}$ - Value \\
\hline $450-200$ & 0.47 & 0.010 \\
\hline $700-200$ & 1.26 & 0.000 \\
\hline $700-450$ & 0.79 & 0.000 \\
\hline
\end{tabular}

Since time produced a small p-value from the ANOVA, it is statistically significant.

From the individual value plot shown above in Figure 20, it seemed like time did make a difference to the amount of oil removed. The small p-value confirmed this because the null hypothesis was rejected. In addition, the Tukey pairwise comparison is shown below in Table 14. The Tukey pairwise comparison was done for time because the small p-value from the ANOVA indicated that this was statistically significant. Since the grouping labels for the Tukey comparison were different, it meant that the time produced values that are statistically different. In this case, it was noted that when the fries spent more time in the centrifuge, it was very likely that more oil was removed from the fries. 
Table 13 - Grouping Information Using Tukey Comparison for Angular Velocity

\begin{tabular}{|c|c|c|}
\hline Time (s) & Mean of Percent Change in Mass & Grouping \\
\hline 120 & 1.78 & $\mathrm{~A}$ \\
\hline 60 & 1.52 & $\mathrm{~B}$ \\
\hline
\end{tabular}

Also, for this experimental run, it is important to note that $39.6 \%$ of the fries at $450 \mathrm{rpm}$ were damaged, while $45.8 \%$ of the fries at $700 \mathrm{rpm}$ were damaged.

From the data obtained after running the third experiment with a new home-cooked recipe, it was concluded that angular velocity and time affected the amount of oil extracted. This conclusion was drawn by using ANOVA and Tukey comparisons done in Minitab 17, a statistical analysis software. See Appendix B and Appendix C for more details on the statistical analysis using Minitab 17.

\subsection{Combined Data for all Three Experiments}

Since a significant amount of data was collected for the various types of fries, all the data was compiled into one model for statistical analysis. Combining all the data together from the three experiments provided more meaningful statistical information regarding the angular velocity, the duration, and the type of fry. One of the more important aspects of combining all the data is understanding if there exist any interactions between the variables. An interaction occurs when the output variable (percent change in mass) consists of a more complicated relationship with the independent variables. Thus, the independent variables cannot sufficiently describe the amount of oil removed from fries individually because they depend on the other factor(s) as well. 


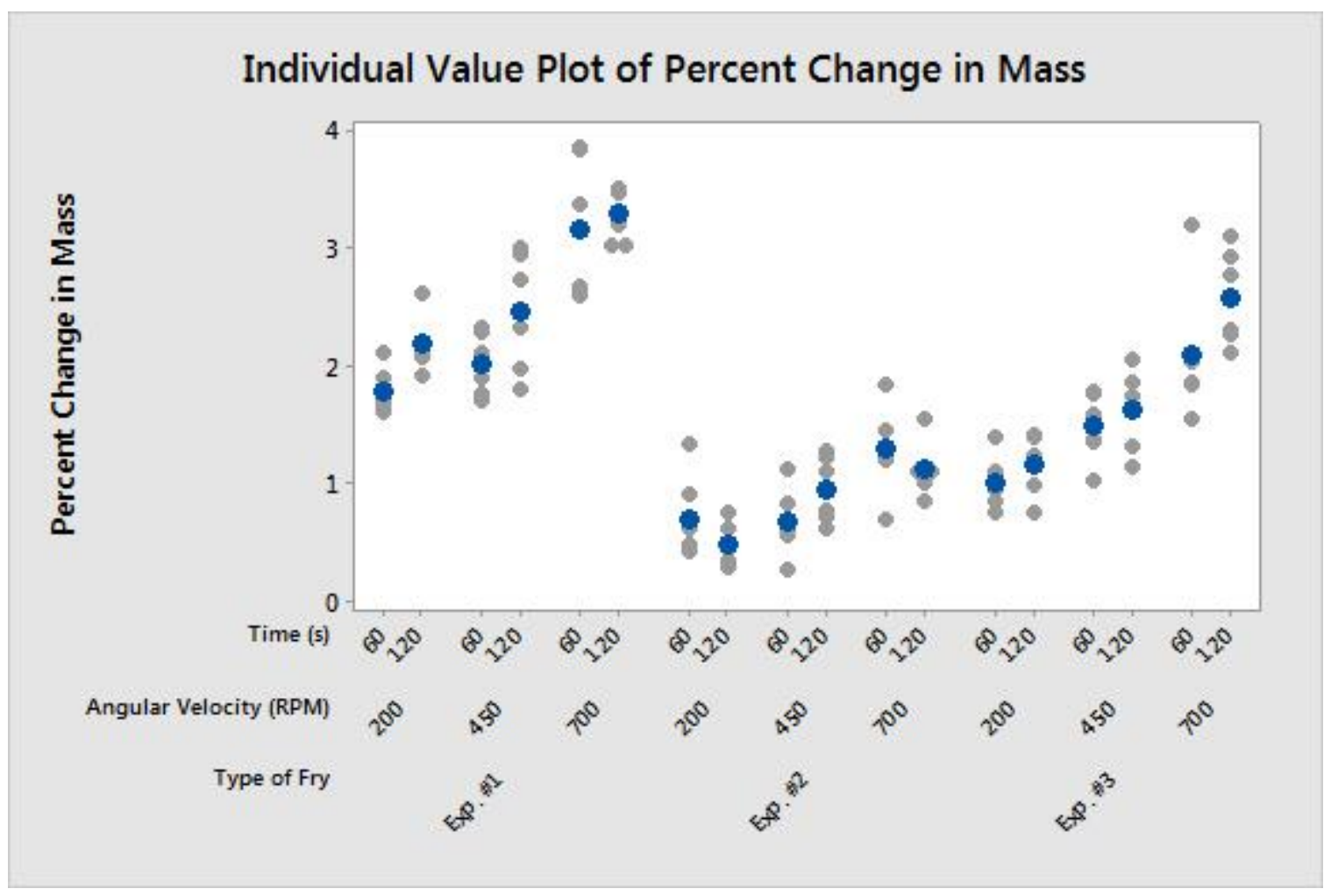

Figure 21 - Individual Value Plot for Experimental Run \#1-3

Figure 21 shown above, demonstrates the individual value plot for the data of all the experimental runs. The grey points are the average values of the four fries for each trial, while the blue dots depict the average value for that specific treatment of six trials. From this plot alone, there definitely seems to be a few trends present with the compiled data. One of the first things noticed from this plot is the trend caused by the different type of fries. There were three different experiments with three different types of fries which seem to produce varying percent changes in masses.

From Table 14 below, the ANOVA produced a p-value of zero for the type of fry. This means that the null hypothesis was rejected and the type of fry was very likely to produce a difference in the percent change in mass. A small p-value also means that the data was 
statistically significant and the Tukey comparisons can provide additional useful information.

Table 14 - p-Values from Experimental Run \#1-3 Obtained via ANOVA

\begin{tabular}{|c|c|}
\hline Factor & p-Value \\
\hline Type of Fry & 0.000 \\
\hline Angular Velocity & 0.000 \\
\hline Time & 0.007 \\
\hline Type of Fry * Time & 0.072 \\
\hline Type of Fry * Angular Velocity & 0.005 \\
\hline Time * Angular Velocity & 0.531 \\
\hline
\end{tabular}

The grouping information for the Tukey comparison is shown below for the three types of fries used in experimental run one through three. Since all three types of fries are grouped separately, they are statistically different from each other. Experimental run one used a simple home-made recipe that produced the highest mean percent change in mass at $2.48 \%$. This was most likely due to the microstructure generated from this recipe. Since this type of fry was not very crunchy and had the softest crust of the three types of fries, it may be the reason the most amount of oil was extracted. While experimental run \#2 used store-bought frozen fries that produced the least amount of oil removed, averaging $0.86 \%$ change in mass. These fries were significantly crunchier than those of experimental run \#1. This can imply that there is another underlying trend in terms of texture and amount of oil extracted. This is not however, the scope of this report but can be a topic for further study. In addition, the difference of means obtained from the Tukey comparison also confirmed that each type of fry was statistically different from one another. Shown in Table 15 below, all fry types are likely to be different from each other in terms of amount of oil removed. This was true because all comparisons have a small pvalue, which means the null hypothesis as rejected. Therefore, it can be concluded that 
the type of fry will produce different results for the amount of oil removed after centrifugation.

Table 15 - Grouping Information Using Tukey Comparison for Type of Fry

\begin{tabular}{|c|c|c|}
\hline Type of Fry & Mean Percent Change in Mass & Grouping \\
\hline Exp. \#1 & 2.48 & A \\
\hline Exp. \#3 & 1.65 & B \\
\hline Exp. \#2 & 0.86 & C \\
\hline
\end{tabular}

Table 16 - Difference of Means using Tukey Comparison for Type of Fry

\begin{tabular}{|c|c|c|}
\hline Difference of Type of Fry Levels & $\begin{array}{c}\text { Difference of Means } \\
\text { (\% Change in Mass) }\end{array}$ & $\mathbf{p}$ - Value \\
\hline Exp. \#2 - Exp. \#1 & 1.61 & $<0.0005$ \\
\hline Exp. \#3 - Exp. \#1 & 0.83 & $<0.0005$ \\
\hline Exp. \#3 - Exp. \#2 & 0.79 & $<0.0005$ \\
\hline
\end{tabular}

Subsequently, as the individual value plot on Figure 21 above shows, the angular velocity does in fact seem to affect the amount of oil extracted for every type of fry. A p-value of zero was obtained from ANOVA. This means that the null hypothesis is rejected and it is very likely that the angular velocity will affect the amount of oil extracted. Since the small p-value also indicates that the data is statistically significant for angular velocity, the Tukey comparisons can be performed. Using both the grouping and difference of mean Tukey comparisons, it can be concluded that all the angular velocities tested are statistically different from each other. This is confirmed because each angular velocity has been assigned to a different group according to the grouping information from the Tukey comparison. At $700 \mathrm{rpm}$ averaging the most amount of oil removed while at 200 $\mathrm{rpm}$, the least amount of oil removed. This is what would be expected since it logically makes sense. The difference of mean comparison yielded very small or zero p-values for 
all difference of angular velocity levels. This implies that each angular velocity produces results that are statistically different from each other.

Table 17 - Grouping Information Using Tukey Comparison for Angular Velocity

\begin{tabular}{|c|c|c|}
\hline Angular Velocity (rpm) & Mean of Percent Change in Mass & Grouping \\
\hline 700 & 2.25 & $\mathrm{~A}$ \\
\hline 450 & 1.53 & $\mathrm{~B}$ \\
\hline 200 & 1.21 & $\mathrm{C}$ \\
\hline
\end{tabular}

Table 18 - Difference of Means using Tukey Comparison for Angular Velocity

\begin{tabular}{|c|c|c|}
\hline Difference of Angular Velocity Levels & $\begin{array}{c}\text { Difference of Means } \\
\text { (\% Change in Mass) }\end{array}$ & $\mathbf{p}$ - Value \\
\hline $450-200$ & 0.32 & 0.001 \\
\hline $700-200$ & 1.04 & $<0.0005$ \\
\hline $700-450$ & 0.73 & $<0.0005$ \\
\hline
\end{tabular}

From the results of the analysis for angular velocity, it can be concluded that angular velocity does in fact affect the amount of oil removed from fries spun in the centrifuge. Particularly, increasing the angular velocity will yield a larger percent change in mass.

The amount of time fries spend in the centrifuge also played a role in the amount of oil removed. From the ANOVA, a p-value of 0.007 or $0.7 \%$ was obtained. This indicated that the null hypothesis was rejected and it was very likely that the amount of time fries spend in the centrifuge will affect the amount of oil removed. Since the time data is statistically significant, confirmed by the small p-value, the analysis can continue with Tukey comparisons. 
Table 19 - Grouping Information Using Tukey Comparison for Time

\begin{tabular}{|c|c|c|}
\hline Time (s) & Mean of Percent Change in Mass & Grouping \\
\hline 120 & 1.76 & A \\
\hline 60 & 1.57 & B \\
\hline
\end{tabular}

Shown above in Table 19, both times are categorized in separate groups according to the Tukey comparison. This is because after the analysis, Minitab considered these two groups to be statistically different. Time does affect the amount of oil removed from the fries, but it was a lot less than the effect caused by angular velocity or type of fry. Therefore, if a time were to be selected for a process at a fast food establishment, it is more likely that 60 seconds be selected over 120 seconds. Since the difference in mean of percent change in mass is very small, it may be acceptable to reduce the amount of oil extracted while significantly reducing the amount of time it takes for food to be processed. Thus, it can be concluded that time does make a statistical difference, but compared to angular velocity, time does not generate a large effect.

Looking back at Table 14, the last three rows are the interactions between each type of variable. Since there were 118 trials in total, it is a general rule that a p-value of 0.01 or less implies that the data is statistically significant. Thus, time caused an effect in the amount of oil removed, but it is unlikely that the effects of time depends on angular velocity or type of fry. The interaction that matters is between angular velocity and type of fry. The p-value for this, according to the ANOVA, is 0.005 or $0.5 \%$, which means that the null hypothesis was rejected. Therefore, angular velocity and type of fry are likely to be interacting in this experiment. This indicates that the effects of angular velocity on the amount of oil removed depends on which type of fry is being processed. 
The main effects plot shown below in Figure 22 summarizes what has been described previously. Type of fry and angular velocity generate large differences in the amount of oil removed, while time does not produce a large effect.

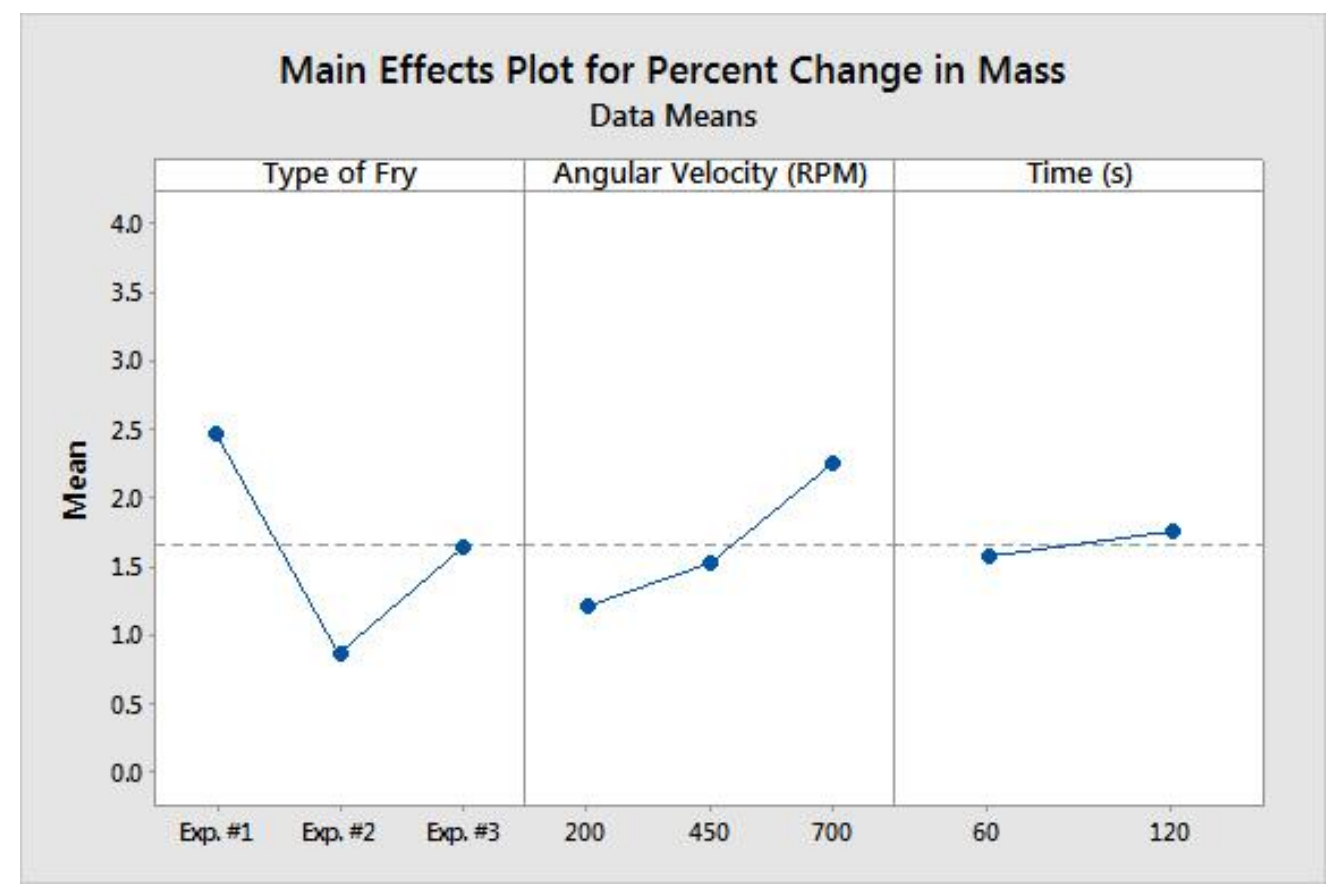

Figure 22 - Main Effects Plot for Experimental Run \#1-3

Given that there was an interaction between the type of fry and the angular velocity, an interaction plot was generated for these variables. See Figure 23 below. To make this easier to understand, one can ask: what effect does the angular velocity have on the amount of oil removed from fries via centrifugation? The answer to this question would be that it depends on what type of fry is being processed. It is obvious that angular velocity has an effect on the amount of oil removed as indicated from the ANOVA. The information that the interaction provides was the amount of percent change in mass that different types of fries have on angular velocity. 


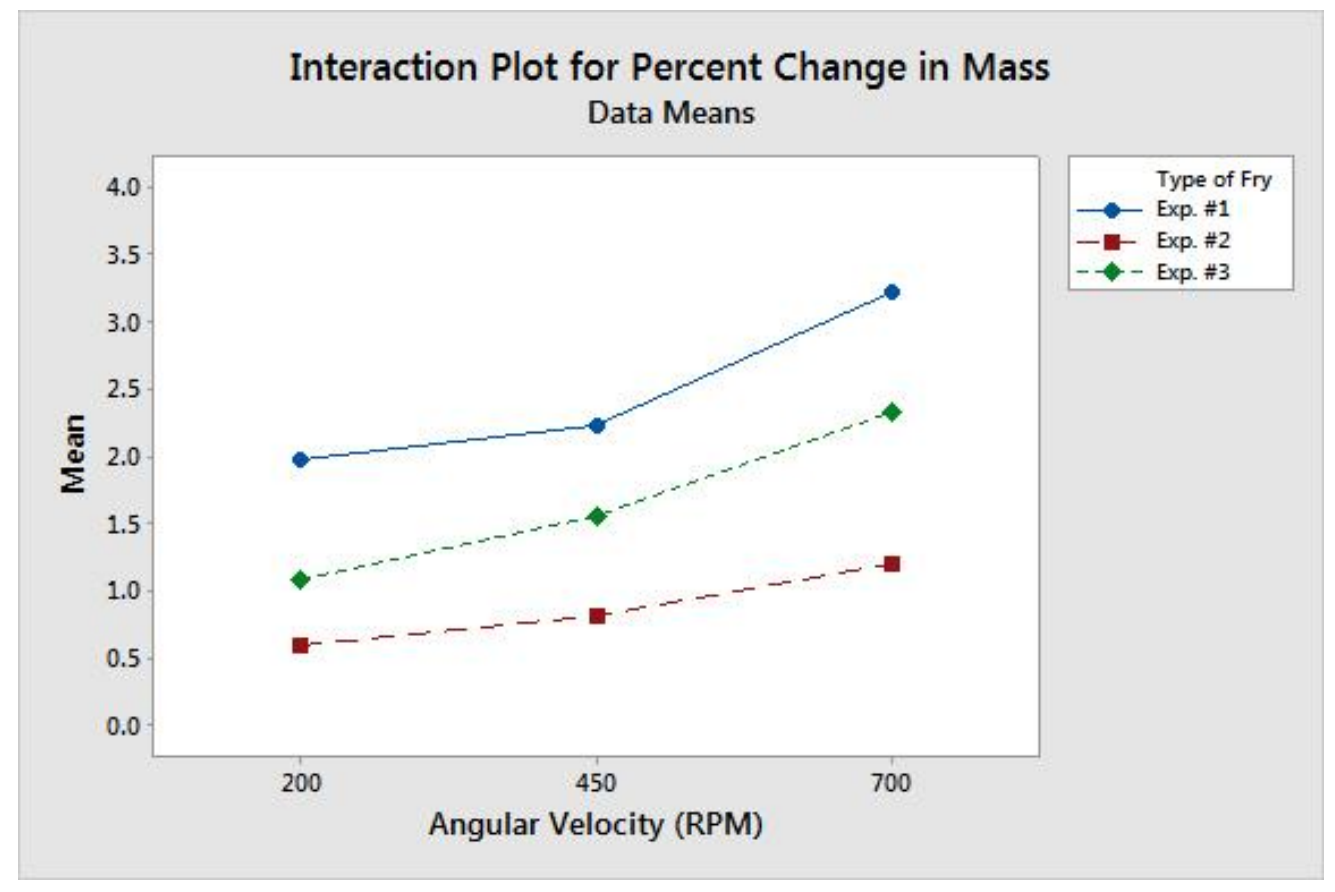

Figure 23 - Interaction Plot for Type of Fry and Angular Velocity

To further dwell into the interaction between angular velocity and type of fry, a Tukey comparison was established. See Table 20 below. It was possible to run a Tukey comparison model because the ANOVA proved that this interaction was statistically significant, hence the small p-value. The table shows the grouping labels assigned for each type of fry and its corresponding angular velocity. For each mean that does not share a letter, it is concluded that those means are significantly different. For instance, the fry used in experimental run one at $700 \mathrm{rpm}$, produced a mean percent change in mass statistically different from every other angular velocity/fry type combination. 
Table 20 - Grouping Information Using Tukey Comparison for Type of Fry

\begin{tabular}{|c|c|c|c|}
\hline Type of Fry & $\begin{array}{c}\text { Angular Velocity } \\
(\mathrm{rpm})\end{array}$ & Mean of Percent Change in Mass & Grouping \\
\hline Exp. \# 1 & 700 & 3.23 & $\mathrm{~A}$ \\
\hline Exp. \# 3 & 700 & 2.33 & $\mathrm{~B}$ \\
\hline Exp. \# 1 & 450 & 2.24 & $\mathrm{~B}$ \\
\hline Exp. \# 1 & 200 & 1.97 & $\mathrm{~B} / \mathrm{C}$ \\
\hline Exp. \# 3 & 450 & 1.55 & $\mathrm{C} / \mathrm{D}$ \\
\hline Exp. \# 2 & 700 & 1.21 & $\mathrm{D} / \mathrm{E}$ \\
\hline Exp. \# 3 & 200 & 1.07 & $\mathrm{E}$ \\
\hline Exp. \# 2 & 450 & 0.80 & $\mathrm{~F}$ \\
\hline Exp. \# 2 & 200 & 0.59 & $\mathrm{~F}$ \\
\hline
\end{tabular}

Therefore, it can be concluded that there exist an interaction between angular velocity and type of fry. This conclusion is based on the results from the ANOVA, interaction plot, and Tukey comparison models. The most amount of oil removed was from experiment one at $700 \mathrm{rpm}$, which were the home-cooked simple recipe fries. While the least amount of oil being removed was from experiment three fries, the store-purchased frozen fries, at $200 \mathrm{rpm}$. 


\section{Chapter 5. Additional Testing and Calculations}

\subsection{Determining Caloric Content}

Determining the caloric content of the fries was necessary to be able to identify the amount of oil removed from the total amount of oil initially present in the fries after being cooked. A cooked and an uncooked fry were both processed through the bomb calorimeter to determine their caloric content. The cooked fry being tested did not go through the centrifugation process because the amount of oil removed from the fries via centrifuge was already known. This phase of the overall project quantified the amount of oil absorbed into the fry after it was fried. The bomb calorimeter was provided by the Cal Poly Mechanical Engineering department, and Professor Glen Thorncroft helped advise its use.

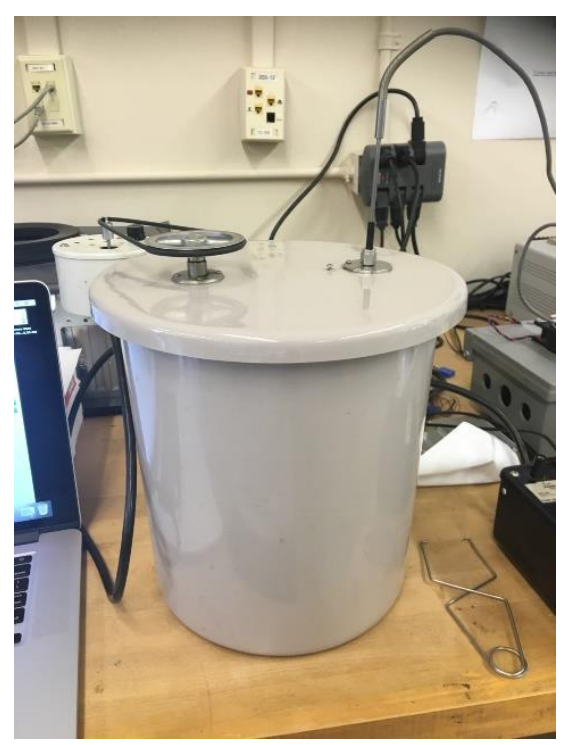

Figure 24 - 1341 Plain Jacket Bomb Calorimeter

The oxygen bomb calorimeter is an insulated container that houses a small steel bucket, which holds water. The fry samples were placed in a second, smaller steel container in 
the water and ignited, causing a measurable increase in the water temperature. That change in temperature was demonstrative of the fries' higher heating value, which was used in the caloric value calculation.

More information on the Parr oxygen bomb calorimeter can be found in Appendix D. The first attempt at using the bomb calorimeter failed. The cooked and uncooked fries could not ignite because of their high moisture content. To resolve this, the fries were placed in an oven at $170 \mathrm{~F}$ for six hours, essentially baking any extra water from them. It was determined that the low cooking temperature would not affect the caloric content of the fries. For the bomb calorimeter testing, the fries were cooked in the fryer and then mashed together. A gram sample from the mashed pile was measured before and after the baking process. Once this was complete, the second trial could begin.

The second attempt with the bomb calorimeter successfully ignited the fries. Two trials were implemented: one with uncooked potatoes and another with cooked fries.

The amount of moisture removed during the oven-baking process was recorded. Four pieces of raw potato and two pieces of cooked fry — all with an initial mass of approximately one gram — were baked until dry and then weighed on a gram scale. See the table below for the mass before and after drying: 
Table 21 - Mass of Samples used for the Bomb Calorimeter

\begin{tabular}{|c|c|c|}
\hline Type of Fry & Mass Before Drying (g) & Mass After Drying (g) \\
\hline Raw Fry & 1.047 & 0.269 \\
\hline Raw Fry & 1.033 & 0.239 \\
\hline Raw Fry & 1.045 & 0.172 \\
\hline Raw Fry & 1.044 & 0.153 \\
\hline Total & $\mathbf{4 . 1 6 9}$ & $\mathbf{0 . 8 3 3}$ \\
\hline Cooked Fry & 1.024 & 0.505 \\
\hline Cooked Fry & 1.036 & 0.501 \\
\hline Total & $\mathbf{2 . 0 6 0}$ & $\mathbf{1 . 0 0 6}$ \\
\hline
\end{tabular}

The bomb calorimeter requires about one gram of testable material to produce decent results. Therefore, four $1 \mathrm{~g}$ samples of raw potato were dried out in the oven because the six-hour baking process would reduce their mass by more than 75 percent. The cooked fries only lost about half of their mass after the baking process, so only two $1 \mathrm{~g}$ cooked fry samples were used. Again, this assumes only water was being lost in the oven-baking process.

The raw potato sample was first to be tested, and yielded conclusive results. The total caloric content for $0.833 \mathrm{~g}$ sample of oven-dried raw potato was $3.011 \mathrm{kcal}$ - Calories on standard food labels are representative of a food's kcal content. A total of $\mathbf{4 . 1 6 9 g}$ of raw potato produced 3.011 Calories.

Meanwhile, in a $4.169 \mathrm{~g}$ sample of raw russet potato, there should be 3.294 Calories, according to the U.S. Department of Agriculture. Meaning the calorimeter test performed for the purposes of this project produced just an $8.6 \%$ variation from the USDA value. This helped confirm the accuracy of the calorimeter, and increased the confidence in using its data to compare the caloric content of cooked fries. 
The caloric content was produced from a few equations, shown in Appendix D. The temperature profile, was also critical in determining the caloric value of the raw fries.

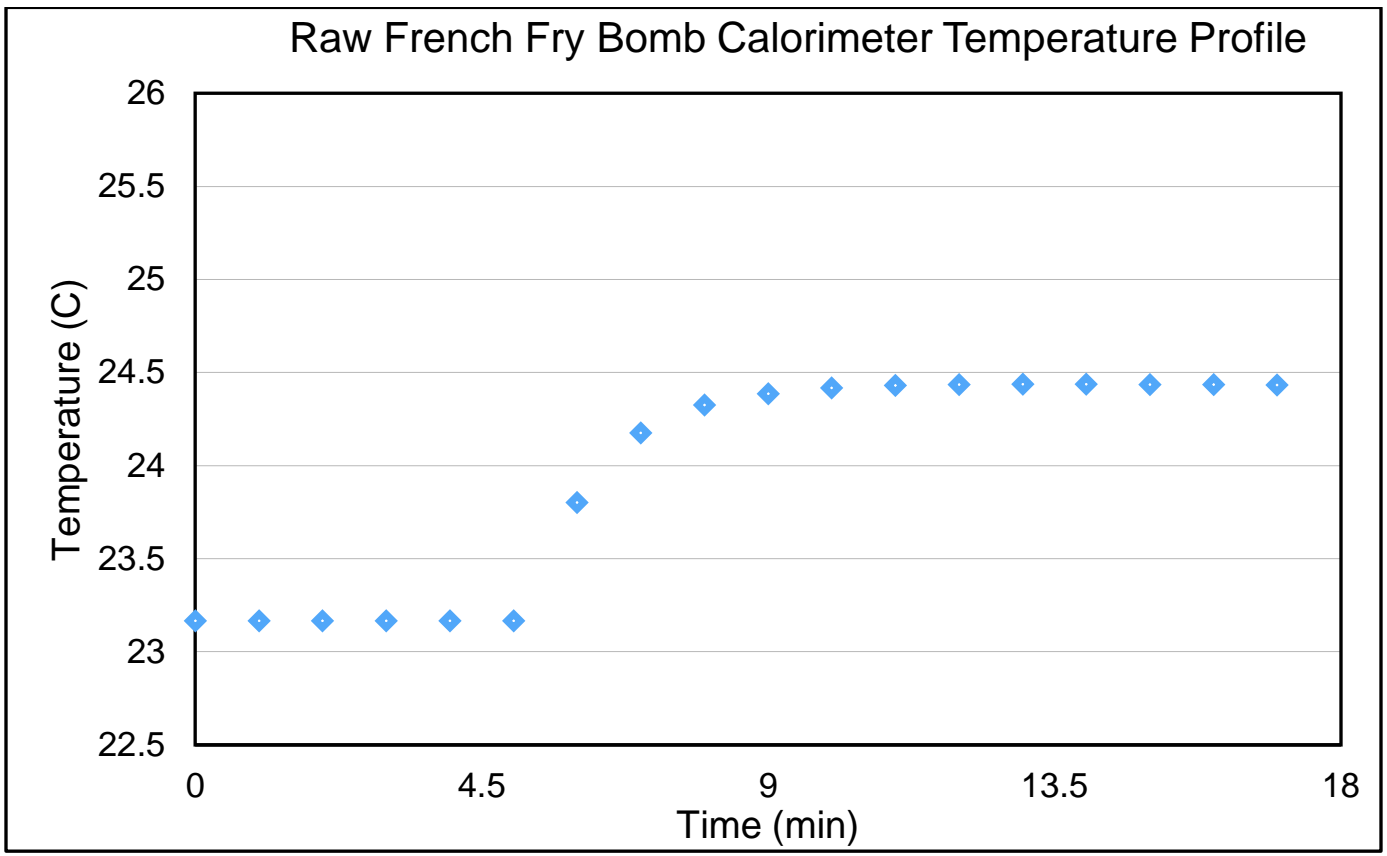

Figure 25 - Temperature Profile of the Raw Fry Bomb Calorimeter Run

A fry weighing $9.5 \mathrm{~g}$ initially contains approximately $\mathbf{6 . 8 6}$ Calories before being cooked. This value was important because it was used to calculate how many calories were added by the frying process. The amount of oil was determined from the information above. The cooked fry run required $2.060 \mathrm{~g}$ in cooked fry to be baked in the oven. After the cooked fries were dried out, the final reading on the scale was $1.006 \mathrm{~g} .1 .006 \mathrm{~g}$ of the fry was ignited, yielding 4.850 Calories of energy. After a 9.5g fry was cooked, on average, the mass was $5.48 \mathrm{~g}$ because of the mass transfer. A $\mathbf{5 . 4 8 g}$ cooked fry will contain approximately 12.93 Calories. 
The table below shows the comparison of caloric content. The temperature profile used to determine the caloric content is also shown on Figure 26 below:

Table 22 - Calorie Comparison Between Raw and Cooked Fries

\begin{tabular}{|c|c|}
\hline Type of Fry & Energy (Cal) \\
\hline Raw Fry (9.5g) & 6.86 \\
\hline Cooked Fry $(5.48 \mathrm{~g})$ & 12.93 \\
\hline
\end{tabular}

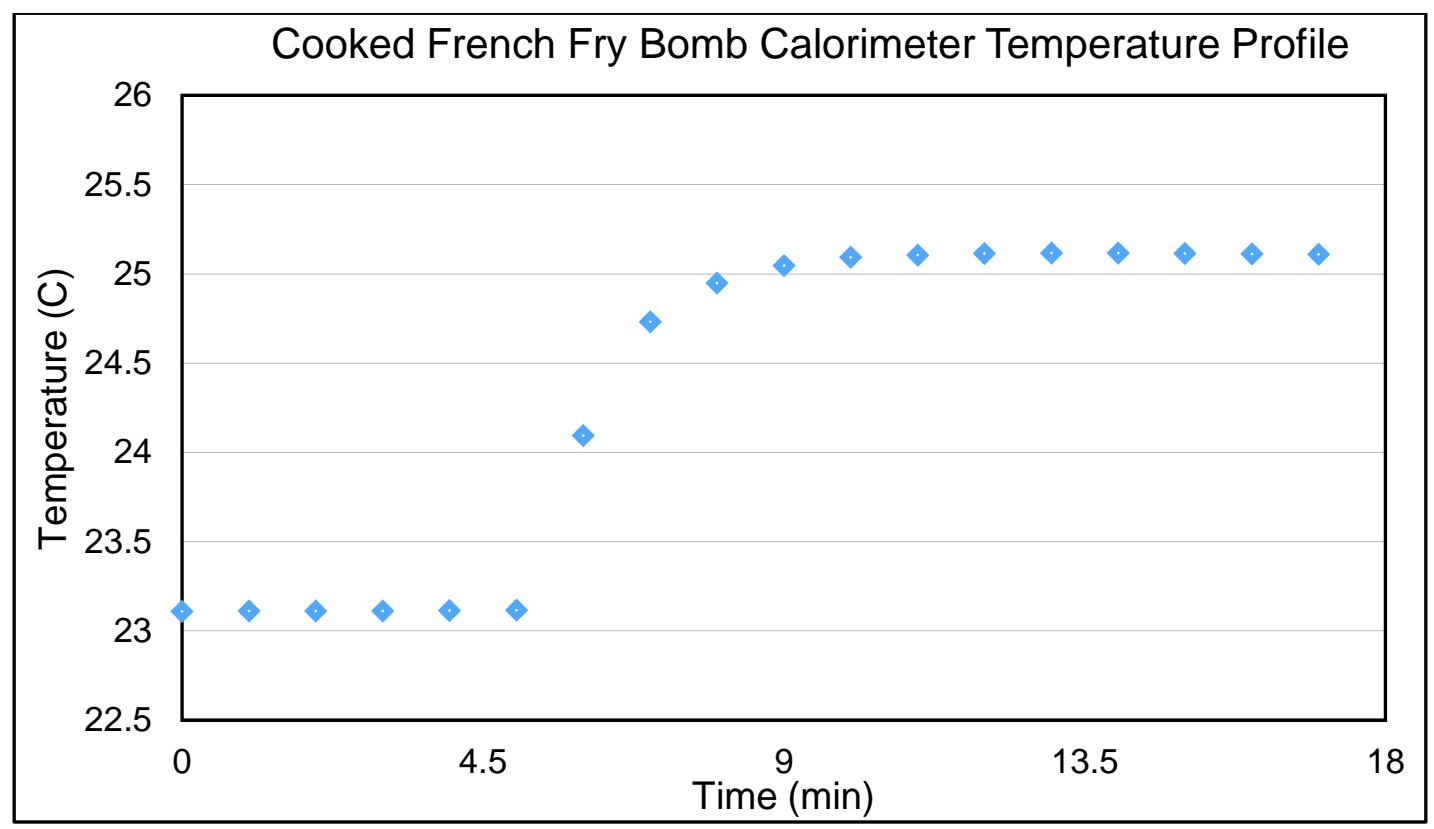

Figure 26 - Temperature Profile of the Cooked Fry Bomb Calorimeter Run

It was determined that the energy gained by cooking the fries is purely from the fries absorbing oil. Thus, approximately $0.7 \mathrm{~g}$ of vegetable oil was absorbed into the fry, according to the nutrition facts provided by the USDA [20]. The $0.7 \mathrm{~g}$ of oil was accounted for by identifying the difference in Calories between cooked and uncooked fries. Then, the nutrition facts were used to calculate the amount of oil in the fries based on Calories. 
Additional information regarding the nutrition facts for $0.7 \mathrm{~g}$ of vegetable oil is shown in Table 23 below:

Table 23 - Nutrition Facts for $0.7 \mathrm{~g}$ of Vegetable Oil [20]

\begin{tabular}{|l|c|}
\hline Serving Size (g) & 0.7 \\
\hline Energy (Calorie) & 6 \\
\hline Total Fat $(\mathbf{g})$ & 0.7 \\
\hline Total Saturated Fats $(\mathbf{g})$ & 0.57 \\
\hline Total Monounsaturated Fats $(\mathbf{g})$ & 0.08 \\
\hline Total Polyunsaturated Fats $(\mathbf{g})$ & 0.01 \\
\hline
\end{tabular}

Fries processed through the centrifuge were not tested in the calorimeter because of the limited access to it. Testing the raw and cooked fry was the best way to obtain results with the least amount of trials.

\subsection{Vibrations}

A motor spinning causes vibrations, especially when parts are not perfectly concentric to the axis of rotation. The mount supporting the motor can be analyzed for its natural frequencies. At the natural frequency — known as resonant frequency — the component will reach the largest displacement caused by vibrations. Figure 27 below is an isometric view of the motor mount. The four small holes on the top were created to mount the motor to this bracket, while the four holes on the bottom are where it was rigidly mounted to the lid: 


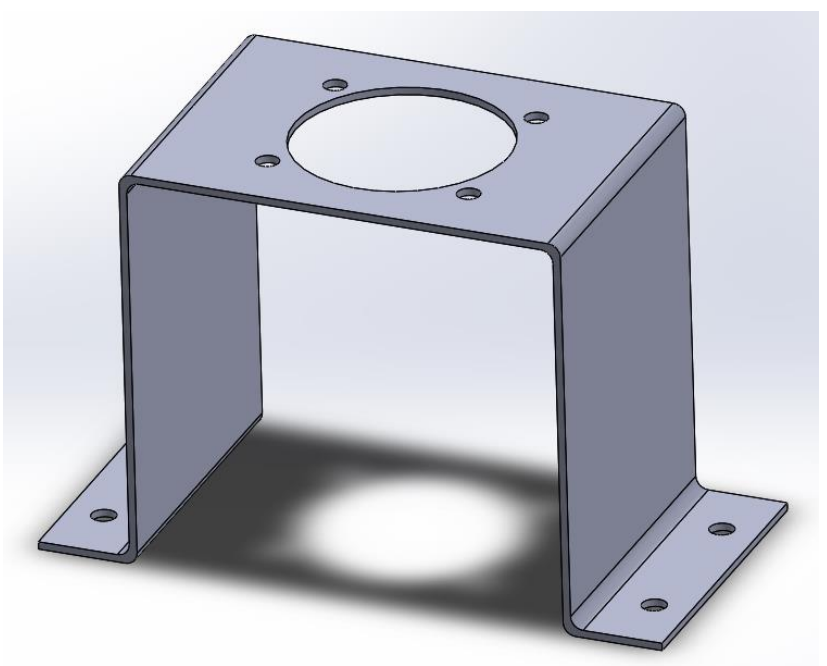

Figure 27 - Isometric View of Motor Mount

The motor mount can be modeled as a frame with two fixed supports where it is mounted onto the lid of the salad spinner. See Figure 28 below:

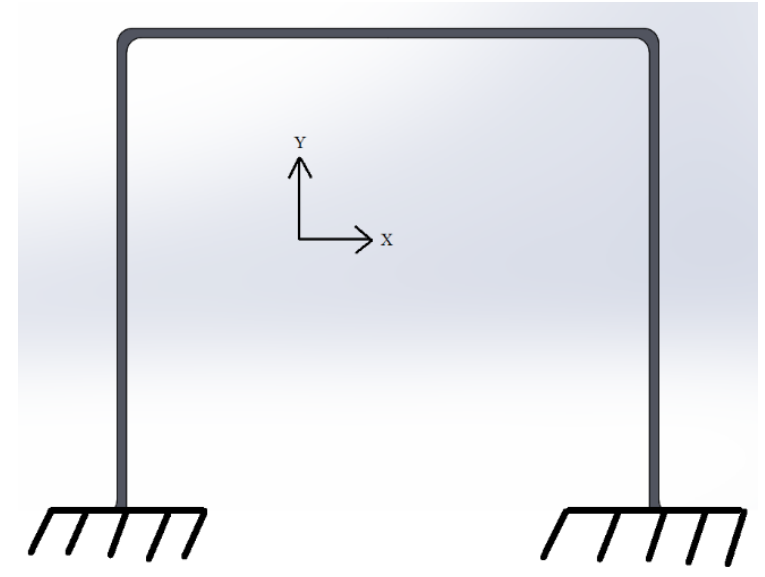

Figure 28 - Side View of Motor Mount with Fixed Supports

The displacement caused by vibrations will occur along the $\mathrm{x}$-axis, evident in the geometry of the motor mount. Using the driving equation shown below:

$$
w_{n}=\sqrt{\frac{k}{m}}
$$


Where $\mathrm{k}$ is the total stiffness of the supports and $\mathrm{m}$ is the mass of the motor for this situation. Because there are two supports, the stiffness will be added up similar to resistors in series. The stiffness for each support is shown below:

$$
k=\frac{3 E I}{l^{3}}
$$

Table 24 below shows the values used to calculate the first natural frequency of the system.

Table 24 - Values for Calculating Natural Frequency of the Motor Mount

\begin{tabular}{|l|c|}
\hline Modulus of Elasticity of Steel (N/m^2) & $2.1 \mathrm{E}+11$ \\
\hline Area Moment of Inertia $\left(\mathbf{m}^{\wedge} \mathbf{4}\right)$ & $3.08 \mathrm{E}-9$ \\
\hline Length (m) & 0.11 \\
\hline Mass (kg) & $0.50 \mathrm{~kg}$ \\
\hline Stiffness (N/m) & $1.35 \mathrm{E}+7$ \\
\hline Total Stiffness (N/m) & $2.70 \mathrm{E}+7$ \\
\hline Natural Frequency $(\mathbf{H z})$ & $7.35 \mathrm{E}+3$ \\
\hline
\end{tabular}

Vibrations were not an issue because the natural frequency is significantly higher than the angular velocity. It would have been an issue if the angular velocity was at the natural frequency, because that is when the displacement would be the maximum on the motor mount. Additional work could be done on the vibrations of this component, but because vibrations were not a huge issue in this project, this level of calculation was determined to have been sufficient.

\subsection{Heat Transfer}

Heat transfer calculations were done on the system to determine the power input required to keep the fries warm. Oil exponentially increases in viscosity as the temperature decreases. Therefore, it would be ideal to maintain the fries at a warm temperature during the entire testing process. Viscosity — along with other properties of the fry and oil — 
can alter the ease of oil removal. This model simulates the fries being transferred into the centrifuge, where they will reach thermal equilibrium with a heat source. The fries will be kept warm in this simulation with a heat lamp. A heat lamp transfers heat via radiation. It is ideal to use a heat lamp because convection and conduction methods of heat transfer would be more complicated and expensive for this application. Using Engineering Equation Solver (EES) software, the heat transfer equations were solved simultaneously.

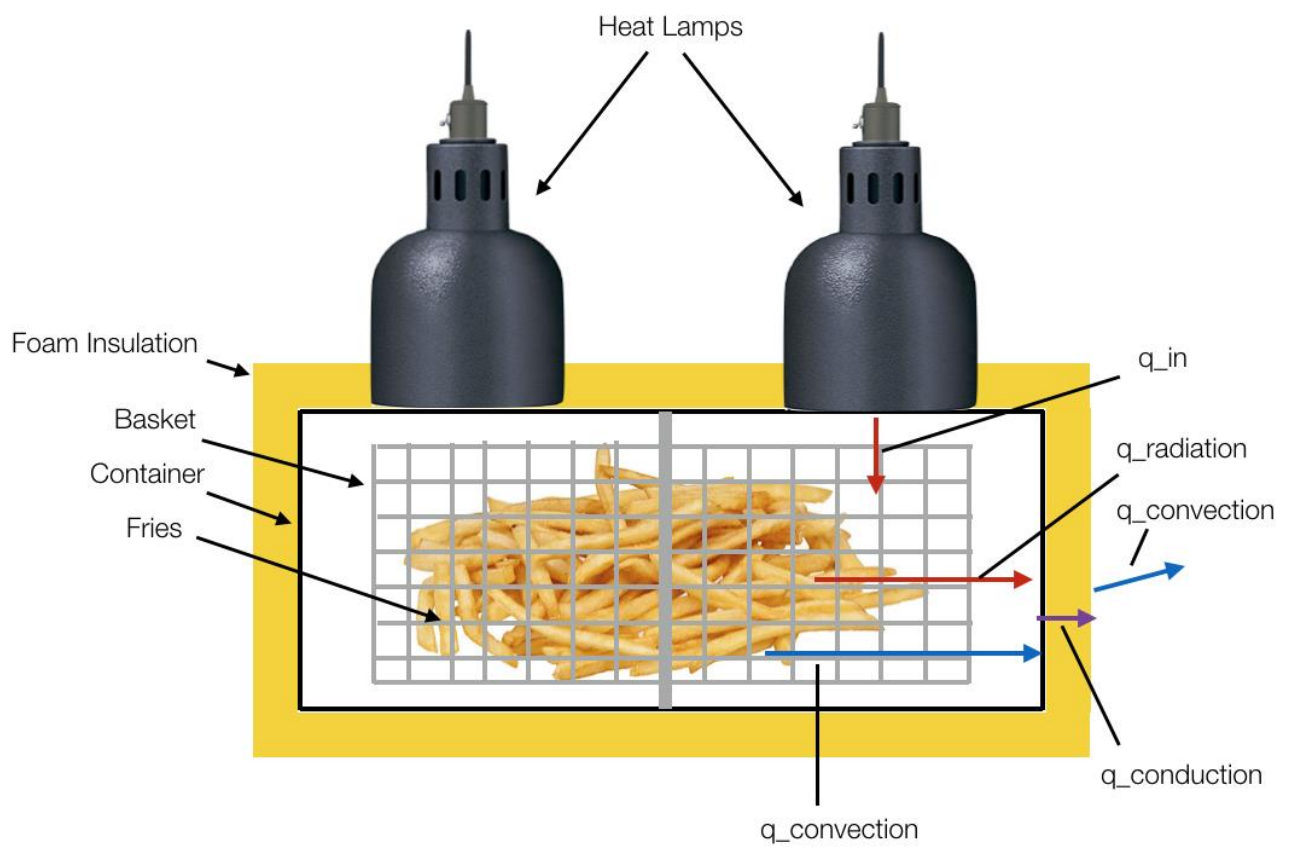

Figure 29 - Heat Transfer Process for Steady State Problem

The nine equations used to model this steady state problem are shown below:

$$
\begin{gathered}
q_{\text {conv } .1}=h A_{\text {fry }}\left(T_{\text {fry }}-T_{\text {air }}\right) \\
q_{\text {conv } .2}=h A_{\text {container }}\left(T_{\text {air }}-T_{\text {container }}\right) \\
q_{\text {rad.1 }}=\frac{A_{\text {side }} \sigma\left(T_{\text {fry }}^{4}-T_{\text {container }}^{4}\right)}{\frac{1}{\epsilon_{\text {fry }}}+\frac{1-\epsilon_{\text {container }}}{\epsilon_{\text {container }}}\left(\frac{r_{\text {basket }}}{r_{\text {container }}}\right)}
\end{gathered}
$$




$$
\begin{gathered}
q_{\text {rad. } 2}=\frac{A_{\text {bottom }} \sigma\left(T_{\text {fry }}^{4}-T_{\text {container }}^{4}\right)}{\frac{1}{\epsilon_{\text {fry }}}+\frac{1}{\epsilon_{\text {container }}}-1} \\
q_{\text {cond }}=\frac{T_{\text {container }}-T_{\text {foam }}}{\left(\frac{L_{\text {container }}}{A_{\text {container }}{ }^{*} \text { container }_{\text {con }}}\right)+\left(\frac{L_{\text {foam }}}{A_{\text {container }} K_{\text {foam }}}\right)} \\
q_{\text {conv.out }}=h_{\text {atm }} A_{\text {foam }}\left(T_{\text {foam }}-T_{\infty}\right) \\
q_{\text {conv. } 1}=q_{\text {conv. } 2} \\
q_{\text {rad. } 1}+q_{\text {rad. } 2}+q_{\text {conv } .1}=q_{\text {cond }} \\
q_{\text {conv.out }}=q_{\text {cond }}
\end{gathered}
$$

Where,

$q_{\text {conv. }}=$ Heat transferred by convection

$q_{\text {rad. }}=$ Heat transferred by radiation

$q_{\text {cond }}=$ Heat transferred by conduction

$h=$ Convection heat transfer coefficient

$A=$ Area

$T=$ Temperature

$\sigma=$ Boltzmann constant $\left(5.67 \times 10^{-8} \mathrm{~W} / \mathrm{m}^{2} \mathrm{~K}^{4}\right)$

$\epsilon=$ Emissivity

$r=$ Radius

$L=$ Thickness

Equation 5, 6, and 10 applied Newton's law of Cooling, and describe the heat transfer via convection within the container and from the outer surface to the environment. Equation 7 applied heat transfer via radiation, assuming long concentric cylinders. Equation 8 applied heat transfer via radiation, assuming large parallel plates. Equation 7 and 8 both 
described the radiation occurring from the fries to the inside of the container. Equation 9 applied heat transfer via conduction for one dimensional composite walls. Lastly, equations 11,12 , and 13 are the energy balance equations. All of the equations mentioned above were used for calculating steady state modeling.

According to the model made in EES, the system would only need a 25 watt heater to maintain the fries at $200^{\circ} \mathrm{F}$ at steady state. $200^{\circ} \mathrm{F}$ was selected to add a factor of safety, because the minimum temperature at which French fries can be consumed before they have the potential to cause illness is $135^{\circ} \mathrm{F}$ [21]. $135^{\circ} \mathrm{F}$ Is the temperature danger zone where typical harmful microorganism can grow to dangerous levels [21]. Additionally, it was determined that the higher the temperature, the easier it would be to extract oil. See Appendix E for the code used to solve the steady state heat transfer problem.

Assuming there was no heat source, when a bunch of fries are placed in the centrifuge, there would be a transient heat transfer problem. A known method for solving transient heat transfer problems is using the lumped capacitance method. The lumped capacitance method is for estimating heat transfer in situations where an object with mass experiences a change in its thermal environment [22]. The equation for the lumped capacitance method is shown below:

$$
T=\left(T_{i}-T_{\infty}\right) \exp \left[-\frac{h A_{s} t}{\rho V c}\right]+T_{\infty}
$$

Where,

$T=$ Temperature

$h=$ Convection heat transfer coefficient 
$A_{s}=$ Area

$t=$ Time

$\rho=$ Density

$V=$ Volume

$c=$ Specific heat

In order to justify the use of the lumped capacitance method, the dimensionless Biot number must first be calculated [22]. When the Biot number is larger than one, it implies that the temperature gradient across the solid is greater than that of the convection occurring [22]. Additionally, when the Biot number is less than 0.1, the error is likely to be small [22]. The Biot number, $\mathrm{Bi}$, is defined by:

$$
B i=\frac{h L_{c}}{k}
$$

Where $\mathrm{h}$ is the heat transfer coefficient, $L_{c}$ is the characteristic length, and $\mathrm{k}$ is the thermal conductivity. Table 25 below depicts the values used for the Biot number calculation.

Table 25 - Biot Number Calculation Values

\begin{tabular}{|l|c|}
\hline Heat Transfer Coefficient $\left(\mathbf{W} /\left(\mathbf{m}^{\wedge} \mathbf{2} * \mathbf{K}\right)\right)$ & 30 \\
\hline Characteristic Length $(\mathbf{m})$ & 0.0032 \\
\hline Thermal Conductivity $(\mathbf{W} /(\mathbf{m} * \mathbf{K}))$ & 0.30 \\
\hline Biot Number & 0.32 \\
\hline
\end{tabular}

The Biot number was not exactly less than 0.1 , but for the sake of obtaining a rough estimate for the transient temperature profile of the fry, it was accepted. Matlab helped calculate the value of the transient heat transfer problem. See Appendix E for the Matlab script. 
The temperature profile of the transient temperature of the fry was obtained theoretically via Matlab. In order to check the theoretical results, a thermocouple was used to experimentally measure the internal temperature of the fry. Measurements were manually recorded every 15 seconds. A thermocouple was placed in the core of the fry and left there throughout the frying and cooling process in order to obtain the temperature profile. Temperatures were recorded once the fry was removed from the hot oil. This would simulate a practical situation, wherein a user would place the fries in the centrifuge immediately after frying. When obtaining the temperature profile via thermocouple, a few other fries were within the vicinity of the probed fry in order to simulate a practical situation.

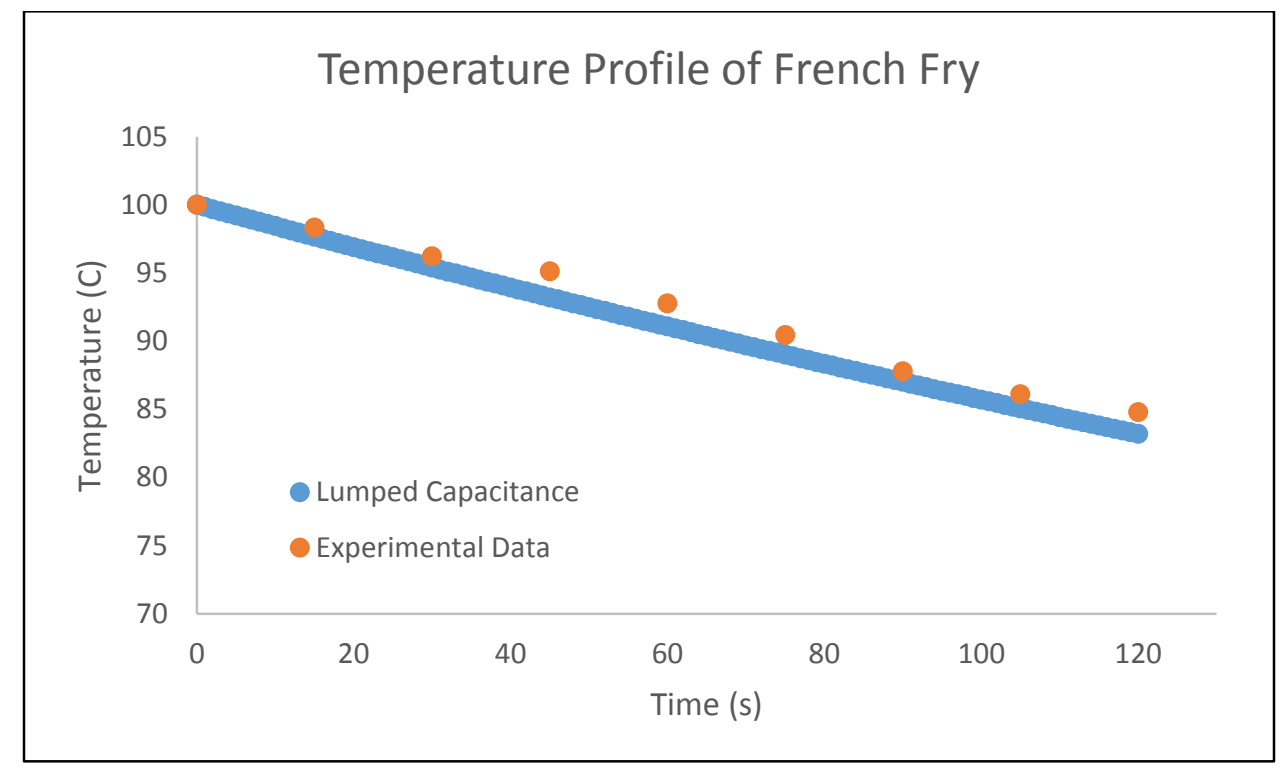

Figure 30 - Temperature Profile of French Fry Experimental vs. Theoretical

The two curves presented from the theoretical and experimental data were nearly identical. This is because the theoretical data had a lot of room for manipulation. The heat convection heat transfer coefficient was manipulated in order to obtain identical 
temperature profiles. Nonetheless, the graph in Figure 30 shown above indicates that the lumped capacitance can accurately portrayed the transient heat transfer occurring in fries.

\section{$5.4 \quad$ Forces}

The forces discussed in this section will tackle the centripetal force on the fries. It was verified during the experimental runs that crunchier fries have the potential to break at $450 \mathrm{rpm}$ and are very likely to break at 700rpm. The third experimental run produced fries that broke more than $50 \%$ of the time at $700 \mathrm{rpm}$. These fries were all identical: about $5.5 \mathrm{~g}$ in mass and approximately $3.5 \mathrm{in}$ long. Because the angular velocity is known, the centripetal force is known. This means the force applied to the fries was known when they were leaning against the outer wall of the basket. Using the equation for centripetal force, the force and bending moment can be found.

$$
F=m r w^{2}
$$

Where $\mathrm{F}$ is the centripetal force, $\mathrm{m}$ is the mass, $\mathrm{r}$ is the radius, and $\mathrm{w}$ is the angular velocity. The table below depicts the values used and obtained for this equation:

Table 26 - Centripetal Force Calculation Data

\begin{tabular}{|l|c|}
\hline Mass of one Fry (kg) & 0.006 \\
\hline Radius (m) & 0.09 \\
\hline Angular Velocity (rpm) & 700 \\
\hline Centripetal Force (N) & 2.90 \\
\hline Maximum Moment on Fry (N*m) & 0.074 \\
\hline
\end{tabular}

The largest moment was found at the middle of the fries, where they broke most often. Now that the centripetal force had been calculated, the angular velocity and radius could be varied while still obtaining the same centripetal force. The reason for manipulating 
those numbers would be for the sake redesigning the centrifuge, keeping the same centrifugal force in mind. 


\section{Chapter 6. Conclusion}

The goal of this paper was to prove if a reasonable amount of oil could be removed from fries by using a centrifuge. By independently changing three variables during experimentation, trends were identified using statistical analysis software Minitab. A repurposed salad spinner with a DC motor was used to run the experimentation. This allowed for easy manipulation of the angular velocity and duration of each trial. Additional analysis was gathered on the design of the project, including heat transfer and vibration calculations.

From the analysis, it was determined that angular velocity, time, and type of fry impact the amount of oil removed from the fries when processed through a centrifuge. Additionally, a statistically significant interaction occurs between the angular velocity and type of fry. This interaction implied that the amount of oil removed relies on the combination of angular velocities and types of fries. As expected, the faster the angular velocity, the more oil was removed from the fries. And as the fries spent more time in the centrifuge, more oil was removed. The concern here was that the faster the angular velocity, the more likely the fries are to break. This became an issue with two of the three types of fries tested. Fries broke at $700 \mathrm{rpm}$ and occasionally $450 \mathrm{rpm}$. Also, in a commercial setting, longer time in spent spinning in the centrifuge requires customers and users to wait longer. 
Looking back at the first experimental run with the simple french fry recipe, the average amount of oil removed was approximately $0.18 \mathrm{~g}$ at $700 \mathrm{rpm}$ for 120 seconds. This combination of variables produced the largest value of oil extraction. It removed $25.7 \%$ of the total oil content in the fries. The fries from the first experimental run were the softest and least crunchy. It is believed that none of those fries broke for that reason. The other type of fries removed less oil at $700 \mathrm{rpm}$ and 120 seconds, and produced broken fries. These test were done with only four fries per trial. If the centrifuge were to be completely full of fries, it would be more challenging to remove equal amount of oil from all the fries. In conclusion, using a centrifuge could remove a reasonable amount of oil from certain types of fries, and potentially other types of fried foods as well.

\subsection{Future Work and Recommendations}

The issue is that fried foods are extremely popular. The downfall of consuming excessive fried foods are various health issues. In order to reduce the amount of oil in fried foods, there may be alternative frying mediums that have not been discovered or utilized, or alternative cooking methods. In an attempt to attack the problem from a different angle, the solution could lie more so in the food science department and less in the engineering department — or could require cooperation between both schools of thought. An alternative method could be designed similar to the air frying method that was introduced in the literature review.

While this study yielded good results for one type of fry, there may still exist methods that could remove a reasonable amount of oil for all types of fries. One thing that was 
noticed throughout testing was that regardless of what variables the fries were exposed to, the outer crust layer was always lightly coated in oil. The centrifuge could be spun at a higher angular velocity to remove additional oil in a different shaped container to prevent breakage. Additionally, considering that the centrifuge mainly extracted oil from one of the four major sides of the fries, there may exist a method to extract oil from all four sides. This could include the use of a centrifuge. Similarly, some people who enjoy fried foods are commonly spotted dabbing oily food with paper towels. This could lead to a machine that soaks up oil from food with an absorbent sheets of reusable material.

Additionally, the types of crust on different fried foods could produce different results. With fries alone, it was noted that using a different recipe could yield more/less oil removal with a centrifuge. Perhaps centrifuges are a food-specific process, wherein some foods could have a large percentage of oil removed using a centrifuge or other mechanical process. 


\section{REFERENCES}

[1] Bouchon, P., P. Hollins, M. Pearson, D.1. Pyle, and M.j. Tobin. "Oil Distribution in Fried Potatoes Monitored by Infrared Microspectroscopy." Journal of Food Science J Food Science 66.7 (2001): 918-23. Web. 5 Feb. 2015.

[2] Pedreschi, Franco, Claudia Cocio, Pedro Moyano, and Elizabeth Troncoso. "Oil Distribution in Potato Slices during Frying." Journal of Food Engineering 87.2 (2008): 200-12. Web. 3 Feb. 2015.

[3] Ziaiifar, Aghsoltan, and Aman Mohammad Ziaiifar. "Theoretical Aspects of DeepFat Frying." (n.d.): n. pag. Web. 13 Feb. 2015.

[4] Myhrvold, Nathan, Chris Young, Maxime Bilet, and Ryan Matthew Smith. "Cooking in Oil." Modernist Cuisine. the Art and Science of Cooking: Techniques and Equipment. Bellevue, WA: Cooking Lab, 2011. 115-28. Print.

[5] Buchon, P., J. M. Aguilera, and D. L. Pyle. "Structure Oil-Absorption Relationships During Deep-Fat Frying." Journal of Food Science J Food Science 68.9 (2003): 2711-716. Web.

[6] Caret, Lucas B., Michael Dinitz, and Desiree Tillo. "Highly Efficient and Effective Removal of Fat from Fried Chicken via Centrifugation." (n.d.): n. pag. Weizmann Institute of Science, Mar.-Apr. 2013. Web. 31 May 2016. <www.cs.jhu.edu>.

[7] Shaker, M. Arafat. "Air Frying a New Technique for Produce of Healthy Fried Potato Strips." JFNS Journal of Food and Nutrition Sciences 2.4 (2014): 200-06. Web. Spring 2015.

[8] Tefal ActiFry. Digital image. Amazon. N.p., n.d. Web. May-June 2016. <http://www.amazon.com/gp/product/B005GM15HE/ref=pd_lpo_sbs_dp_ss_1?pf_ 
rd_p=1944687702\&pf_rd_s=lpo-top-stripe1\&pf_rd_t=201\&pf_rd_i=B002S4MV

EE\&pf_rd_m=ATVPDKIKX0DER\&pf_rd_r=1HPE24S6SJ7NXXZBXY46> .

[9] Garayo, Jagoba, and Rosana Moreira. "Vacuum Frying of Potato Chips." Journal of Food Engineering 55.2 (2002): 181-91. Web. Spring 2015.

[10] Oil Separator For Fried Food. Digital image. Alibaba. N.p., n.d. Web. May-June 2016. <http://www.alibaba.com/product-detail/Oil-Separator-For-Fried-

Food_119389218.html?spm=a2700.7724838.0.0.NwTzBL>.

[11] Honey Extraction. Digital image. Heavenly Honey Apiary. N.p., n.d. Web. MayJune 2016. <http://www.vtbeekeeper.com/honey-extraction.html>.

[12] Oxo Mini Salad Spinner. Digital image. Amazon. N.p., n.d. Web. May-June 2016. <http://www.amazon.com/OXO-Oxo-Mini-Salad-Spinner/dp/B004RR9HW4?ie $=\mathrm{UTF} 8 \&$ keywords=salad\%20spinner\&qid=1465284631\&ref_=sr_1_24\&s=kitchen $\& s r=1-24>$.

[13] Djousse, L., A. B. Petrone, and J. M. Gaziano. "Consumption of Fried Foods and Risk of Heart Failure in the Physicians' Health Study." Journal of the American Heart Association 4.4 (2015): n. pag. Web. Spring 2015.

[14] Sayon-Orea, C., M. Bes-Rastrollo, F.j. Basterra-Gortari, J.j. Beunza, P. GuallarCastillon, C. De La Fuente-Arrillaga, and M.a. Martinez-Gonzalez. "Consumption of Fried Foods and Weight Gain in a Mediterranean Cohort: The SUN Project." Nutrition, Metabolism and Cardiovascular Diseases 23.2 (2013): 14450. ScienceDirect. Web. 10 Jan. 2016.

[15] Burton-Jeangros, Claudine, Stéphane Cullati, Amanda Sacker, and David Blane. A Life Course Perspective on Health Trajectories and Transitions. N.p.: Springer 
International, 2015. Springer Link. Springer International Publishing. Web. 15 Apr. 2016. <www.springer.com>.

[16] 30v 5A Prevision Variable DC Power Supply. Digital image. EBay. N.p., n.d. Web. May-June 2016. <http://www.ebay.com/itm/30V-5A-Precision-Variable-DCPower-Supply-DigitaL-Adjustable-w-Clip-Cable-110V-/391378270581?hash= item5b1ff67 975:g:lokAAOSwQYZWwuB9>.

[17] "Getting Started with Minitab 17." Minitab. N.p., n.d. Web. May-June 2016. <https://www.minitab.com/uploadedFiles/Documents/getting-started/Minitab17 _GettingStarted-en.pdf>.

[18] Fieri, Guy. "Double-Fried French Fries." Food Network. N.p., June 2008. Web. Apr.-May 2016. <http://www.foodnetwork.com/recipes/guy-fieri/double-friedfrench-fries-recipe.html>.

[19] Sanders, Donald H., Smidt, Robert K.. Statistics: A First Course. Sixth ed. New York: McGraw-Hill, 1995. Print.

[20] "Basic Report: 11353, Potatoes, Russet, Flesh and Skin, Raw." United States Department of Agriculture. Agricultural Research Services, n.d. Web. 25 May 2016. <https://ndb.nal.usda.gov/>.

[21] "Temperature Controls of Potentially Hazardous Food." California Department of Education. Nutrition Service Division, n.d. Web. 28 May 2016. $<$ http://www.cde.ca.gov>.

[22] Incropera, Frank P., David P. Dewitt, Theodore L. Bergman, and Adrienne S. Lavine. Foundations of Heat Transfer. 6th ed. Singapore: John Wiley \& Sons, 2013. Print. 


\section{APPENDICES}

\section{Appendix A. Data Collected}

\section{Appendix A1. Motor Calibration Curve Data}

Table 27 - Motor Calibration Curve Data

\begin{tabular}{|c|c|}
\hline Input Voltage & $\begin{array}{c}\text { Angular Velocity } \\
(\mathbf{r p m})\end{array}$ \\
\hline 0.5 & 0 \\
\hline 1 & 24 \\
\hline 1.5 & 37 \\
\hline 2 & 51 \\
\hline 2.5 & 66 \\
\hline 3 & 82 \\
\hline 3.5 & 89 \\
\hline 4 & 104 \\
\hline 4.5 & 119 \\
\hline 5 & 136 \\
\hline 5.5 & 152 \\
\hline 6 & 165 \\
\hline 6.5 & 185 \\
\hline 7 & 202 \\
\hline 7.5 & 217 \\
\hline 8 & 231 \\
\hline 8.5 & 243 \\
\hline 9 & 260 \\
\hline 9.5 & 273 \\
\hline 10 & 298 \\
\hline 10.5 & 317 \\
\hline 11 & 328 \\
\hline 11.5 & 344 \\
\hline 12 & 360 \\
\hline 12.5 & 375 \\
\hline 13 & 391 \\
\hline 13.5 & 408 \\
\hline 14 & 426 \\
\hline 14.5 & 443 \\
\hline 15 & 463 \\
\hline 15.5 & 476 \\
\hline 16 & 491 \\
\hline 16.5 & 509 \\
\hline 17 & 521 \\
\hline 17.5 & 538 \\
\hline 18 & 552 \\
\hline 18.5 & 565 \\
\hline 19 & 578 \\
\hline 19.5 & 593 \\
\hline 20 & 612 \\
\hline
\end{tabular}




\section{Appendix A2. Motor Mount Drawing}

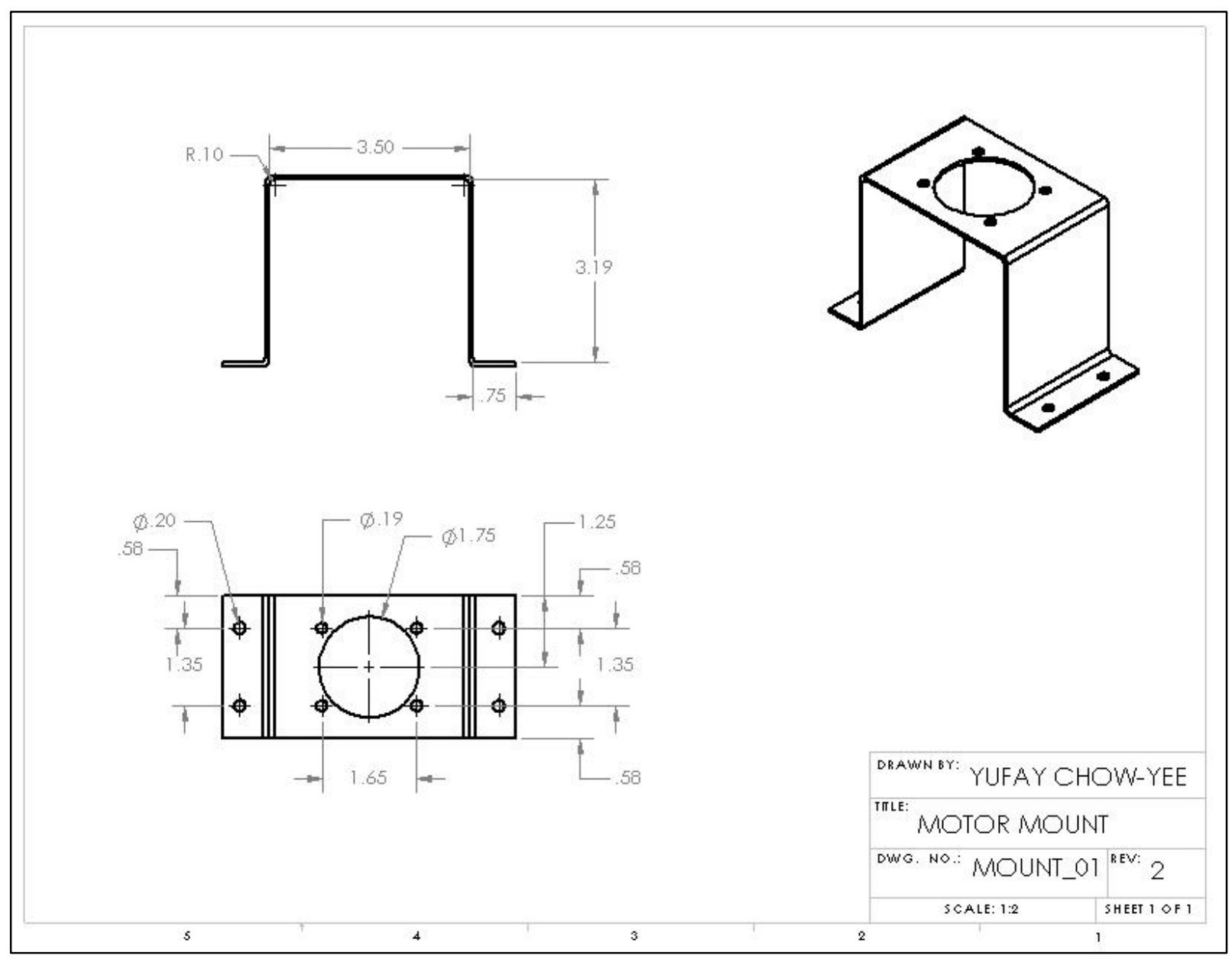

Figure 31 - Prototype Motor Mount Drawing 


\section{Appendix A3. Pilot Test Data}

Table 28 - Raw Data for Pilot Test at $300 \mathrm{rpm}$

\begin{tabular}{|c|c|c|c|c|c|c|}
\hline & \multicolumn{3}{|c|}{300 rpm @ 60 sec. } & \multicolumn{3}{|c|}{300 rpm @ 120 sec. } \\
\hline $\begin{array}{c}\text { Trial } \\
\# 1\end{array}$ & $\begin{array}{l}\text { Mass after } \\
\text { frying }(\mathrm{g})\end{array}$ & $\begin{array}{c}\text { Mass after } \\
\text { Centrifuge }(\mathrm{g})\end{array}$ & $\begin{array}{l}\text { Delta } \\
\text { Mass }\end{array}$ & $\begin{array}{l}\text { Mass after } \\
\text { frying }(\mathrm{g})\end{array}$ & $\begin{array}{c}\text { Mass after } \\
\text { Centrifuge (g) }\end{array}$ & $\begin{array}{l}\text { Delta } \\
\text { Mass }\end{array}$ \\
\hline Fry \#1 & 4.84 & 4.73 & 0.11 & 5.13 & 4.99 & 0.14 \\
\hline Fry \#2 & 4.71 & 4.49 & 0.22 & 5.19 & 5.03 & 0.16 \\
\hline Fry \#3 & 5.05 & 4.84 & 0.21 & 5.01 & 4.9 & 0.11 \\
\hline \multirow[t]{2}{*}{ Fry \#4 } & 5.11 & 4.81 & 0.3 & 5.2 & 5.08 & 0.12 \\
\hline & & AVG Delta & 0.21 & & AVG Delta & 0.13 \\
\hline $\begin{array}{c}\text { Trial } \\
\# 2\end{array}$ & $\begin{array}{l}\text { Mass after } \\
\text { frying }(\mathrm{g})\end{array}$ & $\begin{array}{c}\text { Mass after } \\
\text { Centrifuge }(\mathrm{g})\end{array}$ & $\begin{array}{l}\text { Delta } \\
\text { Mass }\end{array}$ & $\begin{array}{l}\text { Mass after } \\
\text { frying }(\mathrm{g})\end{array}$ & $\begin{array}{c}\text { Mass after } \\
\text { Centrifuge }(\mathrm{g})\end{array}$ & $\begin{array}{l}\text { Delta } \\
\text { Mass }\end{array}$ \\
\hline Fry \#1 & 5.81 & 5.65 & 0.16 & 5.51 & 5.35 & 0.16 \\
\hline Fry \#2 & 6.12 & 5.99 & 0.13 & 5.63 & 5.5 & 0.13 \\
\hline Fry \#3 & 5.82 & 5.61 & 0.21 & 5.18 & 5.06 & 0.12 \\
\hline \multirow[t]{2}{*}{ Fry \#4 } & 5.84 & 5.65 & 0.19 & 5.3 & 5.13 & 0.17 \\
\hline & & AVG Delta & 0.17 & & AVG Delta & 0.15 \\
\hline $\begin{array}{c}\text { Trial } \\
\# 3\end{array}$ & $\begin{array}{l}\text { Mass after } \\
\text { frying }(\mathrm{g})\end{array}$ & $\begin{array}{c}\text { Mass after } \\
\text { Centrifuge }(\mathrm{g})\end{array}$ & $\begin{array}{l}\text { Delta } \\
\text { Mass }\end{array}$ & $\begin{array}{l}\text { Mass after } \\
\text { frying }(\mathrm{g})\end{array}$ & $\begin{array}{c}\text { Mass after } \\
\text { Centrifuge (g) }\end{array}$ & $\begin{array}{l}\text { Delta } \\
\text { Mass }\end{array}$ \\
\hline Fry \#1 & 5.69 & 5.49 & 0.2 & 5.77 & 5.65 & 0.12 \\
\hline Fry \#2 & 5.59 & 5.47 & 0.12 & 5.93 & 5.71 & 0.22 \\
\hline Fry \#3 & 5.64 & 5.48 & 0.16 & 6 & 5.77 & 0.23 \\
\hline \multirow[t]{2}{*}{ Fry \#4 } & 5.42 & 5.3 & 0.12 & 5.75 & 5.54 & 0.21 \\
\hline & & AVG Delta & 0.15 & & AVG Delta & 0.20 \\
\hline $\begin{array}{c}\text { Trial } \\
\# 4\end{array}$ & $\begin{array}{l}\text { Mass after } \\
\text { frying }(\mathrm{g})\end{array}$ & $\begin{array}{c}\text { Mass after } \\
\text { Centrifuge }(\mathrm{g})\end{array}$ & $\begin{array}{l}\text { Delta } \\
\text { Mass }\end{array}$ & $\begin{array}{l}\text { Mass after } \\
\text { frying }(\mathrm{g})\end{array}$ & $\begin{array}{c}\text { Mass after } \\
\text { Centrifuge (g) }\end{array}$ & $\begin{array}{l}\text { Delta } \\
\text { Mass }\end{array}$ \\
\hline Fry \#1 & 5.5 & 5.38 & 0.12 & 4.95 & 4.84 & 0.11 \\
\hline Fry \#2 & 5.35 & 5.25 & 0.1 & 5.1 & 4.91 & 0.19 \\
\hline Fry \#3 & 5.31 & 5.2 & 0.11 & 5.15 & 5 & 0.15 \\
\hline \multirow[t]{2}{*}{ Fry \#4 } & 5.58 & 5.47 & 0.11 & 5.19 & 5.05 & 0.14 \\
\hline & & AVG Delta & 0.11 & & AVG Delta & 0.15 \\
\hline
\end{tabular}


Table 29 - Raw Data for PIlot Test at $550 \mathrm{rpm}$

\begin{tabular}{|c|c|c|c|c|c|c|}
\hline & \multicolumn{3}{|c|}{550 rpm @ 60 sec. } & \multicolumn{3}{|c|}{550 rpm @ 120 sec. } \\
\hline Trial \#1 & $\begin{array}{l}\text { Mass after } \\
\text { frying }(\mathrm{g})\end{array}$ & $\begin{array}{c}\text { Mass after } \\
\text { Centrifuge }(\mathrm{g})\end{array}$ & $\begin{array}{l}\text { Delta } \\
\text { Mass }\end{array}$ & $\begin{array}{l}\text { Mass after } \\
\text { frying }(\mathrm{g})\end{array}$ & $\begin{array}{c}\text { Mass after } \\
\text { Centrifuge (g) }\end{array}$ & $\begin{array}{l}\text { Delta } \\
\text { Mass }\end{array}$ \\
\hline Fry \#1 & 5.63 & 5.45 & 0.18 & 4.61 & 4.29 & 0.32 \\
\hline Fry \#2 & 5.64 & 5.49 & 0.15 & 4.77 & 4.71 & 0.06 \\
\hline Fry \#3 & 5.43 & 5.39 & 0.04 & 4.72 & 4.52 & 0.2 \\
\hline Fry \#4 & 5.51 & 5.39 & 0.12 & 4.61 & 4.53 & 0.08 \\
\hline & & AVG Delta & 0.12 & & AVG Delta & 0.17 \\
\hline Trial \#2 & $\begin{array}{l}\text { Mass after } \\
\text { frying }(\mathrm{g})\end{array}$ & $\begin{array}{c}\text { Mass after } \\
\text { Centrifuge }(\mathrm{g})\end{array}$ & $\begin{array}{l}\text { Delta } \\
\text { Mass }\end{array}$ & $\begin{array}{l}\text { Mass after } \\
\text { frying }(\mathrm{g})\end{array}$ & $\begin{array}{c}\text { Mass after } \\
\text { Centrifuge }(\mathrm{g})\end{array}$ & $\begin{array}{l}\text { Delta } \\
\text { Mass }\end{array}$ \\
\hline Fry \#1 & 5.46 & 5.26 & 0.2 & 5.48 & 5.28 & 0.2 \\
\hline Fry \#2 & 5.29 & 5.09 & 0.2 & 5.55 & 5.3 & 0.25 \\
\hline Fry \#3 & 5.47 & 5.3 & 0.17 & 5.74 & 5.53 & 0.21 \\
\hline Fry \#4 & 5.55 & 5.34 & 0.21 & 5.68 & 5.56 & 0.12 \\
\hline & & AVG Delta & 0.20 & & AVG Delta & 0.20 \\
\hline Trial \#3 & $\begin{array}{l}\text { Mass after } \\
\text { frying }(\mathrm{g})\end{array}$ & $\begin{array}{c}\text { Mass after } \\
\text { Centrifuge }(\mathrm{g})\end{array}$ & $\begin{array}{l}\text { Delta } \\
\text { Mass }\end{array}$ & $\begin{array}{l}\text { Mass after } \\
\text { frying }(\mathrm{g})\end{array}$ & $\begin{array}{c}\text { Mass after } \\
\text { Centrifuge (g) }\end{array}$ & $\begin{array}{l}\text { Delta } \\
\text { Mass }\end{array}$ \\
\hline Fry \#1 & 5.96 & 5.78 & 0.18 & 5.96 & 5.76 & 0.2 \\
\hline Fry \#2 & 5.84 & 5.65 & 0.19 & 5.69 & 5.52 & 0.17 \\
\hline Fry \#3 & 5.82 & 5.6 & 0.22 & 5.67 & 5.51 & 0.16 \\
\hline Fry \#4 & 6.02 & 5.78 & 0.24 & 5.94 & 5.76 & 0.18 \\
\hline & & AVG Delta & 0.21 & & AVG Delta & 0.18 \\
\hline Trial \#4 & $\begin{array}{l}\text { Mass after } \\
\text { frying }(\mathrm{g})\end{array}$ & $\begin{array}{c}\text { Mass after } \\
\text { Centrifuge }(\mathrm{g})\end{array}$ & $\begin{array}{l}\text { Delta } \\
\text { Mass }\end{array}$ & $\begin{array}{l}\text { Mass after } \\
\text { frying }(\mathrm{g})\end{array}$ & $\begin{array}{c}\text { Mass after } \\
\text { Centrifuge (g) }\end{array}$ & $\begin{array}{l}\text { Delta } \\
\text { Mass }\end{array}$ \\
\hline Fry \#1 & 5.07 & 4.87 & 0.2 & 5.23 & 5.08 & 0.15 \\
\hline Fry \#2 & 5.27 & 5.15 & 0.12 & 5.34 & 5.19 & 0.15 \\
\hline Fry \#3 & 5.11 & 4.93 & 0.18 & 5.6 & 5.47 & 0.13 \\
\hline Fry \#4 & 5.44 & 5.3 & 0.14 & 5.53 & 5.38 & 0.15 \\
\hline & & AVG Delta & 0.16 & & AVG Delta & 0.15 \\
\hline Trial \#5 & & & & $\begin{array}{l}\text { Mass after } \\
\text { frying }(g)\end{array}$ & $\begin{array}{c}\text { Mass after } \\
\text { Centrifuge (g) }\end{array}$ & $\begin{array}{l}\text { Delta } \\
\text { Mass }\end{array}$ \\
\hline Fry \#1 & & & & 5.01 & 4.87 & 0.14 \\
\hline Fry \#2 & & & & 5.48 & 5.36 & 0.12 \\
\hline Fry \#3 & & & & 5.36 & 5.27 & 0.09 \\
\hline Fry \#4 & & & & 5.09 & 4.9 & 0.19 \\
\hline & & & & & AVG Delta & 0.14 \\
\hline Trial \#6 & & & & $\begin{array}{l}\text { Mass after } \\
\text { frying }(\mathrm{g})\end{array}$ & $\begin{array}{c}\text { Mass after } \\
\text { Centrifuge (g) }\end{array}$ & $\begin{array}{l}\text { Delta } \\
\text { Mass }\end{array}$ \\
\hline Fry \#1 & & & & 5.42 & 5.3 & 0.12 \\
\hline Fry \#2 & & & & 5.38 & 5.19 & 0.19 \\
\hline Fry \#3 & & & & 5.68 & 5.56 & 0.12 \\
\hline Fry \#4 & & & & 5.38 & 5.19 & 0.19 \\
\hline & & & & & AVG Delta & 0.16 \\
\hline Trial \#5 & & & & $\begin{array}{l}\text { Mass after } \\
\text { frying }(\mathrm{g})\end{array}$ & $\begin{array}{c}\text { Mass after } \\
\text { Centrifuge }(\mathrm{g})\end{array}$ & $\begin{array}{l}\text { Delta } \\
\text { Mass }\end{array}$ \\
\hline Fry \#1 & & & & 5.01 & 4.86 & 0.15 \\
\hline Fry \#2 & & & & 5.33 & 5.15 & 0.18 \\
\hline
\end{tabular}




\begin{tabular}{|c|c|c|c|c|}
\hline & 550 rpm @ 60 sec. & \multicolumn{3}{|c|}{550 rpm@120 sec. } \\
\hline Fry \#3 & & 5.02 & 4.87 & 0.15 \\
\hline Fry \#4 & & 5.23 & 5.1 & 0.13 \\
\hline & & & $\overline{\text { AVG Delta }}$ & 0.15 \\
\hline Trial \#6 & & $\begin{array}{l}\text { Mass after } \\
\text { frying }(\mathrm{g})\end{array}$ & $\begin{array}{c}\text { Mass after } \\
\text { Centrifuge (g) }\end{array}$ & $\begin{array}{l}\text { Delta } \\
\text { Mass } \\
\end{array}$ \\
\hline Fry \#1 & & 4.94 & 4.73 & 0.21 \\
\hline Fry \#2 & & 5.05 & 4.87 & 0.18 \\
\hline Fry \#3 & & 5.16 & 4.88 & 0.28 \\
\hline Fry \#4 & & 4.93 & 4.69 & 0.24 \\
\hline & & & AVG Delta & 0.23 \\
\hline
\end{tabular}

Table 30 - Data Obtained From Pilot Test

\begin{tabular}{|c|c|c|}
\hline Change in Mass (g) & Angular Velocity (RPM) & Time (s) \\
\hline 0.12 & 550 & 60 \\
\hline 0.2 & 550 & 60 \\
\hline 0.21 & 550 & 60 \\
\hline 0.16 & 550 & 60 \\
\hline 0.17 & 550 & 120 \\
\hline 0.2 & 550 & 120 \\
\hline 0.18 & 550 & 120 \\
\hline 0.15 & 550 & 120 \\
\hline 0.14 & 550 & 120 \\
\hline 0.16 & 550 & 120 \\
\hline 0.15 & 550 & 120 \\
\hline 0.23 & 550 & 120 \\
\hline 0.21 & 300 & 60 \\
\hline 0.17 & 300 & 60 \\
\hline 0.15 & 300 & 60 \\
\hline 0.11 & 300 & 60 \\
\hline 0.13 & 300 & 120 \\
\hline 0.15 & 300 & 120 \\
\hline 0.2 & 300 & 120 \\
\hline 0.15 & 300 & 120 \\
\hline & & \\
\hline
\end{tabular}




\section{Appendix A4. Experimental Run \#1 Data}

Table 31 - Raw Data From Experimental Run \#1 at 200 rpm

\begin{tabular}{|c|c|c|c|c|c|c|c|c|}
\hline & \multicolumn{3}{|c|}{200 rpm @60 sec. } & \multicolumn{5}{|c|}{200 rpm @ 120 sec. } \\
\hline $\begin{array}{c}\text { Trial } \\
\# 1\end{array}$ & $\begin{array}{l}\text { Mass after } \\
\text { frying }(\mathrm{g})\end{array}$ & $\begin{array}{c}\text { Mass after } \\
\text { Centrifuge }(\mathrm{g})\end{array}$ & $\begin{array}{l}\text { Delta } \\
\text { Mass }\end{array}$ & $\begin{array}{c}\% \\
\text { difference }\end{array}$ & $\begin{array}{l}\text { Mass after } \\
\text { frying }(\mathrm{g})\end{array}$ & $\begin{array}{c}\text { Mass after } \\
\text { Centrifuge (g) }\end{array}$ & $\begin{array}{l}\text { Delta } \\
\text { Mass }\end{array}$ & $\begin{array}{c}\% \\
\text { difference }\end{array}$ \\
\hline Fry \#1 & 5.79 & 5.68 & 0.11 & 1.90 & 5.17 & 5.06 & 0.11 & 2.29 \\
\hline Fry \#2 & 5.89 & 5.77 & 0.12 & 2.04 & 5.34 & 5.27 & 0.07 & 3.91 \\
\hline Fry \#3 & 5.66 & 5.54 & 0.12 & 2.12 & 5.63 & 5.48 & 0.15 & 1.84 \\
\hline \multirow[t]{2}{*}{ Fry \#4 } & 5.85 & 5.76 & 0.09 & 1.54 & 5.63 & 5.5 & 0.13 & 1.28 \\
\hline & & AVG Delta & 0.11 & 1.90 & & AVG Delta & 0.12 & 2.33 \\
\hline $\begin{array}{c}\text { Trial } \\
\# 2\end{array}$ & $\begin{array}{l}\text { Mass after } \\
\text { frying }(\mathrm{g})\end{array}$ & $\begin{array}{c}\text { Mass after } \\
\text { Centrifuge }(\mathrm{g})\end{array}$ & $\begin{array}{l}\text { Delta } \\
\text { Mass }\end{array}$ & $\begin{array}{c}\% \\
\text { difference }\end{array}$ & $\begin{array}{l}\text { Mass after } \\
\text { frying }(\mathrm{g})\end{array}$ & $\begin{array}{c}\text { Mass after } \\
\text { Centrifuge (g) }\end{array}$ & $\begin{array}{l}\text { Delta } \\
\text { Mass }\end{array}$ & $\begin{array}{c}\% \\
\text { difference }\end{array}$ \\
\hline Fry \#1 & 4.48 & 4.44 & 0.04 & 0.89 & 5.08 & 4.98 & 0.10 & 1.09 \\
\hline Fry \#2 & 5.1 & 5.04 & 0.06 & 1.18 & 4.96 & 4.88 & 0.08 & 2.73 \\
\hline Fry \#3 & 4.66 & 4.55 & 0.11 & 2.36 & 4.85 & 4.73 & 0.12 & 1.34 \\
\hline \multirow[t]{2}{*}{ Fry \#4 } & 4.43 & 4.33 & 0.10 & 2.26 & 5.19 & 5.05 & 0.14 & 1.82 \\
\hline & & AVG Delta & 0.08 & 1.67 & & AVG Delta & 0.11 & 1.75 \\
\hline $\begin{array}{c}\text { Trial } \\
\# 3\end{array}$ & $\begin{array}{l}\text { Mass after } \\
\text { frying }(\mathrm{g})\end{array}$ & $\begin{array}{c}\text { Mass after } \\
\text { Centrifuge }(\mathrm{g})\end{array}$ & $\begin{array}{l}\text { Delta } \\
\text { Mass }\end{array}$ & $\begin{array}{c}\% \\
\text { difference }\end{array}$ & $\begin{array}{l}\text { Mass after } \\
\text { frying ( } g)\end{array}$ & $\begin{array}{c}\text { Mass after } \\
\text { Centrifuge (g) }\end{array}$ & $\begin{array}{l}\text { Delta } \\
\text { Mass }\end{array}$ & $\begin{array}{c}\% \\
\text { difference }\end{array}$ \\
\hline Fry \#1 & 5.45 & 5.34 & 0.11 & 2.02 & 5.4 & 5.31 & 0.09 & 1.53 \\
\hline Fry \#2 & 5.54 & 5.45 & 0.09 & 1.62 & 5.27 & 5.14 & 0.13 & 2.38 \\
\hline Fry \#3 & 5.16 & 5.07 & 0.09 & 1.74 & 5.49 & 5.38 & 0.11 & 1.91 \\
\hline \multirow[t]{2}{*}{ Fry \#4 } & 5.14 & 5.08 & 0.06 & 1.17 & 5.63 & 5.48 & 0.15 & 2.57 \\
\hline & & AVG Delta & 0.09 & 1.64 & & AVG Delta & 0.12 & 2.10 \\
\hline $\begin{array}{c}\text { Trial } \\
\# 4\end{array}$ & $\begin{array}{l}\text { Mass after } \\
\text { frying }(\mathrm{g})\end{array}$ & $\begin{array}{c}\text { Mass after } \\
\text { Centrifuge }(\mathrm{g})\end{array}$ & $\begin{array}{l}\text { Delta } \\
\text { Mass }\end{array}$ & $\begin{array}{c}\% \\
\text { difference }\end{array}$ & $\begin{array}{l}\text { Mass after } \\
\text { frying ( } g)\end{array}$ & $\begin{array}{c}\text { Mass after } \\
\text { Centrifuge (g) }\end{array}$ & $\begin{array}{l}\text { Delta } \\
\text { Mass }\end{array}$ & $\begin{array}{c}\% \\
\text { difference }\end{array}$ \\
\hline Fry \#1 & 5.66 & 5.55 & 0.11 & 1.94 & 6.08 & 5.91 & 0.17 & 0.96 \\
\hline Fry \#2 & 5.62 & 5.5 & 0.12 & 2.14 & 5.87 & 5.72 & 0.15 & 2.00 \\
\hline Fry \#3 & 5.6 & 5.55 & 0.05 & 0.89 & 6.01 & 5.83 & 0.18 & 2.40 \\
\hline \multirow[t]{2}{*}{ Fry \#4 } & 5.44 & 5.36 & 0.08 & 1.47 & 5.76 & 5.64 & 0.12 & 2.23 \\
\hline & & AVG Delta & 0.09 & 1.61 & & AVG Delta & 0.16 & 1.90 \\
\hline $\begin{array}{c}\text { Trial } \\
\# 5\end{array}$ & $\begin{array}{l}\text { Mass after } \\
\text { frying }(\mathrm{g})\end{array}$ & $\begin{array}{c}\text { Mass after } \\
\text { Centrifuge }(\mathrm{g})\end{array}$ & $\begin{array}{l}\text { Delta } \\
\text { Mass }\end{array}$ & $\begin{array}{c}\% \\
\text { difference }\end{array}$ & $\begin{array}{l}\text { Mass after } \\
\text { frying ( } g)\end{array}$ & $\begin{array}{c}\text { Mass after } \\
\text { Centrifuge (g) }\end{array}$ & $\begin{array}{l}\text { Delta } \\
\text { Mass }\end{array}$ & $\begin{array}{c}\% \\
\text { difference }\end{array}$ \\
\hline Fry \#1 & 5.7 & 5.56 & 0.14 & 2.46 & 5.59 & 5.49 & 0.10 & 1.55 \\
\hline Fry \#2 & 5.66 & 5.59 & 0.07 & 1.24 & 5.85 & 5.75 & 0.10 & 1.33 \\
\hline Fry \#3 & 5.48 & 5.37 & 0.11 & 2.01 & 5.92 & 5.75 & 0.17 & 1.58 \\
\hline \multirow[t]{2}{*}{ Fry \#4 } & 5.54 & 5.39 & 0.15 & 2.71 & 5.91 & 5.8 & 0.11 & 2.31 \\
\hline & & AVG Delta & 0.12 & 2.10 & & AVG Delta & 0.12 & 1.69 \\
\hline $\begin{array}{c}\text { Trial } \\
\# 6\end{array}$ & $\begin{array}{l}\text { Mass after } \\
\text { frying }(\mathrm{g})\end{array}$ & $\begin{array}{c}\text { Mass after } \\
\text { Centrifuge }(\mathrm{g})\end{array}$ & $\begin{array}{l}\text { Delta } \\
\text { Mass }\end{array}$ & $\begin{array}{c}\% \\
\text { difference }\end{array}$ & $\begin{array}{l}\text { Mass after } \\
\text { frying ( } g)\end{array}$ & $\begin{array}{c}\text { Mass after } \\
\text { Centrifuge (g) }\end{array}$ & $\begin{array}{l}\text { Delta } \\
\text { Mass }\end{array}$ & $\begin{array}{c}\% \\
\text { difference }\end{array}$ \\
\hline Fry \#1 & 5.25 & 5.16 & 0.09 & 1.71 & 5.8 & 5.7 & 0.10 & 1.72 \\
\hline Fry \#2 & 5.46 & 5.32 & 0.14 & 2.56 & 5.82 & 5.69 & 0.13 & 2.38 \\
\hline Fry \#3 & 5.03 & 5 & 0.03 & 0.60 & 5.28 & 5.18 & 0.10 & 2.35 \\
\hline \multirow[t]{2}{*}{ Fry \#4 } & 5.36 & 5.26 & 0.10 & 1.87 & 5.56 & 5.46 & 0.10 & 2.71 \\
\hline & & AVG Delta & 0.09 & 1.69 & & AVG Delta & 0.11 & 2.29 \\
\hline
\end{tabular}


Table 32 - Raw Data From Experimental Run \#1 at 450 rpm

\begin{tabular}{|c|c|c|c|c|c|c|c|c|}
\hline & \multicolumn{3}{|c|}{450 rpm @60 sec. } & & \multicolumn{3}{|c|}{450 rpm @120 sec. } & \multirow[b]{2}{*}{$\begin{array}{c}\% \\
\text { difference }\end{array}$} \\
\hline $\begin{array}{c}\text { Trial } \\
\# 1\end{array}$ & $\begin{array}{l}\text { Mass after } \\
\text { frying }(g)\end{array}$ & $\begin{array}{c}\text { Mass after } \\
\text { Centrifuge }(\mathrm{g})\end{array}$ & $\begin{array}{l}\text { Delta } \\
\text { Mass }\end{array}$ & $\begin{array}{c}\% \\
\text { difference }\end{array}$ & $\begin{array}{l}\text { Mass after } \\
\text { frying }(\mathrm{g})\end{array}$ & $\begin{array}{c}\text { Mass after } \\
\text { Centrifuge (g) }\end{array}$ & $\begin{array}{l}\text { Delta } \\
\text { Mass }\end{array}$ & \\
\hline Fry \#1 & 5.24 & 5.12 & 0.12 & 2.29 & 5.8 & 5.7 & 0.10 & 1.72 \\
\hline Fry \#2 & 5.12 & 4.92 & 0.20 & 3.91 & 6.07 & 5.9 & 0.17 & 2.80 \\
\hline Fry \#3 & 5.43 & 5.33 & 0.10 & 1.84 & 5.53 & 5.37 & 0.16 & 2.89 \\
\hline \multirow[t]{2}{*}{ Fry \#4 } & 5.47 & 5.4 & 0.07 & 1.28 & 6.14 & 5.87 & 0.27 & 4.40 \\
\hline & & AVG Delta & 0.12 & 2.33 & & AVG Delta & 0.18 & 2.95 \\
\hline $\begin{array}{c}\text { Trial } \\
\text { \#2 }\end{array}$ & $\begin{array}{l}\text { Mass after } \\
\text { frying }(\mathrm{g})\end{array}$ & $\begin{array}{c}\text { Mass after } \\
\text { Centrifuge }(\mathrm{g})\end{array}$ & $\begin{array}{l}\text { Delta } \\
\text { Mass }\end{array}$ & $\begin{array}{c}\% \\
\text { difference }\end{array}$ & $\begin{array}{l}\text { Mass after } \\
\text { frying }(\mathrm{g})\end{array}$ & $\begin{array}{c}\text { Mass after } \\
\text { Centrifuge (g) }\end{array}$ & $\begin{array}{l}\text { Delta } \\
\text { Mass }\end{array}$ & $\begin{array}{c}\% \\
\text { difference }\end{array}$ \\
\hline Fry \#1 & 5.48 & 5.42 & 0.06 & 1.09 & 4.98 & 4.82 & 0.16 & 3.21 \\
\hline Fry \#2 & 5.12 & 4.98 & 0.14 & 2.73 & 5.39 & 5.22 & 0.17 & 3.15 \\
\hline Fry \#3 & 5.24 & 5.17 & 0.07 & 1.34 & 5.11 & 4.94 & 0.17 & 3.33 \\
\hline \multirow[t]{2}{*}{ Fry \#4 } & 4.95 & 4.86 & 0.09 & 1.82 & 5.6 & 5.47 & 0.13 & 2.32 \\
\hline & & AVG Delta & 0.09 & 1.75 & & AVG Delta & 0.16 & 3.00 \\
\hline $\begin{array}{c}\text { Trial } \\
\# 3\end{array}$ & $\begin{array}{l}\text { Mass after } \\
\text { frying }(g)\end{array}$ & $\begin{array}{c}\text { Mass after } \\
\text { Centrifuge }(\mathrm{g})\end{array}$ & $\begin{array}{l}\text { Delta } \\
\text { Mass }\end{array}$ & $\begin{array}{c}\% \\
\text { difference }\end{array}$ & $\begin{array}{l}\text { Mass after } \\
\text { frying }(\mathrm{g})\end{array}$ & $\begin{array}{c}\text { Mass after } \\
\text { Centrifuge (g) }\end{array}$ & $\begin{array}{l}\text { Delta } \\
\text { Mass }\end{array}$ & $\begin{array}{c}\% \\
\text { difference }\end{array}$ \\
\hline Fry \#1 & 5.23 & 5.15 & 0.08 & 1.53 & 5.52 & 5.35 & 0.17 & 3.08 \\
\hline Fry \#2 & 5.04 & 4.92 & 0.12 & 2.38 & 5.31 & 5.16 & 0.15 & 2.82 \\
\hline Fry \#3 & 5.24 & 5.14 & 0.10 & 1.91 & 5.43 & 5.28 & 0.15 & 2.76 \\
\hline \multirow[t]{2}{*}{ Fry \#4 } & 5.45 & 5.31 & 0.14 & 2.57 & 5.47 & 5.35 & 0.12 & 2.19 \\
\hline & & AVG Delta & 0.11 & 2.10 & & AVG Delta & 0.15 & 2.72 \\
\hline $\begin{array}{c}\text { Trial } \\
\# 4\end{array}$ & $\begin{array}{l}\text { Mass after } \\
\text { frying }(\mathrm{g})\end{array}$ & $\begin{array}{c}\text { Mass after } \\
\text { Centrifuge }(\mathrm{g})\end{array}$ & $\begin{array}{l}\text { Delta } \\
\text { Mass }\end{array}$ & $\begin{array}{c}\% \\
\text { difference }\end{array}$ & $\begin{array}{l}\text { Mass after } \\
\text { frying }(\mathrm{g})\end{array}$ & $\begin{array}{c}\text { Mass after } \\
\text { Centrifuge (g) }\end{array}$ & $\begin{array}{l}\text { Delta } \\
\text { Mass }\end{array}$ & $\begin{array}{c}\% \\
\text { difference }\end{array}$ \\
\hline Fry \#1 & 5.2 & 5.15 & 0.05 & 0.96 & 5.38 & 5.31 & 0.07 & 1.30 \\
\hline Fry \#2 & 5.49 & 5.38 & 0.11 & 2.00 & 5.2 & 5.12 & 0.08 & 1.54 \\
\hline Fry \#3 & 5.84 & 5.7 & 0.14 & 2.40 & 4.93 & 4.83 & 0.10 & 2.03 \\
\hline \multirow[t]{2}{*}{ Fry \#4 } & 5.82 & 5.69 & 0.13 & 2.23 & 5.13 & 5.01 & 0.12 & 2.34 \\
\hline & & AVG Delta & 0.11 & 1.90 & & AVG Delta & 0.09 & 1.80 \\
\hline $\begin{array}{c}\text { Trial } \\
\# 5\end{array}$ & $\begin{array}{l}\text { Mass after } \\
\text { frying }(\mathrm{g})\end{array}$ & $\begin{array}{c}\text { Mass after } \\
\text { Centrifuge }(\mathrm{g})\end{array}$ & $\begin{array}{l}\text { Delta } \\
\text { Mass }\end{array}$ & $\begin{array}{c}\% \\
\text { difference }\end{array}$ & $\begin{array}{l}\text { Mass after } \\
\text { frying }(\mathrm{g})\end{array}$ & $\begin{array}{c}\text { Mass after } \\
\text { Centrifuge (g) }\end{array}$ & $\begin{array}{l}\text { Delta } \\
\text { Mass }\end{array}$ & $\begin{array}{c}\% \\
\text { difference }\end{array}$ \\
\hline Fry \#1 & 5.8 & 5.71 & 0.09 & 1.55 & 5.48 & 5.39 & 0.09 & 1.64 \\
\hline Fry \#2 & 6 & 5.92 & 0.08 & 1.33 & 5.59 & 5.5 & 0.09 & 1.61 \\
\hline Fry \#3 & 5.71 & 5.62 & 0.09 & 1.58 & 5.61 & 5.49 & 0.12 & 2.14 \\
\hline \multirow[t]{2}{*}{ Fry \#4 } & 5.63 & 5.5 & 0.13 & 2.31 & 5.25 & 5.12 & 0.13 & 2.48 \\
\hline & & AVG Delta & 0.10 & 1.69 & & AVG Delta & 0.11 & 1.97 \\
\hline $\begin{array}{c}\text { Trial } \\
\# 6\end{array}$ & $\begin{array}{l}\text { Mass after } \\
\text { frying }(\mathrm{g})\end{array}$ & $\begin{array}{c}\text { Mass after } \\
\text { Centrifuge }(\mathrm{g})\end{array}$ & $\begin{array}{l}\text { Delta } \\
\text { Mass }\end{array}$ & $\begin{array}{c}\% \\
\text { difference }\end{array}$ & $\begin{array}{l}\text { Mass after } \\
\text { frying }(\mathrm{g})\end{array}$ & $\begin{array}{c}\text { Mass after } \\
\text { Centrifuge (g) }\end{array}$ & $\begin{array}{l}\text { Delta } \\
\text { Mass }\end{array}$ & $\begin{array}{c}\% \\
\text { difference }\end{array}$ \\
\hline Fry \#1 & 5.82 & 5.72 & 0.10 & 1.72 & 5.87 & 5.77 & 0.10 & 1.70 \\
\hline Fry \#2 & 5.46 & 5.33 & 0.13 & 2.38 & 5.19 & 5.08 & 0.11 & 2.12 \\
\hline Fry \#3 & 5.53 & 5.4 & 0.13 & 2.35 & 5.39 & 5.22 & 0.17 & 3.15 \\
\hline \multirow[t]{2}{*}{ Fry \#4 } & 5.53 & 5.38 & 0.15 & 2.71 & 5.61 & 5.48 & 0.13 & 2.32 \\
\hline & & AVG Delta & 0.13 & 2.29 & & AVG Delta & 0.13 & 2.32 \\
\hline
\end{tabular}


Table 33 - Raw Data From Experimental Run \#1 at 700 rpm

\begin{tabular}{|c|c|c|c|c|c|c|c|c|}
\hline \multicolumn{4}{|c|}{700 rpm @ 60 sec. } & \multicolumn{4}{|c|}{700 rpm @ 120 sec. } & \multirow[b]{2}{*}{$\begin{array}{c}\% \\
\text { difference }\end{array}$} \\
\hline $\begin{array}{c}\text { Trial } \\
\# 1\end{array}$ & $\begin{array}{l}\text { Mass after } \\
\text { frying }(\mathrm{g})\end{array}$ & $\begin{array}{c}\text { Mass after } \\
\text { Centrifuge (g) }\end{array}$ & $\begin{array}{l}\text { Delta } \\
\text { Mass }\end{array}$ & $\begin{array}{c}\% \\
\text { difference }\end{array}$ & $\begin{array}{l}\text { Mass after } \\
\text { frying }(\mathrm{g})\end{array}$ & $\begin{array}{c}\text { Mass after } \\
\text { Centrifuge (g) }\end{array}$ & $\begin{array}{l}\text { Delta } \\
\text { Mass }\end{array}$ & \\
\hline Fry \#1 & 5.88 & 5.75 & 0.13 & 2.21 & 5.66 & 5.44 & 0.22 & 3.89 \\
\hline Fry \#2 & 6.07 & 5.87 & 0.20 & 3.29 & 5.84 & 5.62 & 0.22 & 3.77 \\
\hline Fry \#3 & 5.65 & 5.52 & 0.13 & 2.30 & 5.24 & 5.06 & 0.18 & 3.44 \\
\hline \multirow[t]{2}{*}{ Fry \#4 } & 5.85 & 5.68 & 0.17 & 2.91 & 5.47 & 5.31 & 0.16 & 2.93 \\
\hline & & AVG Delta & 0.16 & 2.68 & & AVG Delta & 0.20 & 3.50 \\
\hline $\begin{array}{c}\text { Trial } \\
\# 2\end{array}$ & $\begin{array}{l}\text { Mass after } \\
\text { frying }(\mathrm{g})\end{array}$ & $\begin{array}{c}\text { Mass after } \\
\text { Centrifuge }(\mathrm{g})\end{array}$ & $\begin{array}{l}\text { Delta } \\
\text { Mass }\end{array}$ & $\begin{array}{c}\% \\
\text { difference }\end{array}$ & $\begin{array}{l}\text { Mass after } \\
\text { frying }(\mathrm{g})\end{array}$ & $\begin{array}{c}\text { Mass after } \\
\text { Centrifuge (g) }\end{array}$ & $\begin{array}{l}\text { Delta } \\
\text { Mass }\end{array}$ & $\begin{array}{c}\% \\
\text { difference }\end{array}$ \\
\hline Fry \#1 & 5.14 & 5 & 0.14 & 2.72 & 5.59 & 5.43 & 0.16 & 2.86 \\
\hline Fry \#2 & 5.38 & 5.17 & 0.21 & 3.90 & 5.56 & 5.36 & 0.20 & 3.60 \\
\hline Fry \#3 & 5.04 & 4.81 & 0.23 & 4.56 & 5.42 & 5.25 & 0.17 & 3.14 \\
\hline \multirow[t]{2}{*}{ Fry \#4 } & 4.85 & 4.65 & 0.20 & 4.12 & 6.28 & 6.08 & 0.20 & 3.18 \\
\hline & & AVG Delta & 0.20 & 3.83 & & AVG Delta & 0.18 & 3.20 \\
\hline $\begin{array}{c}\text { Trial } \\
\text { \#3 }\end{array}$ & $\begin{array}{l}\text { Mass after } \\
\text { frying }(\mathrm{g})\end{array}$ & $\begin{array}{c}\text { Mass after } \\
\text { Centrifuge }(\mathrm{g})\end{array}$ & $\begin{array}{l}\text { Delta } \\
\text { Mass }\end{array}$ & $\begin{array}{c}\% \\
\text { difference }\end{array}$ & $\begin{array}{l}\text { Mass after } \\
\text { frying }(\mathrm{g})\end{array}$ & $\begin{array}{c}\text { Mass after } \\
\text { Centrifuge (g) }\end{array}$ & $\begin{array}{l}\text { Delta } \\
\text { Mass }\end{array}$ & $\begin{array}{c}\% \\
\text { difference }\end{array}$ \\
\hline Fry \#1 & 5.04 & 4.92 & 0.12 & 2.38 & 5.12 & 4.92 & 0.20 & 3.91 \\
\hline Fry \#2 & 4.84 & 4.62 & 0.22 & 4.55 & 4.86 & 4.7 & 0.16 & 3.29 \\
\hline Fry \#3 & 4.86 & 4.71 & 0.15 & 3.09 & 5.06 & 4.94 & 0.12 & 2.37 \\
\hline \multirow[t]{2}{*}{ Fry \#4 } & 5.03 & 4.76 & 0.27 & 5.37 & 5.19 & 5.06 & 0.13 & 2.50 \\
\hline & & AVG Delta & 0.19 & 3.85 & & AVG Delta & 0.15 & 3.02 \\
\hline $\begin{array}{c}\text { Trial } \\
\# 4\end{array}$ & $\begin{array}{l}\text { Mass after } \\
\text { frying }(\mathrm{g})\end{array}$ & $\begin{array}{c}\text { Mass after } \\
\text { Centrifuge }(\mathrm{g})\end{array}$ & $\begin{array}{l}\text { Delta } \\
\text { Mass }\end{array}$ & $\begin{array}{c}\% \\
\text { difference }\end{array}$ & $\begin{array}{l}\text { Mass after } \\
\text { frying }(\mathrm{g})\end{array}$ & $\begin{array}{c}\text { Mass after } \\
\text { Centrifuge (g) }\end{array}$ & $\begin{array}{l}\text { Delta } \\
\text { Mass }\end{array}$ & $\begin{array}{c}\% \\
\text { difference }\end{array}$ \\
\hline Fry \#1 & 5.24 & 5.13 & 0.11 & 2.10 & 5.68 & 5.5 & 0.18 & 3.17 \\
\hline Fry \#2 & 5.16 & 5.04 & 0.12 & 2.33 & 5.23 & 5.08 & 0.15 & 2.87 \\
\hline Fry \#3 & 5.14 & 4.92 & 0.22 & 4.28 & 5.9 & 5.78 & 0.12 & 2.03 \\
\hline \multirow[t]{2}{*}{ Fry \#4 } & 5.32 & 5.23 & 0.09 & 1.69 & 5.23 & 5.02 & 0.21 & 4.02 \\
\hline & & AVG Delta & 0.14 & 2.60 & & AVG Delta & 0.17 & 3.02 \\
\hline $\begin{array}{c}\text { Trial } \\
\# 5\end{array}$ & $\begin{array}{l}\text { Mass after } \\
\text { frying }(\mathrm{g})\end{array}$ & $\begin{array}{c}\text { Mass after } \\
\text { Centrifuge (g) }\end{array}$ & $\begin{array}{l}\text { Delta } \\
\text { Mass }\end{array}$ & $\begin{array}{c}\% \\
\text { difference }\end{array}$ & $\begin{array}{l}\text { Mass after } \\
\text { frying }(\mathrm{g})\end{array}$ & $\begin{array}{c}\text { Mass after } \\
\text { Centrifuge (g) }\end{array}$ & $\begin{array}{l}\text { Delta } \\
\text { Mass }\end{array}$ & $\begin{array}{c}\% \\
\text { difference }\end{array}$ \\
\hline Fry \#1 & 5.83 & 5.62 & 0.21 & 3.60 & 5.62 & 5.47 & 0.15 & 2.67 \\
\hline Fry \#2 & 5.96 & 5.78 & 0.18 & 3.02 & 5.2 & 4.99 & 0.21 & 4.04 \\
\hline Fry \#3 & 5.83 & 5.64 & 0.19 & 3.26 & 5.41 & 5.2 & 0.21 & 3.88 \\
\hline \multirow[t]{2}{*}{ Fry \#4 } & 5.3 & 5.11 & 0.19 & 3.58 & 5.53 & 5.34 & 0.19 & 3.44 \\
\hline & & AVG Delta & 0.19 & 3.37 & & AVG Delta & 0.19 & 3.51 \\
\hline $\begin{array}{c}\text { Trial } \\
\# 6\end{array}$ & $\begin{array}{l}\text { Mass after } \\
\text { frying }(\mathrm{g})\end{array}$ & $\begin{array}{c}\text { Mass after } \\
\text { Centrifuge (g) }\end{array}$ & $\begin{array}{l}\text { Delta } \\
\text { Mass }\end{array}$ & $\begin{array}{c}\% \\
\text { difference }\end{array}$ & $\begin{array}{l}\text { Mass after } \\
\text { frying }(\mathrm{g})\end{array}$ & $\begin{array}{c}\text { Mass after } \\
\text { Centrifuge }(\mathrm{g})\end{array}$ & $\begin{array}{l}\text { Delta } \\
\text { Mass }\end{array}$ & $\begin{array}{c}\% \\
\text { difference }\end{array}$ \\
\hline Fry \#1 & 5.59 & 5.42 & 0.17 & 3.04 & 5.38 & 5.21 & 0.17 & 3.16 \\
\hline Fry \#2 & 5.88 & 5.71 & 0.17 & 2.89 & 5.51 & 5.36 & 0.15 & 2.72 \\
\hline Fry \#3 & 5.97 & 5.81 & 0.16 & 2.68 & 5.95 & 5.74 & 0.21 & 3.53 \\
\hline \multirow[t]{2}{*}{ Fry \#4 } & 5.38 & 5.27 & 0.11 & 2.04 & 5.38 & 5.14 & 0.24 & 4.46 \\
\hline & & AVG Delta & 0.15 & 2.66 & & AVG Delta & 0.19 & 3.47 \\
\hline
\end{tabular}


Table 34 - Combined Data for Experimental Run \#1

\begin{tabular}{|c|c|c|c|}
\hline Oil Extracted (g) & Percent Change in Mass & Angular Velocity (rpm) & Time (s) \\
\hline 0.11 & 0.48 & 200 & 60 \\
\hline 0.08 & 1.32 & 200 & 60 \\
\hline 0.09 & 0.9 & 200 & 60 \\
\hline 0.09 & 0.41 & 200 & 60 \\
\hline 0.12 & 0.6 & 200 & 60 \\
\hline 0.09 & 0.44 & 200 & 60 \\
\hline 0.12 & 0.27 & 200 & 120 \\
\hline 0.11 & 0.74 & 200 & 120 \\
\hline 0.12 & 0.49 & 200 & 120 \\
\hline 0.16 & 0.43 & 200 & 120 \\
\hline 0.12 & 0.34 & 200 & 120 \\
\hline 0.11 & 0.61 & 200 & 120 \\
\hline 0.12 & 0.56 & 450 & 60 \\
\hline 0.09 & 1.12 & 450 & 60 \\
\hline 0.11 & 0.25 & 450 & 60 \\
\hline 0.11 & 0.83 & 450 & 60 \\
\hline 0.1 & 0.57 & 450 & 60 \\
\hline 0.13 & 0.64 & 450 & 60 \\
\hline 0.18 & 1.09 & 450 & 120 \\
\hline 0.16 & 1.22 & 450 & 120 \\
\hline 0.15 & 0.76 & 450 & 120 \\
\hline 0.09 & 1.28 & 450 & 120 \\
\hline 0.11 & 0.61 & 450 & 120 \\
\hline 0.13 & 0.7 & 450 & 120 \\
\hline 0.16 & 1.19 & 700 & 60 \\
\hline 0.2 & 1.31 & 700 & 60 \\
\hline 0.19 & 0.69 & 700 & 60 \\
\hline 0.14 & 1.45 & 700 & 60 \\
\hline 0.19 & 1.83 & 700 & 60 \\
\hline 0.15 & 1.27 & 700 & 60 \\
\hline 0.2 & 10 & 700 & 120 \\
\hline 0.18 & 1.09 & 700 & 120 \\
\hline 0.15 & 1.09 & 700 & 120 \\
\hline 0.17 & 0.85 & 700 & 120 \\
\hline 0.19 & 1.55 & 700 & 120 \\
\hline 0.19 & 1.14 & 700 & 120 \\
\hline
\end{tabular}




\section{Appendix A5. Experimental Run \#2 Data}

Table 35 - Raw Data From Experimental Run \#2 at 200 rpm

\begin{tabular}{|c|c|c|c|c|c|c|c|c|}
\hline & \multicolumn{3}{|c|}{200 rpm @ 60 sec. } & & \multicolumn{3}{|c|}{200 rpm @120 sec. } & \multirow[b]{2}{*}{$\begin{array}{c}\% \\
\text { difference }\end{array}$} \\
\hline $\begin{array}{c}\text { Trial } \\
\# 1 \\
\end{array}$ & $\begin{array}{l}\text { Mass after } \\
\text { frying (g) }\end{array}$ & $\begin{array}{c}\text { Mass after } \\
\text { Centrifuge }(\mathrm{g}) \\
\end{array}$ & $\begin{array}{l}\text { Delta } \\
\text { Mass } \\
\end{array}$ & $\begin{array}{c}\% \\
\text { difference } \\
\end{array}$ & $\begin{array}{l}\text { Mass after } \\
\text { frying }(\mathrm{g})\end{array}$ & $\begin{array}{c}\text { Mass after } \\
\text { Centrifuge (g) }\end{array}$ & $\begin{array}{l}\text { Delta } \\
\text { Mass } \\
\end{array}$ & \\
\hline Fry \#1 & 4.83 & 4.8 & 0.03 & 0.62 & 3.44 & 3.44 & 0.00 & 0.00 \\
\hline Fry \#2 & 4.63 & 4.63 & 0.00 & 0.00 & 4.58 & 4.53 & 0.05 & 1.09 \\
\hline Fry \#3 & 4.94 & 4.91 & 0.03 & 0.60 & 2.83 & 2.83 & 0.00 & 0.00 \\
\hline \multirow[t]{2}{*}{ Fry \#4 } & 2.89 & 2.87 & 0.02 & 0.69 & 3.89 & 3.89 & 0.00 & 0.00 \\
\hline & & AVG Delta & 0.02 & 0.4801 & & AVG Delta & 0.01 & 0.27 \\
\hline $\begin{array}{c}\text { Trial } \\
\# 2\end{array}$ & $\begin{array}{l}\text { Mass after } \\
\text { frying }(\mathrm{g})\end{array}$ & $\begin{array}{c}\text { Mass after } \\
\text { Centrifuge }(\mathrm{g})\end{array}$ & $\begin{array}{l}\text { Delta } \\
\text { Mass }\end{array}$ & $\begin{array}{c}\% \\
\text { difference }\end{array}$ & $\begin{array}{l}\text { Mass after } \\
\text { frying }(\mathrm{g})\end{array}$ & $\begin{array}{c}\text { Mass after } \\
\text { Centrifuge }(\mathrm{g})\end{array}$ & $\begin{array}{l}\text { Delta } \\
\text { Mass }\end{array}$ & $\begin{array}{c}\% \\
\text { difference }\end{array}$ \\
\hline Fry \#1 & 3.76 & 3.74 & 0.02 & 0.53 & 3.92 & 3.91 & 0.01 & 0.25 \\
\hline Fry \#2 & 2.93 & 2.9 & 0.03 & 1.02 & 4.13 & 4.11 & 0.02 & 0.48 \\
\hline Fry \#3 & 2.82 & 2.77 & 0.05 & 1.77 & 3.45 & 3.4 & 0.05 & 1.45 \\
\hline \multirow[t]{2}{*}{ Fry \#4 } & 1.54 & 1.51 & 0.03 & 1.94 & 2.57 & 2.55 & 0.02 & 0.78 \\
\hline & & AVG Delta & 0.03 & 1.31 & & AVG Delta & 0.02 & 0.74 \\
\hline $\begin{array}{c}\text { Trial } \\
\# 3\end{array}$ & $\begin{array}{l}\text { Mass after } \\
\text { frying }(\mathrm{g})\end{array}$ & $\begin{array}{c}\text { Mass after } \\
\text { Centrifuge }(\mathrm{g})\end{array}$ & $\begin{array}{l}\text { Delta } \\
\text { Mass }\end{array}$ & $\begin{array}{c}\% \\
\text { difference }\end{array}$ & $\begin{array}{l}\text { Mass after } \\
\text { frying }(\mathrm{g})\end{array}$ & $\begin{array}{c}\text { Mass after } \\
\text { Centrifuge (g) }\end{array}$ & $\begin{array}{l}\text { Delta } \\
\text { Mass }\end{array}$ & $\begin{array}{c}\% \\
\text { difference }\end{array}$ \\
\hline Fry \#1 & 3.91 & 3.88 & 0.03 & 0.76 & 3.96 & 3.95 & 0.01 & 0.25 \\
\hline Fry \#2 & 3.48 & 3.43 & 0.05 & 1.43 & 3.62 & 3.6 & 0.02 & 0.55 \\
\hline Fry \#3 & 3.69 & 3.65 & 0.04 & 1.08 & 4.75 & 4.75 & 0.00 & 0.00 \\
\hline \multirow[t]{2}{*}{ Fry \#4 } & 3.16 & 3.15 & 0.01 & 0.31 & 3.44 & 3.4 & 0.04 & 1.16 \\
\hline & & AVG Delta & 0.03 & 0.90 & & AVG Delta & 0.02 & 0.49 \\
\hline $\begin{array}{c}\text { Trial } \\
\# 4\end{array}$ & $\begin{array}{l}\text { Mass after } \\
\text { frying }(\mathrm{g})\end{array}$ & $\begin{array}{c}\text { Mass after } \\
\text { Centrifuge }(\mathrm{g})\end{array}$ & $\begin{array}{l}\text { Delta } \\
\text { Mass }\end{array}$ & $\begin{array}{c}\% \\
\text { difference }\end{array}$ & $\begin{array}{l}\text { Mass after } \\
\text { frying }(\mathrm{g})\end{array}$ & $\begin{array}{c}\text { Mass after } \\
\text { Centrifuge }(\mathrm{g})\end{array}$ & $\begin{array}{l}\text { Delta } \\
\text { Mass }\end{array}$ & $\begin{array}{c}\% \\
\text { difference }\end{array}$ \\
\hline Fry \#1 & 4.22 & 4.2 & 0.02 & 0.47 & 4.5 & 4.49 & 0.01 & 0.22 \\
\hline Fry \#2 & 2.24 & 2.23 & 0.01 & 0.44 & 3.14 & 3.13 & 0.01 & 0.32 \\
\hline Fry \#3 & 4.09 & 4.07 & 0.02 & 0.48 & 3.49 & 3.48 & 0.01 & 0.29 \\
\hline \multirow[t]{2}{*}{ Fry \#4 } & 4.46 & 4.45 & 0.01 & 0.22 & 4.46 & 4.42 & 0.04 & 0.90 \\
\hline & & AVG Delta & 0.01 & 0.4084 & & AVG Delta & 0.02 & 0.43 \\
\hline $\begin{array}{c}\text { Trial } \\
\# 5\end{array}$ & $\begin{array}{l}\text { Mass after } \\
\text { frying }(\mathrm{g})\end{array}$ & $\begin{array}{c}\text { Mass after } \\
\text { Centrifuge }(\mathrm{g})\end{array}$ & $\begin{array}{l}\text { Delta } \\
\text { Mass }\end{array}$ & $\begin{array}{c}\% \\
\text { difference }\end{array}$ & $\begin{array}{l}\text { Mass after } \\
\text { frying }(\mathrm{g})\end{array}$ & $\begin{array}{c}\text { Mass after } \\
\text { Centrifuge }(\mathrm{g})\end{array}$ & $\begin{array}{l}\text { Delta } \\
\text { Mass }\end{array}$ & $\begin{array}{c}\% \\
\text { difference }\end{array}$ \\
\hline Fry \#1 & 6.5 & 6.5 & 0.00 & 0.00 & 8.06 & 8.05 & 0.01 & 0.12 \\
\hline Fry \#2 & 5.76 & 5.68 & 0.08 & 1.39 & 5.47 & 5.47 & 0.00 & 0.00 \\
\hline Fry \#3 & 3.99 & 3.99 & 0.00 & 0.00 & 6.07 & 6.03 & 0.04 & 0.66 \\
\hline \multirow[t]{2}{*}{ Fry \#4 } & 4.88 & 4.83 & 0.05 & 1.02 & 3.58 & 3.56 & 0.02 & 0.56 \\
\hline & & AVG Delta & 0.03 & 0.60 & & AVG Delta & 0.02 & 0.3354 \\
\hline $\begin{array}{c}\text { Trial } \\
\# 6\end{array}$ & $\begin{array}{l}\text { Mass after } \\
\text { frying }(\mathrm{g})\end{array}$ & $\begin{array}{c}\text { Mass after } \\
\text { Centrifuge }(\mathrm{g})\end{array}$ & $\begin{array}{l}\text { Delta } \\
\text { Mass }\end{array}$ & $\begin{array}{c}\% \\
\text { difference }\end{array}$ & $\begin{array}{l}\text { Mass after } \\
\text { frying }(\mathrm{g})\end{array}$ & $\begin{array}{c}\text { Mass after } \\
\text { Centrifuge }(\mathrm{g})\end{array}$ & $\begin{array}{l}\text { Delta } \\
\text { Mass }\end{array}$ & $\begin{array}{c}\% \\
\text { difference }\end{array}$ \\
\hline Fry \#1 & 5.49 & 5.48 & 0.01 & 0.18 & 7.44 & 7.4 & 0.04 & 0.54 \\
\hline Fry \#2 & 5.23 & 5.22 & 0.01 & 0.19 & 6.04 & 6 & 0.04 & 0.66 \\
\hline Fry \#3 & 5.1 & 5.03 & 0.07 & 1.37 & 3.26 & 3.22 & 0.04 & 1.23 \\
\hline \multirow[t]{2}{*}{ Fry \#4 } & 3.04 & 3.04 & 0.00 & 0.00 & 5.25 & 5.25 & 0.00 & 0.00 \\
\hline & & AVG Delta & 0.02 & 0.44 & & AVG Delta & 0.03 & 0.61 \\
\hline
\end{tabular}


Table 36 - Raw Data From Experimental Run \#2 at 450 rpm

\begin{tabular}{|c|c|c|c|c|c|c|c|c|}
\hline & \multicolumn{3}{|c|}{450 rpm @60 sec. } & & \multicolumn{3}{|c|}{450 rpm @ 120 sec. } & \multirow[b]{2}{*}{$\begin{array}{c}\% \\
\text { difference }\end{array}$} \\
\hline $\begin{array}{c}\text { Trial } \\
\# 1\end{array}$ & $\begin{array}{l}\text { Mass after } \\
\text { frying (g) }\end{array}$ & $\begin{array}{c}\text { Mass after } \\
\text { Centrifuge (g) }\end{array}$ & $\begin{array}{l}\text { Delta } \\
\text { Mass }\end{array}$ & $\begin{array}{c}\% \\
\text { difference }\end{array}$ & $\begin{array}{l}\text { Mass after } \\
\text { frying }(\mathrm{g})\end{array}$ & $\begin{array}{c}\text { Mass after } \\
\text { Centrifuge }(\mathrm{g})\end{array}$ & $\begin{array}{l}\text { Delta } \\
\text { Mass }\end{array}$ & \\
\hline Fry \#1 & 6.25 & 6.22 & 0.03 & 0.48 & 3.84 & 3.79 & 0.05 & 1.3021 \\
\hline Fry \#2 & 5.39 & 5.36 & 0.03 & 0.56 & 4.84 & 4.79 & 0.05 & 1.0331 \\
\hline Fry \#3 & 5.05 & 5.02 & 0.03 & 0.59 & 6.27 & 6.22 & 0.05 & 0.7974 \\
\hline \multirow[t]{2}{*}{ Fry \#4 } & 3.37 & 3.35 & 0.02 & 0.59 & 4.03 & 3.98 & 0.05 & 1.2407 \\
\hline & & AVG Delta & 0.03 & 0.56 & & AVG Delta & 0.05 & 1.0933 \\
\hline $\begin{array}{c}\text { Trial } \\
\# 2\end{array}$ & $\begin{array}{l}\text { Mass after } \\
\text { frying }(\mathrm{g})\end{array}$ & $\begin{array}{c}\text { Mass after } \\
\text { Centrifuge (g) }\end{array}$ & $\begin{array}{l}\text { Delta } \\
\text { Mass }\end{array}$ & $\begin{array}{c}\% \\
\text { difference }\end{array}$ & $\begin{array}{l}\text { Mass after } \\
\text { frying }(\mathrm{g})\end{array}$ & $\begin{array}{c}\text { Mass after } \\
\text { Centrifuge (g) }\end{array}$ & $\begin{array}{l}\text { Delta } \\
\text { Mass }\end{array}$ & $\begin{array}{c}\% \\
\text { difference }\end{array}$ \\
\hline Fry \#1 & 3.22 & 3.22 & 0.00 & 0.00 & 7.82 & 7.75 & 0.07 & 0.89 \\
\hline Fry \#2 & 4.53 & 4.51 & 0.02 & 0.44 & 3.8 & 3.75 & 0.05 & 1.36 \\
\hline Fry \#3 & 2.78 & 2.74 & 0.04 & 1.44 & 3.39 & 3.33 & 0.06 & 1.77 \\
\hline \multirow[t]{2}{*}{ Fry \#4 } & 4.26 & 4.15 & 0.11 & 2.58 & 3.32 & 3.29 & 0.03 & 0.90 \\
\hline & & AVG Delta & 0.04 & 1.12 & & AVG Delta & 0.05 & 1.22 \\
\hline $\begin{array}{c}\text { Trial } \\
\# 3\end{array}$ & $\begin{array}{l}\text { Mass after } \\
\text { frying }(\mathrm{g})\end{array}$ & $\begin{array}{c}\text { Mass after } \\
\text { Centrifuge (g) }\end{array}$ & $\begin{array}{l}\text { Delta } \\
\text { Mass }\end{array}$ & $\begin{array}{c}\% \\
\text { difference }\end{array}$ & $\begin{array}{l}\text { Mass after } \\
\text { frying }(\mathrm{g})\end{array}$ & $\begin{array}{c}\text { Mass after } \\
\text { Centrifuge (g) }\end{array}$ & $\begin{array}{l}\text { Delta } \\
\text { Mass }\end{array}$ & $\begin{array}{c}\% \\
\text { difference }\end{array}$ \\
\hline Fry \#1 & 5.4 & 5.39 & 0.01 & 0.18 & 2.84 & 2.84 & 0.00 & 0.00 \\
\hline Fry \#2 & 3.79 & 3.78 & 0.01 & 0.26 & 2.83 & 2.83 & 0.00 & 0.00 \\
\hline Fry \#3 & 3.59 & 3.59 & 0.00 & 0.00 & 3.76 & 3.74 & 0.02 & 0.53 \\
\hline \multirow[t]{2}{*}{ Fry \#4 } & 5.47 & 5.44 & 0.03 & 0.55 & 2.38 & 2.32 & 0.06 & 2.52 \\
\hline & & AVG Delta & 0.01 & 0.25 & & AVG Delta & 0.02 & 0.76 \\
\hline $\begin{array}{c}\text { Trial } \\
\# 4\end{array}$ & $\begin{array}{l}\text { Mass after } \\
\text { frying }(\mathrm{g})\end{array}$ & $\begin{array}{c}\text { Mass after } \\
\text { Centrifuge (g) }\end{array}$ & $\begin{array}{l}\text { Delta } \\
\text { Mass }\end{array}$ & $\begin{array}{c}\% \\
\text { difference }\end{array}$ & $\begin{array}{l}\text { Mass after } \\
\text { frying }(\mathrm{g})\end{array}$ & $\begin{array}{c}\text { Mass after } \\
\text { Centrifuge (g) }\end{array}$ & $\begin{array}{l}\text { Delta } \\
\text { Mass }\end{array}$ & $\begin{array}{c}\% \\
\text { difference }\end{array}$ \\
\hline Fry \#1 & 6.89 & 6.85 & 0.04 & 0.58 & 5.03 & 4.99 & 0.04 & 0.80 \\
\hline Fry \#2 & 4.54 & 4.46 & 0.08 & 1.76 & 5.38 & 5.3 & 0.08 & 1.49 \\
\hline Fry \#3 & 4.24 & 4.22 & 0.02 & 0.47 & 3.45 & 3.42 & 0.03 & 0.87 \\
\hline \multirow[t]{2}{*}{ Fry \#4 } & 3.84 & 3.82 & 0.02 & 0.52 & 4.08 & 4 & 0.08 & 1.96 \\
\hline & & AVG Delta & 0.04 & 0.83 & & AVG Delta & 0.06 & 1.29 \\
\hline $\begin{array}{c}\text { Trial } \\
\# 5\end{array}$ & $\begin{array}{l}\text { Mass after } \\
\text { frying }(\mathrm{g})\end{array}$ & $\begin{array}{c}\text { Mass after } \\
\text { Centrifuge }(\mathrm{g})\end{array}$ & $\begin{array}{l}\text { Delta } \\
\text { Mass }\end{array}$ & $\begin{array}{c}\% \\
\text { difference }\end{array}$ & $\begin{array}{l}\text { Mass after } \\
\text { frying }(\mathrm{g})\end{array}$ & $\begin{array}{c}\text { Mass after } \\
\text { Centrifuge }(\mathrm{g})\end{array}$ & $\begin{array}{l}\text { Delta } \\
\text { Mass }\end{array}$ & $\begin{array}{c}\% \\
\text { difference }\end{array}$ \\
\hline Fry \#1 & 9.28 & 9.26 & 0.02 & 0.21 & 6.13 & 6.11 & 0.02 & 0.32 \\
\hline Fry \#2 & 6.71 & 6.65 & 0.06 & 0.89 & 6.88 & 6.85 & 0.03 & 0.43 \\
\hline Fry \#3 & 6.72 & 6.69 & 0.03 & 0.44 & 6.52 & 6.47 & 0.05 & 0.76 \\
\hline \multirow[t]{2}{*}{ Fry \#4 } & 5.55 & 5.51 & 0.04 & 0.72 & 5.58 & 5.53 & 0.05 & 0.89 \\
\hline & & AVG Delta & 0.04 & 0.57 & & AVG Delta & 0.04 & 0.60 \\
\hline $\begin{array}{c}\text { Trial } \\
\# 6\end{array}$ & $\begin{array}{l}\text { Mass after } \\
\text { frying }(\mathrm{g})\end{array}$ & $\begin{array}{c}\text { Mass after } \\
\text { Centrifuge (g) }\end{array}$ & $\begin{array}{l}\text { Delta } \\
\text { Mass } \\
\end{array}$ & $\begin{array}{c}\% \\
\text { difference }\end{array}$ & $\begin{array}{l}\text { Mass after } \\
\text { frying }(\mathrm{g})\end{array}$ & $\begin{array}{c}\text { Mass after } \\
\text { Centrifuge (g) }\end{array}$ & $\begin{array}{l}\text { Delta } \\
\text { Mass }\end{array}$ & $\begin{array}{c}\% \\
\text { difference }\end{array}$ \\
\hline Fry \#1 & 5.36 & 5.34 & 0.02 & 0.37 & 5.17 & 5.15 & 0.02 & 0.39 \\
\hline Fry \#2 & 6.34 & 6.32 & 0.02 & 0.32 & 6.35 & 6.32 & 0.03 & 0.47 \\
\hline Fry \#3 & 6.25 & 6.2 & 0.05 & 0.80 & 5.35 & 5.31 & 0.04 & 0.75 \\
\hline \multirow[t]{2}{*}{ Fry \#4 } & 7.38 & 7.3 & 0.08 & 1.08 & 4.22 & 4.17 & 0.05 & 1.18 \\
\hline & & AVG Delta & 0.04 & 0.64 & & AVG Delta & 0.03 & 0.70 \\
\hline
\end{tabular}


Table 37 - Raw Data From Experimental Run \#2 at 700 rpm

\begin{tabular}{|c|c|c|c|c|c|c|c|c|}
\hline & \multicolumn{3}{|c|}{700 rpm @60 sec. } & & \multicolumn{3}{|c|}{700 rpm @ 120 sec. } & \multirow[b]{2}{*}{$\begin{array}{c}\% \\
\text { difference }\end{array}$} \\
\hline $\begin{array}{c}\text { Trial } \\
\# 1\end{array}$ & $\begin{array}{l}\text { Mass after } \\
\text { frying (g) }\end{array}$ & $\begin{array}{c}\text { Mass after } \\
\text { Centrifuge (g) }\end{array}$ & $\begin{array}{l}\text { Delta } \\
\text { Mass }\end{array}$ & $\begin{array}{c}\% \\
\text { difference }\end{array}$ & $\begin{array}{l}\text { Mass after } \\
\text { frying }(\mathrm{g})\end{array}$ & $\begin{array}{c}\text { Mass after } \\
\text { Centrifuge (g) }\end{array}$ & $\begin{array}{l}\text { Delta } \\
\text { Mass }\end{array}$ & \\
\hline Fry \#1 & 3.86 & 3.82 & 0.04 & 1.04 & 4.33 & 4.27 & 0.06 & 1.39 \\
\hline Fry \#2 & 5.35 & 5.29 & 0.06 & 1.12 & 5.19 & 5.18 & 0.01 & 0.19 \\
\hline Fry \#3 & 3.55 & 3.52 & 0.03 & 0.85 & 3.29 & 3.27 & 0.02 & 0.61 \\
\hline \multirow[t]{2}{*}{ Fry \#4 } & 7.33 & 7.20 & 0.13 & 1.77 & 3.32 & 3.26 & 0.06 & 1.81 \\
\hline & & AVG Delta & 0.06 & 1.19 & & AVG Delta & 0.04 & 1.00 \\
\hline $\begin{array}{c}\text { Trial } \\
\# 2\end{array}$ & $\begin{array}{l}\text { Mass after } \\
\text { frying }(\mathrm{g})\end{array}$ & $\begin{array}{c}\text { Mass after } \\
\text { Centrifuge (g) }\end{array}$ & $\begin{array}{l}\text { Delta } \\
\text { Mass }\end{array}$ & $\begin{array}{c}\% \\
\text { difference }\end{array}$ & $\begin{array}{l}\text { Mass after } \\
\text { frying }(\mathrm{g})\end{array}$ & $\begin{array}{c}\text { Mass after } \\
\text { Centrifuge (g) }\end{array}$ & $\begin{array}{l}\text { Delta } \\
\text { Mass }\end{array}$ & $\begin{array}{c}\% \\
\text { difference }\end{array}$ \\
\hline Fry \#1 & 5.61 & 5.56 & 0.05 & 0.89 & 4.56 & 4.52 & 0.04 & 0.88 \\
\hline Fry \#2 & 5.00 & 5.00 & 0.00 & 0.00 & 3.43 & 3.40 & 0.03 & 0.87 \\
\hline Fry \#3 & 3.29 & 3.18 & 0.11 & 3.34 & 5.98 & 5.92 & 0.06 & 1.00 \\
\hline \multirow[t]{2}{*}{ Fry \#4 } & 4.02 & 3.98 & 0.04 & 1.00 & 4.37 & 4.30 & 0.07 & 1.60 \\
\hline & & AVG Delta & 0.05 & 1.31 & & AVG Delta & 0.05 & 1.09 \\
\hline $\begin{array}{c}\text { Trial } \\
\# 3\end{array}$ & $\begin{array}{l}\text { Mass after } \\
\text { frying }(\mathrm{g})\end{array}$ & $\begin{array}{c}\text { Mass after } \\
\text { Centrifuge (g) }\end{array}$ & $\begin{array}{l}\text { Delta } \\
\text { Mass }\end{array}$ & $\begin{array}{c}\% \\
\text { difference }\end{array}$ & $\begin{array}{l}\text { Mass after } \\
\text { frying }(\mathrm{g})\end{array}$ & $\begin{array}{c}\text { Mass after } \\
\text { Centrifuge (g) }\end{array}$ & $\begin{array}{l}\text { Delta } \\
\text { Mass }\end{array}$ & $\begin{array}{c}\% \\
\text { difference }\end{array}$ \\
\hline Fry \#1 & 3.22 & 3.19 & 0.03 & 0.93 & 4.62 & 4.57 & 0.05 & 1.08 \\
\hline Fry \#2 & 2.85 & 2.83 & 0.02 & 0.70 & 4.91 & 4.80 & 0.11 & 2.24 \\
\hline Fry \#3 & 3.02 & 3.02 & 0.00 & 0.00 & 2.83 & 2.81 & 0.02 & 0.71 \\
\hline \multirow[t]{2}{*}{ Fry \#4 } & 3.50 & 3.46 & 0.04 & 1.14 & 3.17 & 3.16 & 0.01 & 0.32 \\
\hline & & AVG Delta & 0.02 & 0.69 & & AVG Delta & 0.05 & 1.09 \\
\hline $\begin{array}{c}\text { Trial } \\
\# 4\end{array}$ & $\begin{array}{l}\text { Mass after } \\
\text { frying }(\mathrm{g})\end{array}$ & $\begin{array}{c}\text { Mass after } \\
\text { Centrifuge (g) }\end{array}$ & $\begin{array}{l}\text { Delta } \\
\text { Mass }\end{array}$ & $\begin{array}{c}\% \\
\text { difference }\end{array}$ & $\begin{array}{l}\text { Mass after } \\
\text { frying }(\mathrm{g})\end{array}$ & $\begin{array}{c}\text { Mass after } \\
\text { Centrifuge }(\mathrm{g})\end{array}$ & $\begin{array}{l}\text { Delta } \\
\text { Mass }\end{array}$ & $\begin{array}{c}\% \\
\text { difference }\end{array}$ \\
\hline Fry \#1 & 4.56 & 4.52 & 0.04 & 0.88 & 6.04 & 5.97 & 0.07 & 1.16 \\
\hline Fry \#2 & 4.76 & 4.67 & 0.09 & 1.89 & 3.80 & 3.77 & 0.03 & 0.79 \\
\hline Fry \#3 & 5.18 & 5.09 & 0.09 & 1.74 & 6.26 & 6.23 & 0.03 & 0.48 \\
\hline \multirow[t]{2}{*}{ Fry \#4 } & 3.90 & 3.85 & 0.05 & 1.28 & 4.04 & 4.00 & 0.04 & 0.99 \\
\hline & & AVG Delta & 0.07 & 1.45 & & AVG Delta & 0.04 & 0.85 \\
\hline $\begin{array}{c}\text { Trial } \\
\# 5\end{array}$ & $\begin{array}{l}\text { Mass after } \\
\text { frying }(\mathrm{g})\end{array}$ & $\begin{array}{c}\text { Mass after } \\
\text { Centrifuge (g) }\end{array}$ & $\begin{array}{l}\text { Delta } \\
\text { Mass }\end{array}$ & $\begin{array}{c}\% \\
\text { difference }\end{array}$ & $\begin{array}{l}\text { Mass after } \\
\text { frying }(\mathrm{g})\end{array}$ & $\begin{array}{c}\text { Mass after } \\
\text { Centrifuge }(\mathrm{g})\end{array}$ & $\begin{array}{l}\text { Delta } \\
\text { Mass }\end{array}$ & $\begin{array}{c}\% \\
\text { difference }\end{array}$ \\
\hline Fry \#1 & 4.17 & 3.98 & 0.19 & 4.56 & 7.32 & 7.26 & 0.06 & 0.82 \\
\hline Fry \#2 & 2.86 & 2.80 & 0.06 & 2.10 & 6.43 & 6.30 & 0.13 & 2.02 \\
\hline Fry \#3 & 2.98 & 2.96 & 0.02 & 0.67 & 3.34 & 3.24 & 0.10 & 2.99 \\
\hline \multirow[t]{2}{*}{ Fry \#4 } & 3.69 & 3.69 & 0.00 & 0.00 & 5.62 & 5.60 & 0.02 & 0.36 \\
\hline & & AVG Delta & 0.07 & 1.83 & & AVG Delta & 0.08 & 1.55 \\
\hline $\begin{array}{c}\text { Trial } \\
\# 6\end{array}$ & $\begin{array}{l}\text { Mass after } \\
\text { frying }(\mathrm{g})\end{array}$ & $\begin{array}{c}\text { Mass after } \\
\text { Centrifuge (g) }\end{array}$ & $\begin{array}{l}\text { Delta } \\
\text { Mass }\end{array}$ & $\begin{array}{c}\% \\
\text { difference }\end{array}$ & $\begin{array}{l}\text { Mass after } \\
\text { frying (g) }\end{array}$ & $\begin{array}{c}\text { Mass after } \\
\text { Centrifuge }(\mathrm{g})\end{array}$ & $\begin{array}{l}\text { Delta } \\
\text { Mass }\end{array}$ & $\begin{array}{c}\% \\
\text { difference }\end{array}$ \\
\hline Fry \#1 & 6.67 & 6.61 & 0.06 & 0.90 & 5.79 & 5.73 & 0.06 & 1.04 \\
\hline Fry \#2 & 7.09 & 7.02 & 0.07 & 0.99 & 5.65 & 5.54 & 0.11 & 1.95 \\
\hline Fry \#3 & 4.77 & 4.70 & 0.07 & 1.47 & 5.53 & 5.53 & 0.00 & 0.00 \\
\hline \multirow[t]{2}{*}{ Fry \#4 } & 3.50 & 3.44 & 0.06 & 1.71 & 6.36 & 6.26 & 0.10 & 1.57 \\
\hline & & AVG Delta & 0.06 & 1.27 & & AVG Delta & 0.07 & 1.14 \\
\hline
\end{tabular}


Table 38 - Combined Data for Experimental Run \#2

\begin{tabular}{|c|c|c|c|}
\hline Oil Extracted (g) & Percent Change in Mass & Angular Velocity (rpm) & Time (s) \\
\hline 0.03 & 0.48 & 200 & 60 \\
\hline 0.03 & 1.32 & 200 & 60 \\
\hline 0.04 & 0.90 & 200 & 60 \\
\hline 0.01 & 0.41 & 200 & 60 \\
\hline 0.04 & 0.60 & 200 & 60 \\
\hline 0.04 & 0.44 & 200 & 60 \\
\hline 0.04 & 0.27 & 200 & 120 \\
\hline 0.05 & 0.74 & 200 & 120 \\
\hline 0.05 & 0.49 & 200 & 120 \\
\hline 0.02 & 0.43 & 200 & 120 \\
\hline 0.06 & 0.34 & 200 & 120 \\
\hline 0.04 & 0.61 & 200 & 120 \\
\hline 0.03 & 0.56 & 450 & 60 \\
\hline 0.06 & 1.12 & 450 & 60 \\
\hline 0.05 & 0.25 & 450 & 60 \\
\hline 0.02 & 0.83 & 450 & 60 \\
\hline 0.07 & 0.57 & 450 & 60 \\
\hline 0.07 & 0.64 & 450 & 60 \\
\hline 0.06 & 1.09 & 450 & 120 \\
\hline 0.04 & 1.22 & 450 & 120 \\
\hline 0.05 & 0.76 & 450 & 120 \\
\hline 0.05 & 1.28 & 450 & 120 \\
\hline 0.04 & 0.61 & 450 & 120 \\
\hline 0.08 & 0.70 & 450 & 120 \\
\hline 0.07 & 1.19 & 700 & 60 \\
\hline 0.03 & 1.31 & 700 & 60 \\
\hline 0.03 & 0.69 & 700 & 60 \\
\hline 0.04 & 1.45 & 700 & 60 \\
\hline 0.01 & 1.83 & 700 & 60 \\
\hline 0.04 & 1.27 & 700 & 60 \\
\hline 0.04 & 1.00 & 700 & 120 \\
\hline 0.04 & 1.09 & 700 & 120 \\
\hline 0.05 & 1.09 & 700 & 120 \\
\hline 0.05 & 0.85 & 700 & 120 \\
\hline 0.02 & 1.55 & 700 & 120 \\
\hline 0.06 & 1.14 & 700 & 120 \\
\hline
\end{tabular}




\section{Appendix A6. Experimental Run \#3 Data}

Table 39 - Raw Data From Experimental Run \#3 at 200 rpm

\begin{tabular}{|c|c|c|c|c|c|c|c|c|}
\hline & \multicolumn{3}{|c|}{200 rpm @ 60 sec. } & & \multicolumn{3}{|c|}{200 rpm @ 120 sec. } & \\
\hline $\begin{array}{c}\text { Trial } \\
\# 1\end{array}$ & $\begin{array}{l}\text { Mass after } \\
\text { frying }(\mathrm{g})\end{array}$ & $\begin{array}{c}\text { Mass after } \\
\text { Centrifuge }(\mathrm{g})\end{array}$ & $\begin{array}{l}\text { Delta } \\
\text { Mass }\end{array}$ & $\begin{array}{c}\% \\
\text { difference }\end{array}$ & $\begin{array}{l}\text { Mass after } \\
\text { frying }(\mathrm{g})\end{array}$ & $\begin{array}{c}\text { Mass after } \\
\text { Centrifuge }(\mathrm{g})\end{array}$ & $\begin{array}{l}\text { Delta } \\
\text { Mass }\end{array}$ & $\begin{array}{c}\% \\
\text { difference }\end{array}$ \\
\hline Fry \#1 & 6.15 & 6.12 & 0.03 & 0.49 & 5.7 & 5.67 & 0.03 & 0.53 \\
\hline Fry \#2 & 5.76 & 5.75 & 0.01 & 0.17 & 5.25 & 5.15 & 0.10 & 1.90 \\
\hline Fry \#3 & 5.96 & 5.92 & 0.04 & 0.67 & 5.5 & 5.45 & 0.05 & 0.91 \\
\hline Fry \#4 & 6 & 5.9 & 0.10 & 1.67 & 5.67 & 5.58 & 0.09 & 1.59 \\
\hline & & AVG Delta & 0.04 & 0.75 & & AVG Delta & 0.07 & 1.23 \\
\hline $\begin{array}{c}\text { Trial } \\
\# 2\end{array}$ & $\begin{array}{l}\text { Mass after } \\
\text { frying }(\mathrm{g})\end{array}$ & $\begin{array}{c}\text { Mass after } \\
\text { Centrifuge }(g)\end{array}$ & $\begin{array}{l}\text { Delta } \\
\text { Mass }\end{array}$ & $\begin{array}{c}\% \\
\text { difference }\end{array}$ & $\begin{array}{l}\text { Mass after } \\
\text { frying }(\mathrm{g})\end{array}$ & $\begin{array}{c}\text { Mass after } \\
\text { Centrifuge (g) }\end{array}$ & $\begin{array}{l}\text { Delta } \\
\text { Mass }\end{array}$ & $\begin{array}{c}\% \\
\text { difference }\end{array}$ \\
\hline Fry \#1 & 5.83 & 5.76 & 0.07 & 1.20 & 5.63 & 5.58 & 0.05 & 0.89 \\
\hline Fry \#2 & 6 & 5.96 & 0.04 & 0.67 & 5.17 & 5.11 & 0.06 & 1.16 \\
\hline Fry \#3 & 6.27 & 6.2 & 0.07 & 1.12 & 4.99 & 4.89 & 0.10 & 2.00 \\
\hline Fry \#4 & 5.85 & 5.7 & 0.15 & 2.56 & 5.17 & 5.09 & 0.08 & 1.55 \\
\hline & & AVG Delta & 0.08 & 1.39 & & & 0.07 & 1.40 \\
\hline $\begin{array}{c}\text { Trial } \\
\# 3\end{array}$ & $\begin{array}{l}\text { Mass after } \\
\text { frying (g) }\end{array}$ & $\begin{array}{c}\text { Mass after } \\
\text { Centrifuge }(\mathrm{g})\end{array}$ & $\begin{array}{l}\text { Delta } \\
\text { Mass }\end{array}$ & $\begin{array}{c}\% \\
\text { difference }\end{array}$ & $\begin{array}{l}\text { Mass after } \\
\text { frying }(\mathrm{g})\end{array}$ & $\begin{array}{c}\text { Mass after } \\
\text { Centrifuge }(\mathrm{g})\end{array}$ & $\begin{array}{l}\text { Delta } \\
\text { Mass }\end{array}$ & $\begin{array}{c}\% \\
\text { difference }\end{array}$ \\
\hline Fry \#1 & 5 & 4.95 & 0.05 & 1.00 & 4.78 & 4.73 & 0.05 & 1.05 \\
\hline Fry \#2 & 4.97 & 4.95 & 0.02 & 0.40 & 5.07 & 5.03 & 0.04 & 0.79 \\
\hline Fry \#3 & 4.46 & 4.41 & 0.05 & 1.12 & 4.49 & 4.41 & 0.08 & 1.78 \\
\hline Fry \#4 & 4.66 & 4.62 & 0.04 & 0.86 & 4.74 & 4.69 & 0.05 & 1.05 \\
\hline & & AVG Delta & 0.04 & 0.85 & & AVG Delta & 0.05 & 1.17 \\
\hline $\begin{array}{c}\text { Trial } \\
\# 4\end{array}$ & $\begin{array}{l}\text { Mass after } \\
\text { frying }(\mathrm{g})\end{array}$ & $\begin{array}{c}\text { Mass after } \\
\text { Centrifuge }(\mathrm{g}) \\
\end{array}$ & $\begin{array}{l}\text { Delta } \\
\text { Mass }\end{array}$ & $\begin{array}{c}\% \\
\text { difference }\end{array}$ & $\begin{array}{l}\text { Mass after } \\
\text { frying }(\mathrm{g})\end{array}$ & $\begin{array}{c}\text { Mass after } \\
\text { Centrifuge }(\mathrm{g}) \\
\end{array}$ & $\begin{array}{l}\text { Delta } \\
\text { Mass }\end{array}$ & $\begin{array}{c}\% \\
\text { difference }\end{array}$ \\
\hline Fry \#1 & 5.07 & 5.01 & 0.06 & 1.18 & 4.83 & 4.76 & 0.07 & 1.45 \\
\hline Fry \#2 & 4.81 & 4.76 & 0.05 & 1.04 & 5.31 & 5.22 & 0.09 & 1.69 \\
\hline Fry \#3 & 5.18 & 5.12 & 0.06 & 1.16 & 5.16 & 5.1 & 0.06 & 1.16 \\
\hline Fry \#4 & 4.96 & 4.91 & 0.05 & 1.01 & 4.91 & 4.85 & 0.06 & 1.22 \\
\hline & & AVG Delta & 0.05 & 1.10 & & AVG Delta & 0.07 & 1.38 \\
\hline $\begin{array}{c}\text { Trial } \\
\# 5\end{array}$ & $\begin{array}{l}\text { Mass after } \\
\text { frying (g) }\end{array}$ & $\begin{array}{c}\text { Mass after } \\
\text { Centrifuge }(\mathrm{g})\end{array}$ & $\begin{array}{l}\text { Delta } \\
\text { Mass }\end{array}$ & $\begin{array}{c}\% \\
\text { difference }\end{array}$ & $\begin{array}{l}\text { Mass after } \\
\text { frying }(\mathrm{g})\end{array}$ & $\begin{array}{c}\text { Mass after } \\
\text { Centrifuge }(\mathrm{g})\end{array}$ & $\begin{array}{l}\text { Delta } \\
\text { Mass }\end{array}$ & $\begin{array}{c}\% \\
\text { difference }\end{array}$ \\
\hline Fry \#1 & 5.11 & 5.08 & 0.03 & 0.59 & 4.64 & 4.63 & 0.01 & 0.22 \\
\hline Fry \#2 & 4.67 & 4.66 & 0.01 & 0.21 & 4.61 & 4.59 & 0.02 & 0.43 \\
\hline Fry \#3 & 4.22 & 4.16 & 0.06 & 1.42 & 4.81 & 4.73 & 0.08 & 1.66 \\
\hline Fry \#4 & 4.67 & 4.6 & 0.07 & 1.50 & 4.35 & 4.28 & 0.07 & 1.61 \\
\hline & & AVG Delta & 0.04 & 0.93 & & AVG Delta & 0.04 & 0.98 \\
\hline $\begin{array}{c}\text { Trial } \\
\# 6\end{array}$ & $\begin{array}{l}\text { Mass after } \\
\text { frying (g) }\end{array}$ & $\begin{array}{c}\text { Mass after } \\
\text { Centrifuge }(\mathrm{g})\end{array}$ & $\begin{array}{l}\text { Delta } \\
\text { Mass }\end{array}$ & $\begin{array}{c}\% \\
\text { difference }\end{array}$ & $\begin{array}{l}\text { Mass after } \\
\text { frying }(\mathrm{g})\end{array}$ & $\begin{array}{c}\text { Mass after } \\
\text { Centrifuge }(\mathrm{g})\end{array}$ & $\begin{array}{l}\text { Delta } \\
\text { Mass }\end{array}$ & $\begin{array}{c}\% \\
\text { difference }\end{array}$ \\
\hline Fry \#1 & 5.12 & 5.08 & 0.04 & 0.78 & 5.34 & 5.28 & 0.06 & 1.12 \\
\hline Fry \#2 & 5.44 & 5.4 & 0.04 & 0.74 & 5.23 & 5.18 & 0.05 & 0.96 \\
\hline Fry \#3 & 5.68 & 5.64 & 0.04 & 0.70 & 5.35 & 5.3 & 0.05 & 0.93 \\
\hline Fry \#4 & 5.15 & 5.07 & 0.08 & 1.55 & 5.15 & 5.15 & 0.00 & 0.00 \\
\hline & & AVG Delta & 0.05 & 0.94 & & AVG Delta & 0.04 & 0.75 \\
\hline
\end{tabular}


Table 40 - Raw Data From Experimental Run \#3 at 450 rpm

\begin{tabular}{|c|c|c|c|c|c|c|c|c|}
\hline & \multicolumn{3}{|c|}{450 rpm @ 60 sec. } & & \multicolumn{3}{|c|}{450 rpm @120 sec. } & \multirow[b]{2}{*}{$\begin{array}{c}\% \\
\text { difference }\end{array}$} \\
\hline $\begin{array}{c}\text { Trial } \\
\# 1\end{array}$ & $\begin{array}{l}\text { Mass after } \\
\text { frying }(\mathrm{g})\end{array}$ & $\begin{array}{c}\text { Mass after } \\
\text { Centrifuge }(\mathrm{g})\end{array}$ & $\begin{array}{l}\text { Delta } \\
\text { Mass }\end{array}$ & $\begin{array}{c}\% \\
\text { difference }\end{array}$ & $\begin{array}{l}\text { Mass after } \\
\text { frying }(\mathrm{g})\end{array}$ & $\begin{array}{c}\text { Mass after } \\
\text { Centrifuge }(\mathrm{g})\end{array}$ & $\begin{array}{l}\text { Delta } \\
\text { Mass }\end{array}$ & \\
\hline Fry \#1 & 5.47 & 5.41 & 0.06 & 1.10 & 5.86 & 5.72 & 0.14 & 2.39 \\
\hline Fry \#2 & 5.37 & 5.26 & 0.11 & 2.05 & 5.71 & 5.64 & 0.07 & 1.23 \\
\hline Fry \#3 & 5.32 & 5.25 & 0.07 & 1.32 & 5.67 & 5.54 & 0.13 & 2.29 \\
\hline \multirow[t]{2}{*}{ Fry \#4 } & 5.49 & 5.35 & 0.14 & 2.55 & 5.85 & 5.76 & 0.09 & 1.54 \\
\hline & & AVG Delta & 0.10 & 1.75 & & AVG Delta & 0.11 & 1.86 \\
\hline $\begin{array}{c}\text { Trial } \\
\# 2\end{array}$ & $\begin{array}{l}\text { Mass after } \\
\text { frying }(\mathrm{g})\end{array}$ & $\begin{array}{c}\text { Mass after } \\
\text { Centrifuge (g) }\end{array}$ & $\begin{array}{l}\text { Delta } \\
\text { Mass }\end{array}$ & $\begin{array}{c}\% \\
\text { difference }\end{array}$ & $\begin{array}{l}\text { Mass after } \\
\text { frying }(\mathrm{g})\end{array}$ & $\begin{array}{c}\text { Mass after } \\
\text { Centrifuge (g) }\end{array}$ & $\begin{array}{l}\text { Delta } \\
\text { Mass }\end{array}$ & $\begin{array}{c}\% \\
\text { difference }\end{array}$ \\
\hline Fry \#1 & 4.67 & 4.62 & 0.05 & 1.07 & 5.77 & 5.65 & 0.12 & 2.08 \\
\hline Fry \#2 & 5.37 & 5.32 & 0.05 & 0.93 & 5.57 & 5.48 & 0.09 & 1.62 \\
\hline Fry \#3 & 4.86 & 4.78 & 0.08 & 1.65 & 5.21 & 5.14 & 0.07 & 1.34 \\
\hline \multirow[t]{2}{*}{ Fry \#4 } & 4.95 & 4.86 & 0.09 & 1.82 & 5.07 & 5 & 0.07 & 1.38 \\
\hline & & AVG Delta & 0.07 & 1.37 & & AVG Delta & 0.09 & 1.60 \\
\hline $\begin{array}{c}\text { Trial } \\
\# 3\end{array}$ & $\begin{array}{l}\text { Mass after } \\
\text { frying }(\mathrm{g})\end{array}$ & $\begin{array}{c}\text { Mass after } \\
\text { Centrifuge (g) }\end{array}$ & $\begin{array}{l}\text { Delta } \\
\text { Mass }\end{array}$ & $\begin{array}{c}\% \\
\text { difference }\end{array}$ & $\begin{array}{l}\text { Mass after } \\
\text { frying }(\mathrm{g})\end{array}$ & $\begin{array}{c}\text { Mass after } \\
\text { Centrifuge (g) }\end{array}$ & $\begin{array}{l}\text { Delta } \\
\text { Mass }\end{array}$ & $\begin{array}{c}\% \\
\text { difference }\end{array}$ \\
\hline Fry \#1 & 4.76 & 4.72 & 0.04 & 0.84 & 5.07 & 5.02 & 0.05 & 0.99 \\
\hline Fry \#2 & 5.05 & 5 & 0.05 & 0.99 & 5.38 & 5.28 & 0.10 & 1.86 \\
\hline Fry \#3 & 4.96 & 4.9 & 0.06 & 1.21 & 5.62 & 5.6 & 0.02 & 0.36 \\
\hline \multirow[t]{2}{*}{ Fry \#4 } & 5.01 & 4.96 & 0.05 & 1.00 & 5.39 & 5.28 & 0.11 & 2.04 \\
\hline & & AVG Delta & 0.05 & 1.01 & & AVG Delta & 0.07 & 1.31 \\
\hline $\begin{array}{c}\text { Trial } \\
\# 4\end{array}$ & $\begin{array}{l}\text { Mass after } \\
\text { frying }(\mathrm{g})\end{array}$ & $\begin{array}{c}\text { Mass after } \\
\text { Centrifuge (g) }\end{array}$ & $\begin{array}{l}\text { Delta } \\
\text { Mass }\end{array}$ & $\begin{array}{c}\% \\
\text { difference } \\
\end{array}$ & $\begin{array}{l}\text { Mass after } \\
\text { frying }(\mathrm{g})\end{array}$ & $\begin{array}{c}\text { Mass after } \\
\text { Centrifuge (g) } \\
\end{array}$ & $\begin{array}{l}\text { Delta } \\
\text { Mass }\end{array}$ & $\begin{array}{c}\% \\
\text { difference }\end{array}$ \\
\hline Fry \#1 & 4.59 & 4.5 & 0.09 & 1.96 & 4.95 & 4.9 & 0.05 & 1.01 \\
\hline Fry \#2 & 4.79 & 4.7 & 0.09 & 1.88 & 4.67 & 4.6 & 0.07 & 1.50 \\
\hline Fry \#3 & 5.13 & 5.04 & 0.09 & 1.75 & 5.31 & 5.16 & 0.15 & 2.82 \\
\hline \multirow[t]{2}{*}{ Fry \#4 } & 5.17 & 5.13 & 0.04 & 0.77 & 4.94 & 4.86 & 0.08 & 1.62 \\
\hline & & AVG Delta & 0.08 & 1.59 & & AVG Delta & 0.09 & 1.74 \\
\hline $\begin{array}{c}\text { Trial } \\
\# 5\end{array}$ & $\begin{array}{l}\text { Mass after } \\
\text { frying }(\mathrm{g})\end{array}$ & $\begin{array}{c}\text { Mass after } \\
\text { Centrifuge (g) }\end{array}$ & $\begin{array}{l}\text { Delta } \\
\text { Mass }\end{array}$ & $\begin{array}{c}\% \\
\text { difference }\end{array}$ & $\begin{array}{l}\text { Mass after } \\
\text { frying }(\mathrm{g})\end{array}$ & $\begin{array}{c}\text { Mass after } \\
\text { Centrifuge (g) }\end{array}$ & $\begin{array}{l}\text { Delta } \\
\text { Mass }\end{array}$ & $\begin{array}{c}\% \\
\text { difference }\end{array}$ \\
\hline Fry \#1 & 4.76 & 4.7 & 0.06 & 1.26 & 4.87 & 4.8 & 0.07 & 1.44 \\
\hline Fry \#2 & 3.99 & 3.91 & 0.08 & 2.01 & 4.45 & 4.39 & 0.06 & 1.35 \\
\hline Fry \#3 & 4.73 & 4.6 & 0.13 & 2.75 & 4.43 & 4.38 & 0.05 & 1.13 \\
\hline \multirow[t]{2}{*}{ Fry \#4 } & 4.45 & 4.4 & 0.05 & 1.12 & 4.63 & 4.6 & 0.03 & 0.65 \\
\hline & & AVG Delta & 0.08 & 1.78 & & AVG Delta & 0.05 & 1.14 \\
\hline $\begin{array}{c}\text { Trial } \\
\# 6\end{array}$ & $\begin{array}{l}\text { Mass after } \\
\text { frying }(\mathrm{g})\end{array}$ & $\begin{array}{c}\text { Mass after } \\
\text { Centrifuge (g) } \\
\end{array}$ & $\begin{array}{l}\text { Delta } \\
\text { Mass }\end{array}$ & $\begin{array}{c}\% \\
\text { difference } \\
\end{array}$ & $\begin{array}{l}\text { Mass after } \\
\text { frying }(\mathrm{g})\end{array}$ & $\begin{array}{c}\text { Mass after } \\
\text { Centrifuge (g) }\end{array}$ & $\begin{array}{l}\text { Delta } \\
\text { Mass }\end{array}$ & $\begin{array}{c}\% \\
\text { difference } \\
\end{array}$ \\
\hline Fry \#1 & 5.16 & 5.13 & 0.03 & 0.58 & 5.4 & 5.29 & 0.11 & 2.04 \\
\hline Fry \#2 & 5.64 & 5.51 & 0.13 & 2.30 & 5.77 & 5.63 & 0.14 & 2.43 \\
\hline Fry \#3 & 5.02 & 4.98 & 0.04 & 0.80 & 5.36 & 5.26 & 0.10 & 1.87 \\
\hline \multirow[t]{2}{*}{ Fry \#4 } & 4.68 & 4.6 & 0.08 & 1.71 & 4.85 & 4.76 & 0.09 & 1.86 \\
\hline & & AVG Delta & 0.07 & 1.35 & & AVG Delta & 0.11 & 2.05 \\
\hline
\end{tabular}


Table 41 - Raw Data From Experimental Run \#3 at 700 rpm

\begin{tabular}{|c|c|c|c|c|c|c|c|c|}
\hline & \multicolumn{4}{|c|}{700 rpm @ 60 sec. } & \multicolumn{4}{|c|}{700 rpm @ 120 sec. } \\
\hline $\begin{array}{c}\text { Trial } \\
\# 1\end{array}$ & $\begin{array}{l}\text { Mass after } \\
\text { frying }(\mathrm{g})\end{array}$ & $\begin{array}{c}\text { Mass after } \\
\text { Centrifuge (g) }\end{array}$ & $\begin{array}{l}\text { Delta } \\
\text { Mass }\end{array}$ & $\begin{array}{c}\% \\
\text { difference }\end{array}$ & $\begin{array}{l}\text { Mass after } \\
\text { frying }(\mathrm{g})\end{array}$ & $\begin{array}{c}\text { Mass after } \\
\text { Centrifuge (g) }\end{array}$ & $\begin{array}{l}\text { Delta } \\
\text { Mass }\end{array}$ & $\begin{array}{c}\% \\
\text { difference }\end{array}$ \\
\hline Fry \#1 & 5.65 & 5.47 & 0.18 & 3.19 & 6.12 & 6.03 & 0.09 & 1.47 \\
\hline Fry \#2 & 5.32 & 5.19 & 0.13 & 2.44 & 5.81 & 5.6 & 0.21 & 3.61 \\
\hline Fry \#3 & 5.75 & 5.54 & 0.21 & 3.65 & 5.34 & 5.17 & 0.17 & 3.18 \\
\hline \multirow[t]{2}{*}{ Fry \#4 } & 5.78 & 5.58 & 0.20 & 3.46 & 5.53 & 5.34 & 0.19 & 3.44 \\
\hline & & AVG Delta & 0.18 & 3.19 & & AVG Delta & 0.17 & 2.93 \\
\hline $\begin{array}{c}\text { Trial } \\
\# 2\end{array}$ & $\begin{array}{l}\text { Mass after } \\
\text { frying }(\mathrm{g})\end{array}$ & $\begin{array}{c}\text { Mass after } \\
\text { Centrifuge (g) }\end{array}$ & $\begin{array}{l}\text { Delta } \\
\text { Mass }\end{array}$ & $\begin{array}{c}\% \\
\text { difference }\end{array}$ & $\begin{array}{l}\text { Mass after } \\
\text { frying }(\mathrm{g})\end{array}$ & $\begin{array}{c}\text { Mass after } \\
\text { Centrifuge }(\mathrm{g})\end{array}$ & $\begin{array}{l}\text { Delta } \\
\text { Mass }\end{array}$ & $\begin{array}{c}\% \\
\text { difference }\end{array}$ \\
\hline Fry \#1 & 5.53 & 5.43 & 0.10 & 1.81 & 4.67 & 4.58 & 0.09 & 1.93 \\
\hline Fry \#2 & 5.56 & 5.43 & 0.13 & 2.34 & 4.3 & 4.22 & 0.08 & 1.86 \\
\hline Fry \#3 & 5.67 & 5.55 & 0.12 & 2.12 & 5.13 & 5 & 0.13 & 2.53 \\
\hline \multirow[t]{2}{*}{ Fry \#4 } & 5.6 & 5.48 & 0.12 & 2.14 & 4.82 & 4.72 & 0.10 & 2.07 \\
\hline & & AVG Delta & 0.12 & 2.10 & & AVG Delta & 0.10 & 2.10 \\
\hline $\begin{array}{c}\text { Trial } \\
\# 3\end{array}$ & $\begin{array}{l}\text { Mass after } \\
\text { frying }(\mathrm{g})\end{array}$ & $\begin{array}{c}\text { Mass after } \\
\text { Centrifuge (g) }\end{array}$ & $\begin{array}{l}\text { Delta } \\
\text { Mass }\end{array}$ & $\begin{array}{c}\% \\
\text { difference }\end{array}$ & $\begin{array}{l}\text { Mass after } \\
\text { frying }(\mathrm{g})\end{array}$ & $\begin{array}{c}\text { Mass after } \\
\text { Centrifuge (g) }\end{array}$ & $\begin{array}{l}\text { Delta } \\
\text { Mass }\end{array}$ & $\begin{array}{c}\% \\
\text { difference }\end{array}$ \\
\hline Fry \#1 & 4.06 & 3.99 & 0.07 & 1.72 & 5.01 & 4.91 & 0.10 & 2.00 \\
\hline Fry \#2 & 4.77 & 4.69 & 0.08 & 1.68 & 5.11 & 4.98 & 0.13 & 2.54 \\
\hline Fry \#3 & 4.55 & 4.45 & 0.10 & 2.20 & 4.82 & 4.69 & 0.13 & 2.70 \\
\hline \multirow[t]{2}{*}{ Fry \#4 } & 4.35 & 4.24 & 0.11 & 2.53 & 4.99 & 4.9 & 0.09 & 1.80 \\
\hline & & AVG Delta & 0.09 & 2.03 & & AVG Delta & 0.11 & 2.26 \\
\hline $\begin{array}{c}\text { Trial } \\
\# 4\end{array}$ & $\begin{array}{l}\text { Mass after } \\
\text { frying }(\mathrm{g})\end{array}$ & $\begin{array}{c}\text { Mass after } \\
\text { Centrifuge (g) }\end{array}$ & $\begin{array}{l}\text { Delta } \\
\text { Mass }\end{array}$ & $\begin{array}{c}\% \\
\text { difference }\end{array}$ & $\begin{array}{l}\text { Mass after } \\
\text { frying }(g)\end{array}$ & $\begin{array}{c}\text { Mass after } \\
\text { Centrifuge (g) }\end{array}$ & $\begin{array}{l}\text { Delta } \\
\text { Mass }\end{array}$ & $\begin{array}{c}\% \\
\text { difference }\end{array}$ \\
\hline Fry \#1 & 5.43 & 5.35 & 0.08 & 1.47 & 5.36 & 5.26 & 0.10 & 1.87 \\
\hline Fry \#2 & 5.03 & 4.93 & 0.10 & 1.99 & 5.01 & 4.85 & 0.16 & 3.19 \\
\hline Fry \#3 & 4.95 & 4.86 & 0.09 & 1.82 & 4.92 & 4.82 & 0.10 & 2.03 \\
\hline \multirow[t]{2}{*}{ Fry \#4 } & 4.67 & 4.57 & 0.10 & 2.14 & 5.23 & 5.12 & 0.11 & 2.10 \\
\hline & & AVG Delta & 0.09 & 1.86 & & AVG Delta & 0.12 & 2.30 \\
\hline $\begin{array}{c}\text { Trial } \\
\# 5\end{array}$ & $\begin{array}{l}\text { Mass after } \\
\text { frying }(\mathrm{g})\end{array}$ & $\begin{array}{c}\text { Mass after } \\
\text { Centrifuge (g) }\end{array}$ & $\begin{array}{l}\text { Delta } \\
\text { Mass }\end{array}$ & $\begin{array}{c}\% \\
\text { difference }\end{array}$ & $\begin{array}{l}\text { Mass after } \\
\text { frying }(\mathrm{g})\end{array}$ & $\begin{array}{c}\text { Mass after } \\
\text { Centrifuge (g) }\end{array}$ & $\begin{array}{l}\text { Delta } \\
\text { Mass }\end{array}$ & $\begin{array}{c}\% \\
\text { difference }\end{array}$ \\
\hline Fry \#1 & 4.51 & 4.46 & 0.05 & 1.11 & 4.88 & 4.78 & 0.10 & 2.05 \\
\hline Fry \#2 & 4.28 & 4.18 & 0.10 & 2.34 & 4.17 & 4.02 & 0.15 & 3.60 \\
\hline Fry \#3 & 4.35 & 4.29 & 0.06 & 1.38 & 4.33 & 4.15 & 0.18 & 4.16 \\
\hline \multirow[t]{2}{*}{ Fry \#4 } & 4.41 & 4.35 & 0.06 & 1.36 & 4.67 & 4.55 & 0.12 & 2.57 \\
\hline & & AVG Delta & 0.07 & 1.55 & & AVG Delta & 0.14 & 3.09 \\
\hline $\begin{array}{c}\text { Trial } \\
\# 6\end{array}$ & $\begin{array}{l}\text { Mass after } \\
\text { frying }(\mathrm{g})\end{array}$ & $\begin{array}{c}\text { Mass after } \\
\text { Centrifuge (g) }\end{array}$ & $\begin{array}{l}\text { Delta } \\
\text { Mass }\end{array}$ & $\begin{array}{c}\% \\
\text { difference }\end{array}$ & $\begin{array}{l}\text { Mass after } \\
\text { frying }(\mathrm{g})\end{array}$ & $\begin{array}{l}\text { Mass after } \\
\text { Centrifuge (g) }\end{array}$ & $\begin{array}{l}\text { Delta } \\
\text { Mass }\end{array}$ & $\begin{array}{c}\% \\
\text { difference }\end{array}$ \\
\hline Fry \#1 & 5.03 & 4.94 & 0.09 & 1.79 & 5.54 & 5.38 & 0.16 & 2.89 \\
\hline Fry \#2 & 4.92 & 4.8 & 0.12 & 2.44 & 5.32 & 5.14 & 0.18 & 3.38 \\
\hline Fry \#3 & 5.08 & 5 & 0.08 & 1.57 & 4.65 & 4.56 & 0.09 & 1.94 \\
\hline \multirow[t]{2}{*}{ Fry \#4 } & 4.88 & 4.8 & 0.08 & 1.64 & 4.61 & 4.48 & 0.13 & 2.82 \\
\hline & & AVG Delta & 0.09 & 1.86 & & AVG Delta & 0.14 & 2.76 \\
\hline
\end{tabular}


Table 42 - Combined Data for Experimental Run \#3

\begin{tabular}{|c|c|c|c|}
\hline Oil Extracted (g) & Percent Change in Mass & Angular Velocity (rpm) & Time (s) \\
\hline 0.04 & 0.75 & 200 & 60 \\
\hline 0.08 & 1.39 & 200 & 60 \\
\hline 0.04 & 0.85 & 200 & 60 \\
\hline 0.05 & 1.1 & 200 & 60 \\
\hline 0.04 & 0.93 & 200 & 60 \\
\hline 0.05 & 0.94 & 200 & 60 \\
\hline 0.07 & 1.23 & 200 & 120 \\
\hline 0.07 & 1.4 & 200 & 120 \\
\hline 0.05 & 1.17 & 200 & 120 \\
\hline 0.07 & 1.38 & 200 & 120 \\
\hline 0.04 & 0.98 & 200 & 120 \\
\hline 0.04 & 0.75 & 200 & 120 \\
\hline 0.1 & 1.75 & 450 & 60 \\
\hline 0.07 & 1.37 & 450 & 60 \\
\hline 0.05 & 1.01 & 450 & 60 \\
\hline 0.08 & 1.59 & 450 & 60 \\
\hline 0.08 & 1.78 & 450 & 60 \\
\hline 0.07 & 1.35 & 450 & 60 \\
\hline 0.11 & 1.86 & 450 & 120 \\
\hline 0.09 & 1.6 & 450 & 120 \\
\hline 0.07 & 1.31 & 450 & 120 \\
\hline 0.09 & 1.74 & 450 & 120 \\
\hline 0.05 & 1.14 & 450 & 120 \\
\hline 0.11 & 2.05 & 450 & 120 \\
\hline 0.18 & 3.19 & 700 & 60 \\
\hline 0.12 & 2.1 & 700 & 60 \\
\hline 0.09 & 2.03 & 700 & 60 \\
\hline 0.09 & 1.83 & 700 & 60 \\
\hline 0.07 & 1.55 & 700 & 60 \\
\hline 0.09 & 1.86 & 700 & 60 \\
\hline 0.17 & 2.93 & 700 & 120 \\
\hline 0.1 & 2.1 & 700 & 120 \\
\hline 0.11 & 2.26 & 700 & 120 \\
\hline 0.12 & 2.3 & 700 & 120 \\
\hline 0.14 & 3.09 & 700 & 120 \\
\hline 0.14 & 2.76 & 700 & 120 \\
\hline
\end{tabular}




\section{Appendix B. Statistics Definitions and Explanations}

Analysis of Variance: $\quad$ Also known as ANOVA, which is used to identify if the arithmetic mean of various populations are likely to be the same [19]. This requires the variance to be calculated which will then be square rooted in order to obtain the standard deviation [19]. Below is the equation for the standard deviation which includes the calculation for variance within.

$$
S=\sqrt{\frac{\sum(x-\bar{x})^{2}}{n-1}}
$$

Where $\mathrm{s}=$ sample standard deviation

$$
\begin{aligned}
& \mathrm{x}=\text { values of the observations } \\
& \bar{x}=\text { mean of the sample } \\
& \mathrm{N}=\text { number of observations in the sample }
\end{aligned}
$$

P-Value: $\quad$ This is a value obtained from the analysis of variance with a few additional steps. It is the "probability of obtaining a difference between the test statistic and the hypothetical population parameter" [19]. The smaller the p-value, the more likely the hypothesis is rejected. As a general rule, a p-value of less than 0.05 or 0.01 can be rejected depending on the application. In addition, the p-value also provides useful information regarding the statistical significance of the data. It follows the same rule as stated above, at small p-values the data is more statistically significant.

Tukey Comparisons: These comparisons are used in ANOVA to generate confidence intervals for the samples with an error rate set by the user on Minitab. There 
are various comparison options to choose from. For Tukey comparisons, there are grouping and difference of mean analysis available on Minitab. 


\section{Appendix C. Minitab - Statistical Analysis}

\section{Appendix C1. Minitab Instructions}

Individual Value Plot: $\quad$ In order to obtain an individual value plot, enter data into the appropriate columns with labels for each column. Next, under Graph select Individual Value Plot.

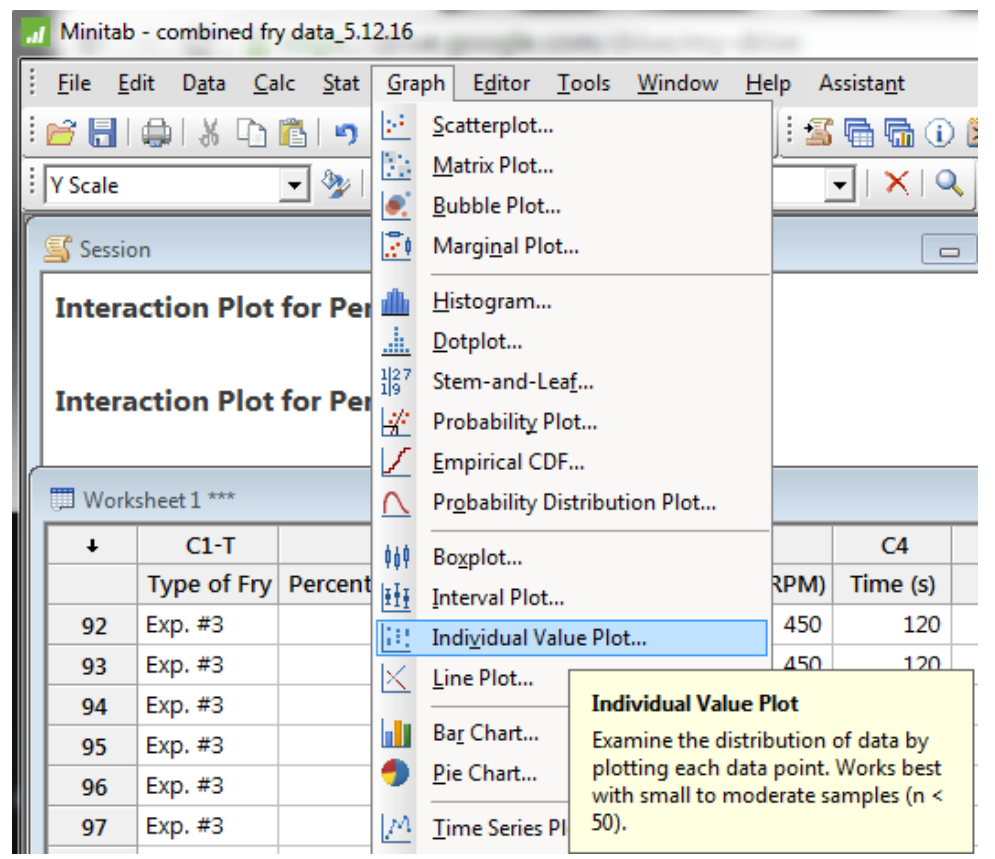

Figure 32 - Individual Value Plot instructions

After selecting the individual value plot, a window pops up, then select Simple or With

Groups depending on the way the data needs to be presented. Select the appropriate option and click $O k$. An individual value plot will pop up. 


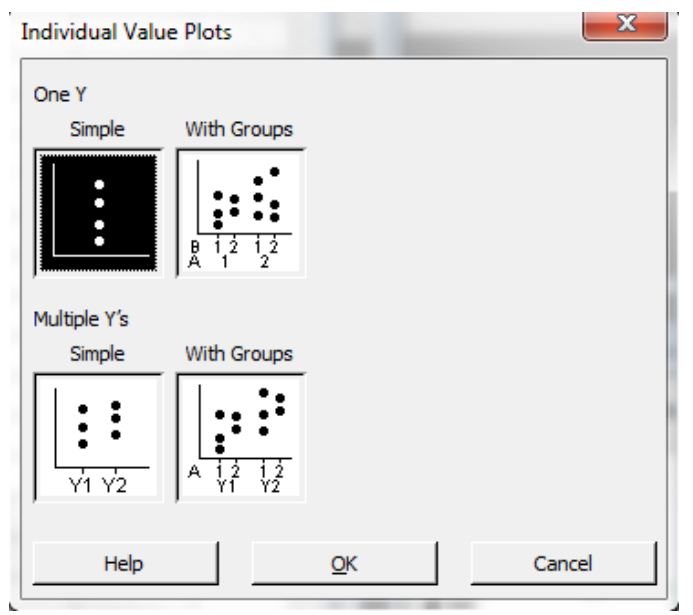

Figure 33 - Individual Value Plot Window

Analysis of Variance (ANOVA): In order to run a ANOVA, insert data in the columns and label the data. Under Stat, select_ANOVA > General Linear Model > Fit General Linear Model.

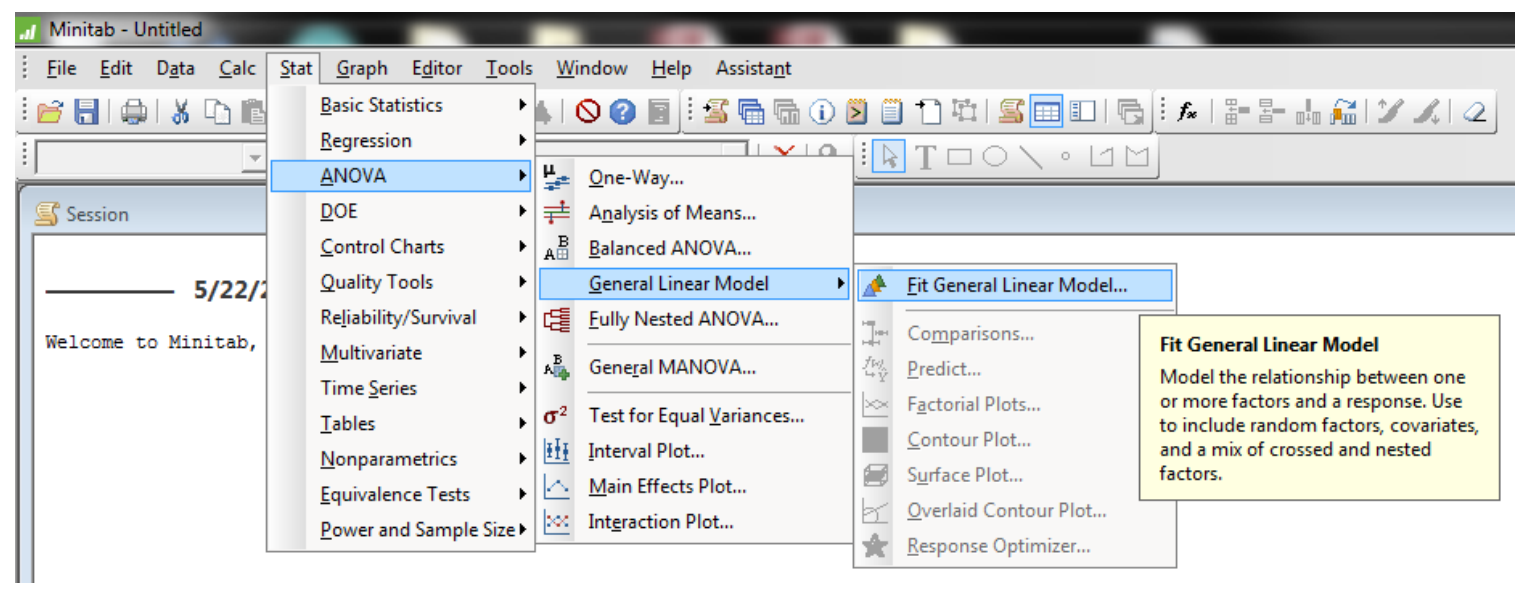

Figure 34 -ANOVA General Linear Model Instructions

A window pops up, fill in the appropriate responses and factors. Then select $O K$ and Minitab will produce the ANOVA model in the session window. 


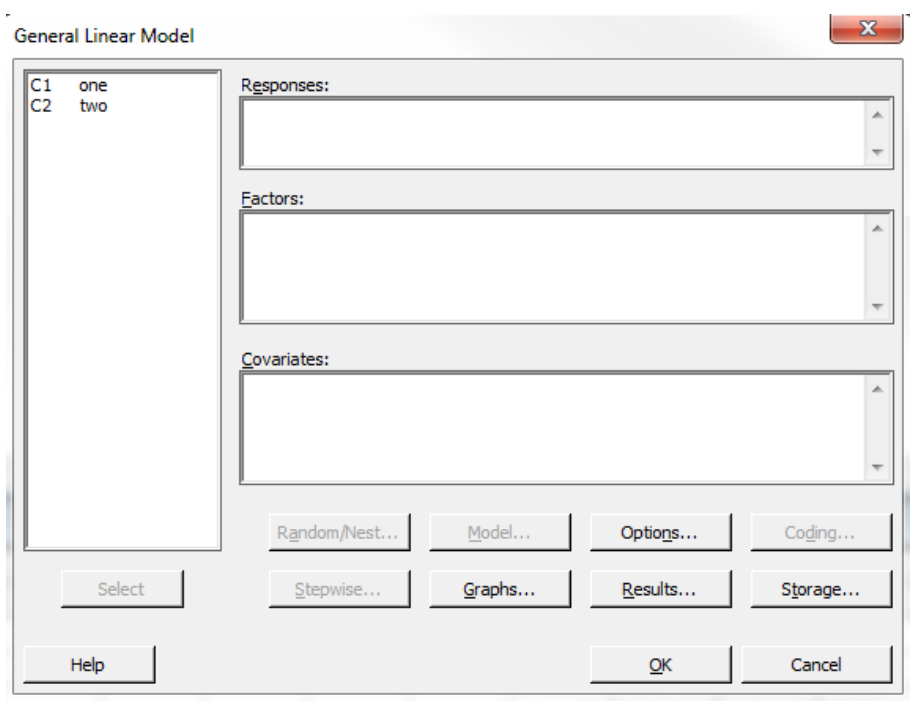

Figure 35 - ANOVA General Linear Model Preview

Tukey Comparisons:

After running the ANOVA, Tukey comparisons can now be modeled. Select Stat, then ANOVA > General Linear Model > Comparisons. Clicking this will cause a window to pop up.

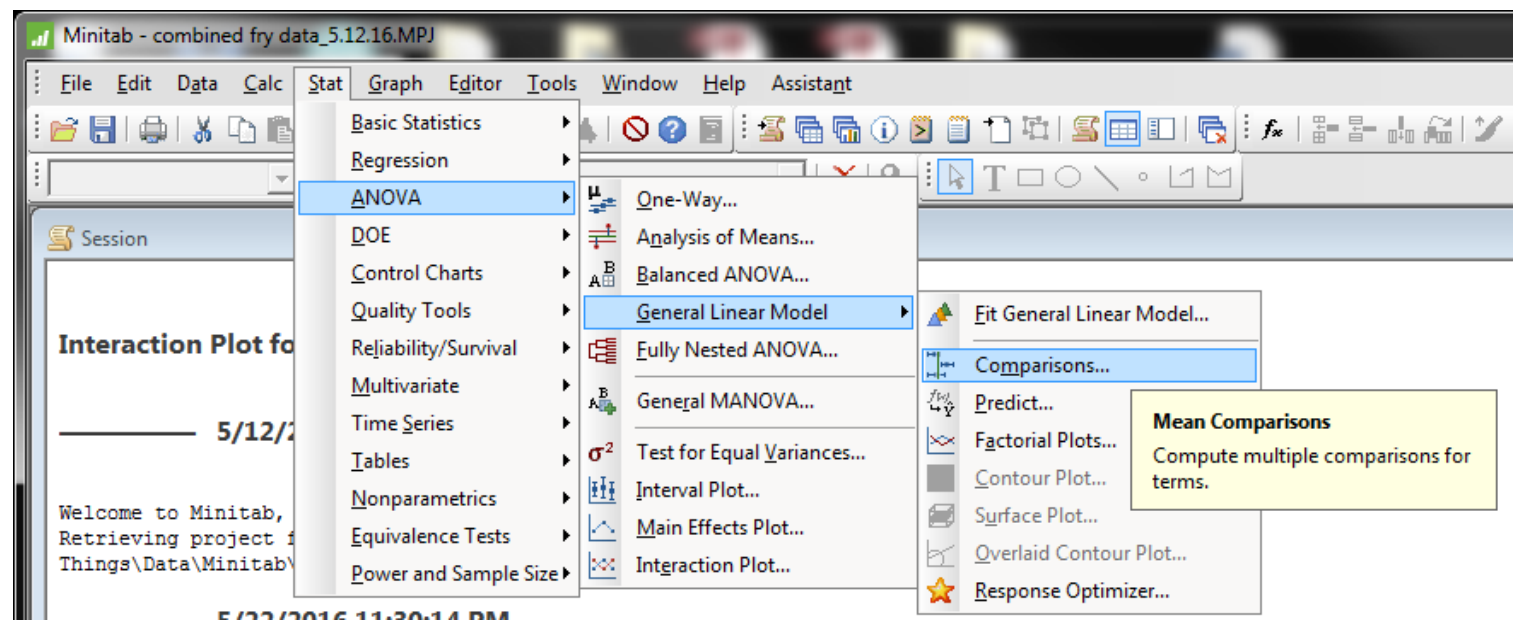

Figure 36 - Tukey Comparisons Instructions

For the comparison's window, select Tukey for the type of method and select all the factors that need to be compared. When they are selected, a $\mathrm{C}$ will pop up on the left side 
of the term. When done selecting, click OK and data will be presented in the session window. Plots will also be generated for each comparison.

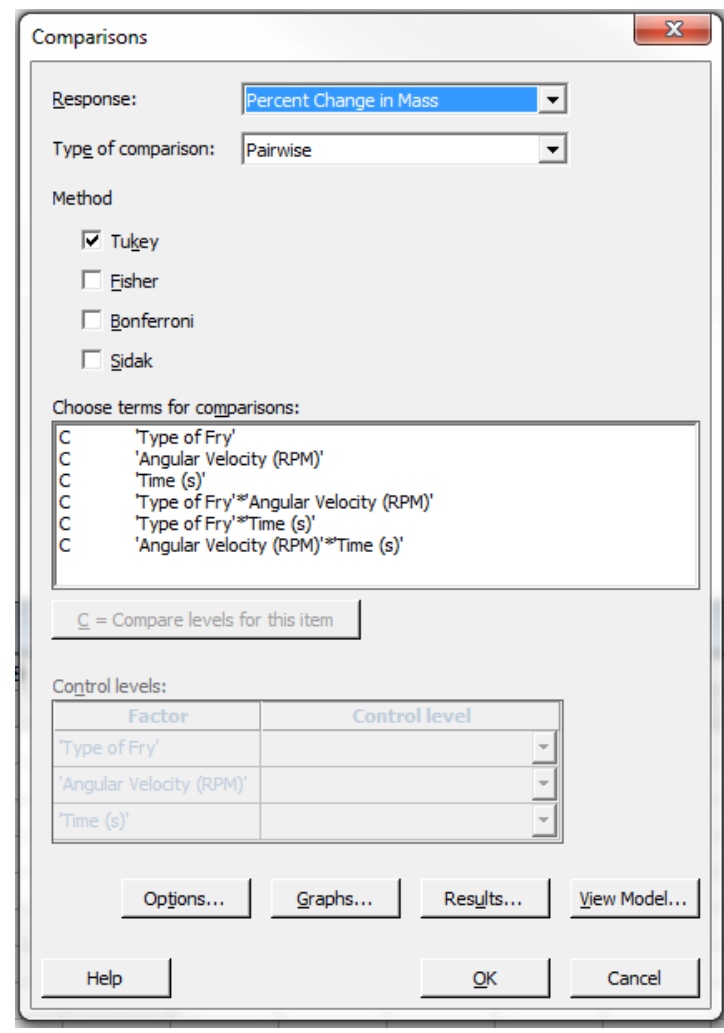

Figure 37 - Comparison's Window

Interaction Plot: $\quad$ After running the ANOVA, an interaction plot can be obtained for the data set. Under Stat, select ANOVA > Interaction Plot. A window should pop up. 


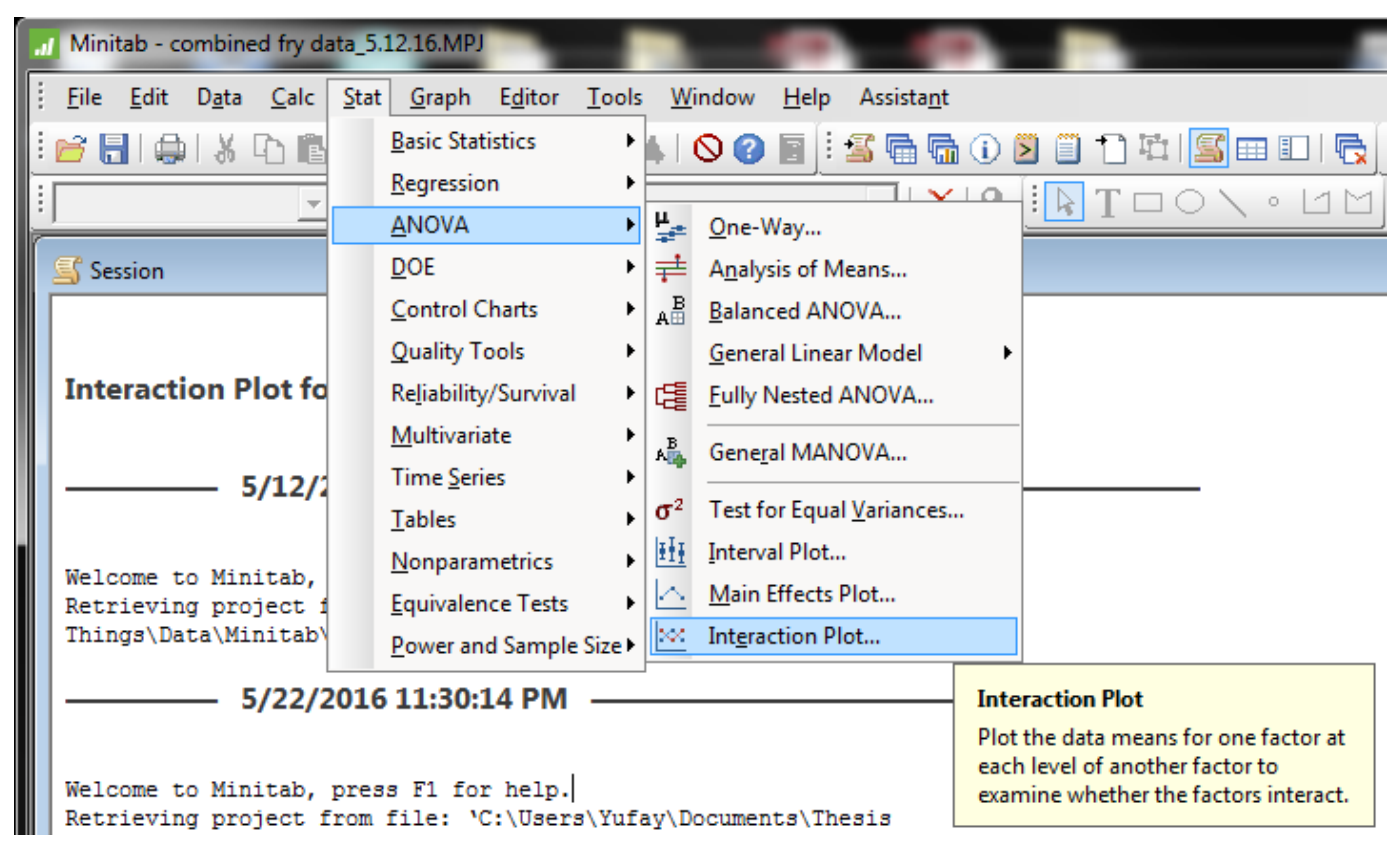

Figure 38 - Interaction Plot Instructions

Select the appropriate responses and factors for the interaction plot and select OK.

Interaction plots will appear.

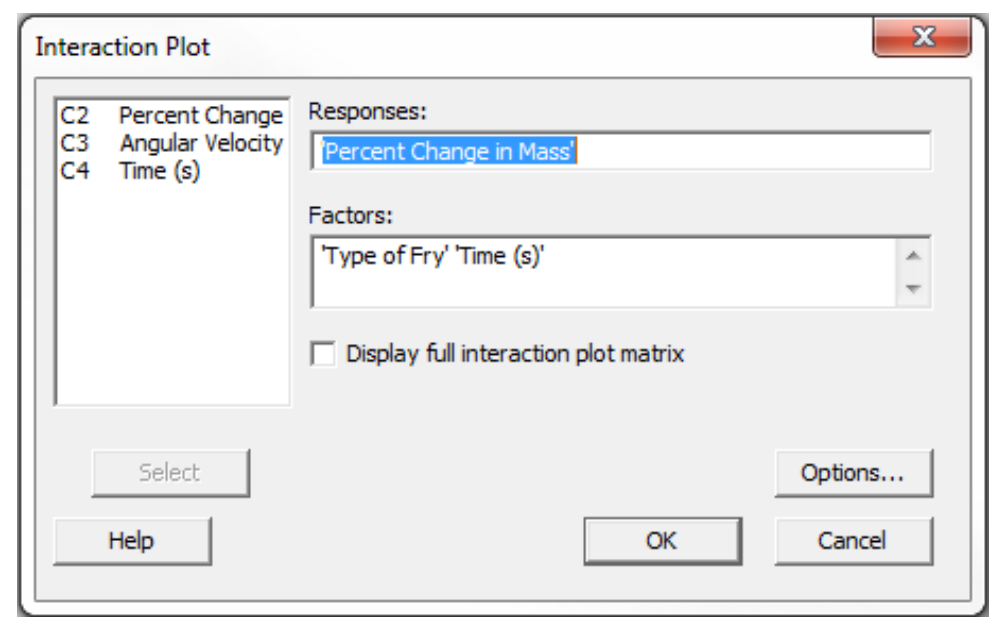

Figure 39 - Interaction Plot Window

Main Effects Plot: Follow the same procedures as the Interaction plot, but instead of selecting Interaction Plot, select Main Effects Plot under ANOVA. 


\section{Appendix C2. Results for Experimental Run \#1}

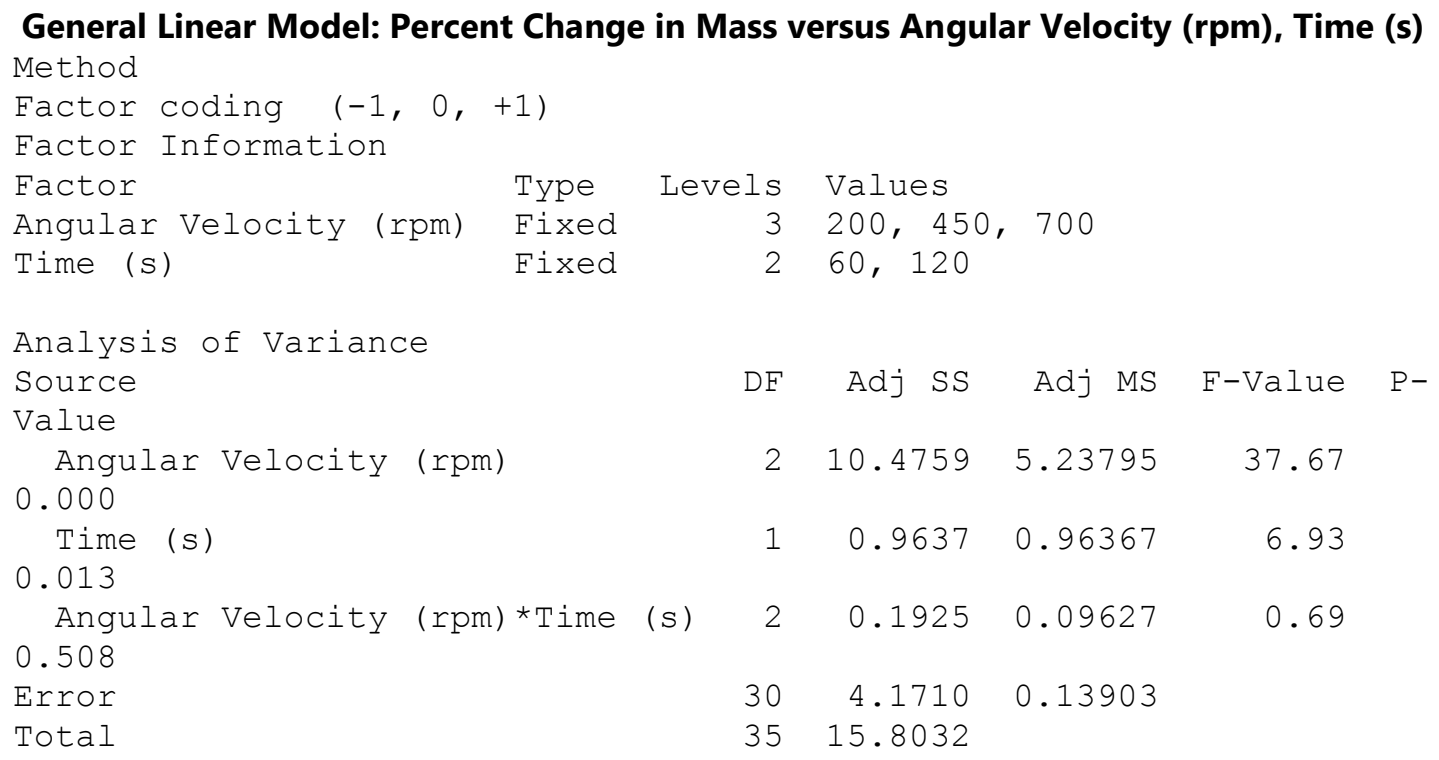

\section{Comparisons for Percent Change in Mass}

Tukey Pairwise Comparisons: Response $=$ Percent Change in Mass, Term $=$ Angular Velocity (rpm)

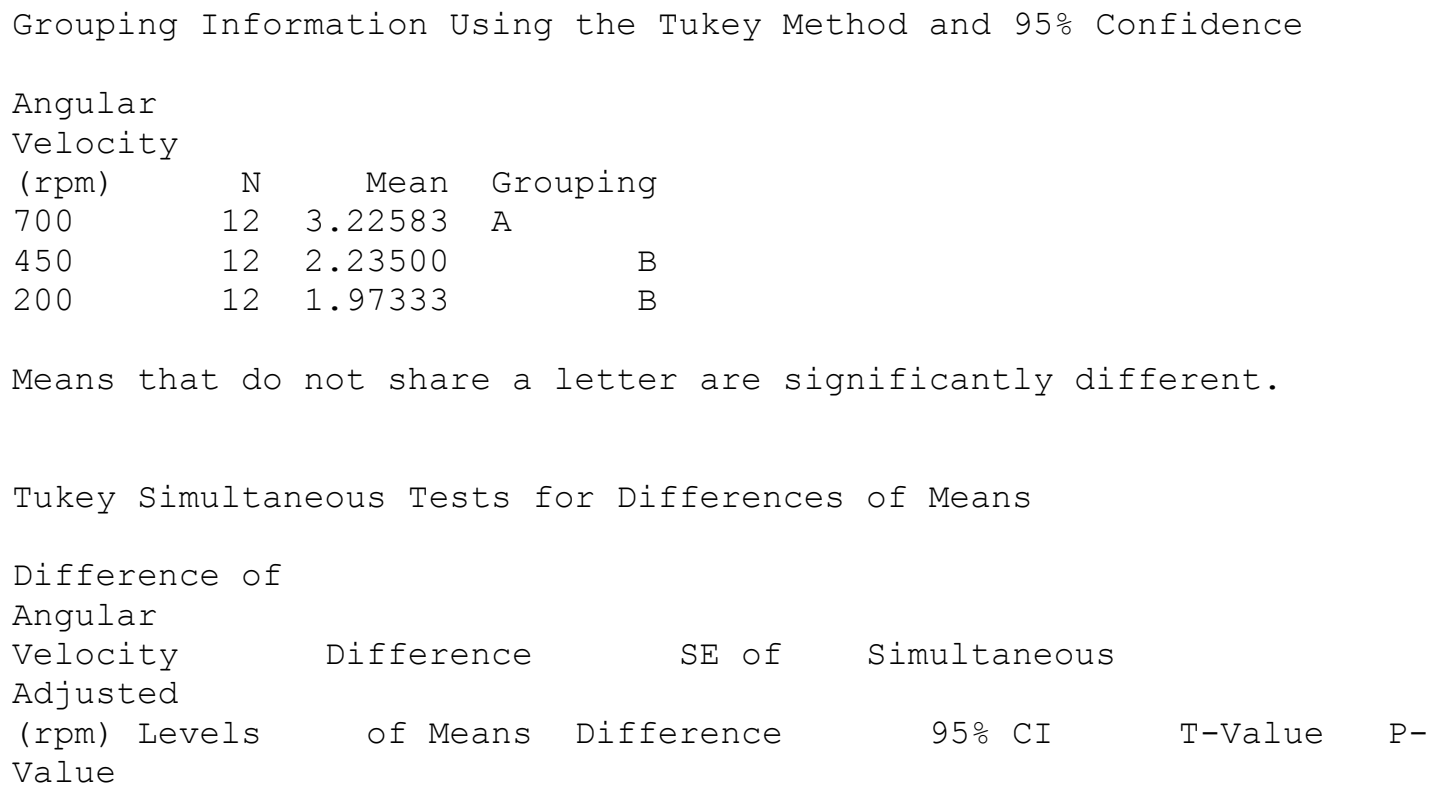




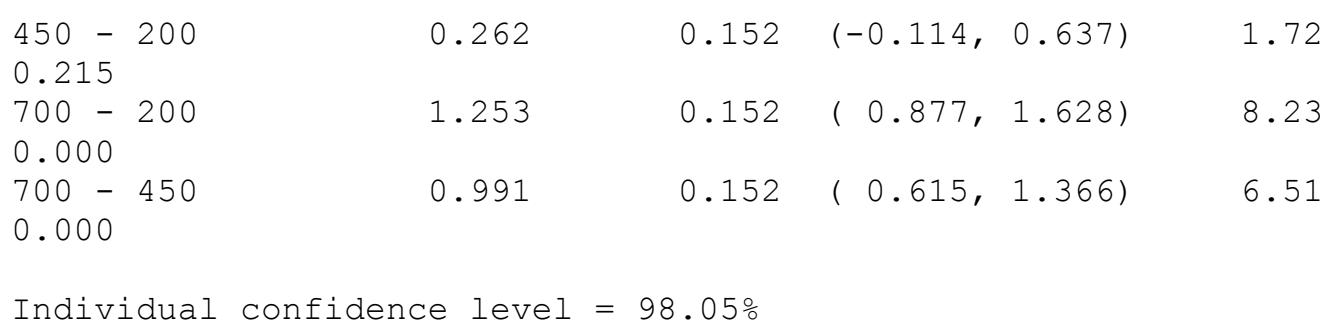

Tukey Pairwise Comparisons: Response = Percent Change in Mass, Term = Time (s)
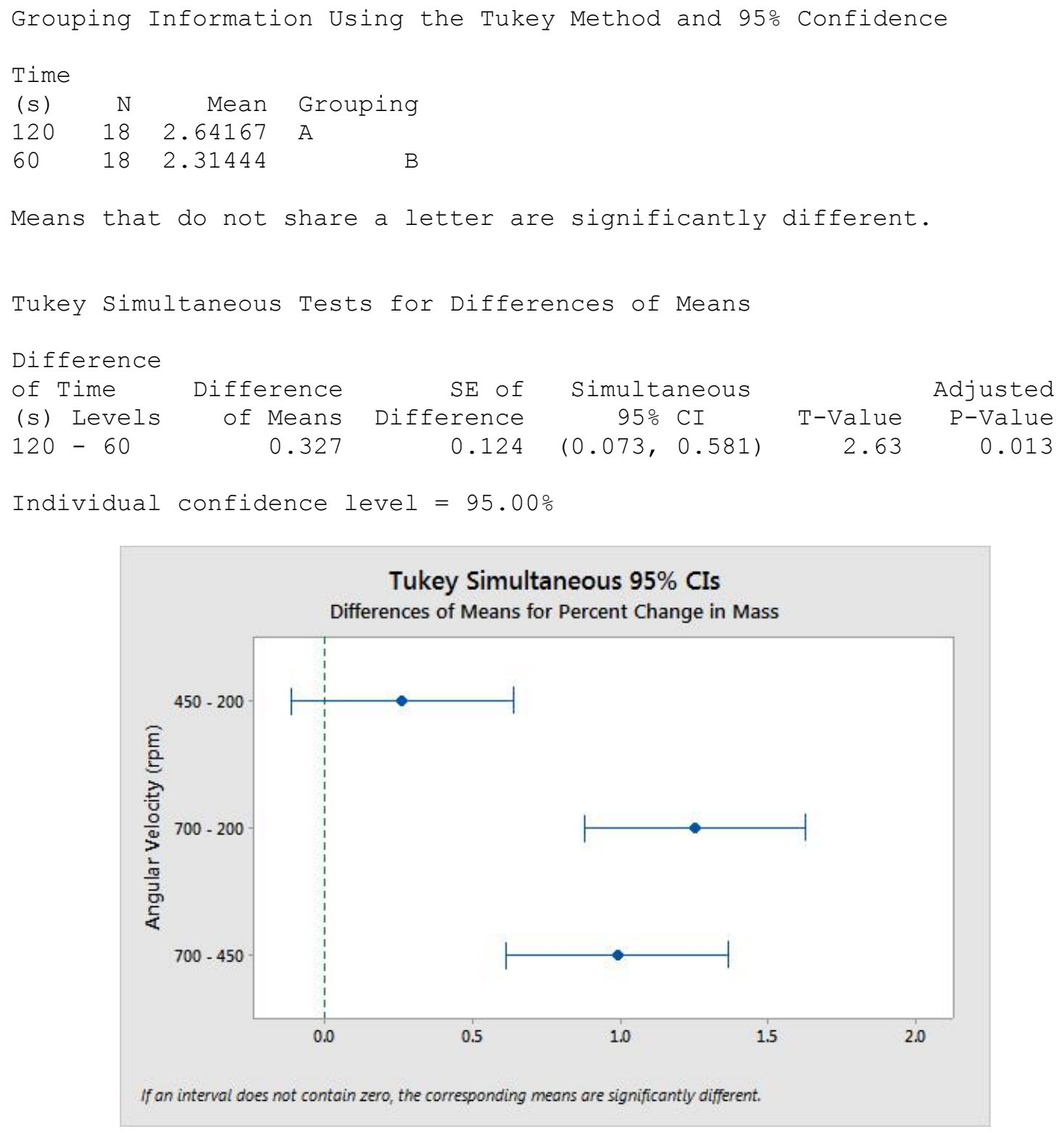

Figure 40 - Experimental Run \#1, Tukey Comparison for Angular Velocity 


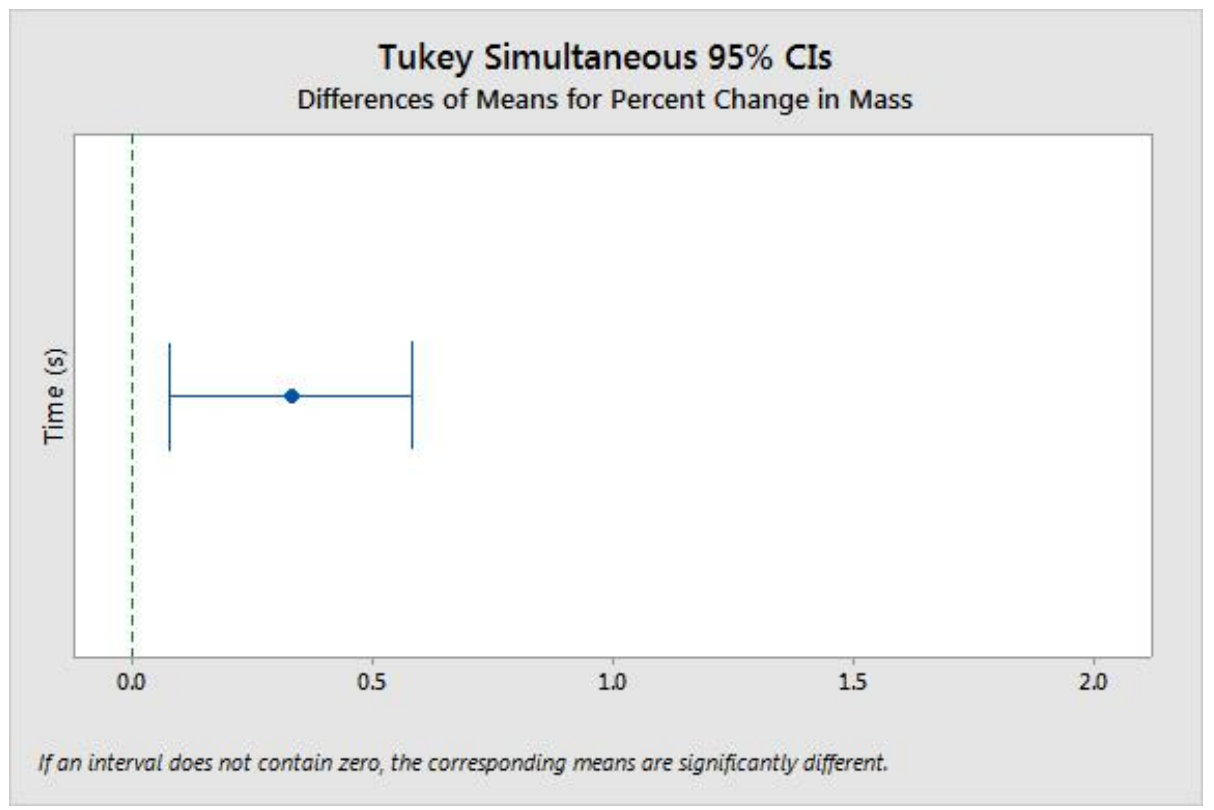

Figure 41 - Experimental Run \#1, Tukey Comparison for Time

\section{Appendix C3. Results for Experimental Run \#2}

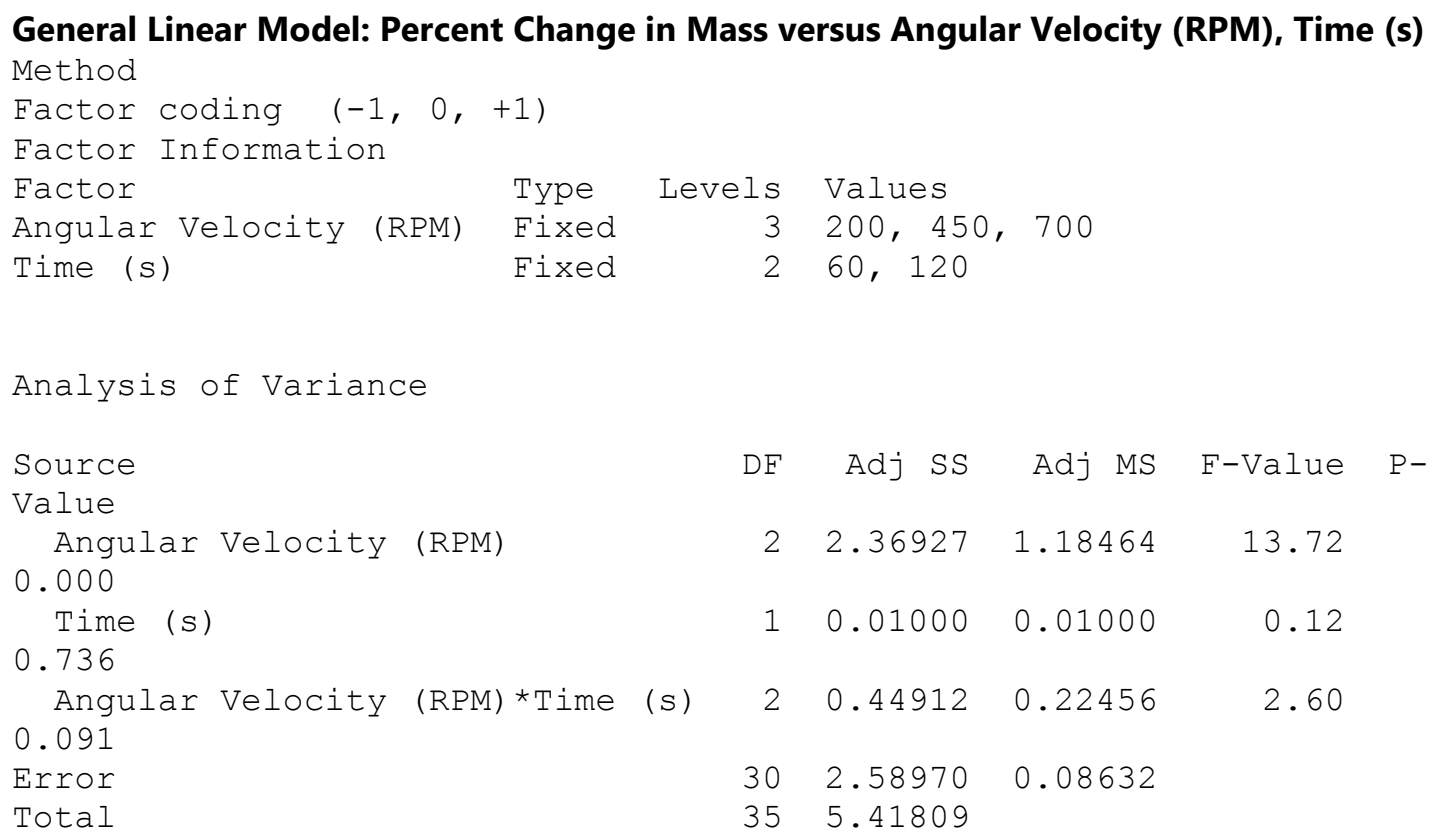

Model Summary

$$
S \quad R-s q \quad R-s q(a d j) \quad R-s q(p r e d)
$$


$0.293808 \quad 52.20 \% \quad 44.24 \% \quad 31.17 \%$

\section{Comparisons for Percent Change in Mass}

Tukey Pairwise Comparisons: Response $=$ Percent Change in Mass, Term $=$ Angular Velocity (RPM)

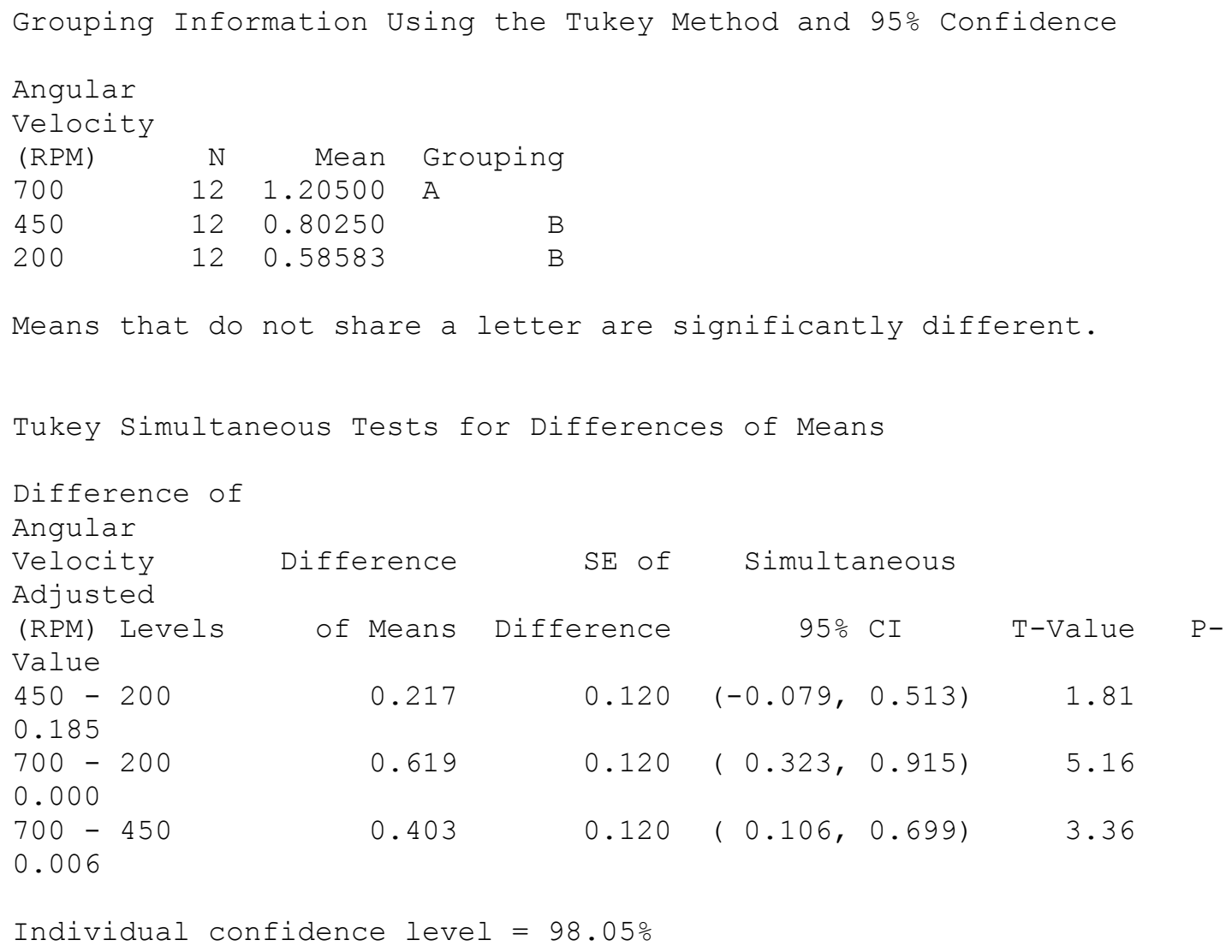

Tukey Pairwise Comparisons: Response $=$ Percent Change in Mass, Term = Time (s)

Grouping Information Using the Tukey Method and 95\% Confidence Time

(s) $\quad \mathrm{N} \quad$ Mean Grouping

$\begin{array}{llll}60 & 18 & 0.881111 & \mathrm{~A}\end{array}$

$\begin{array}{llll}120 & 18 & 0.847778 \quad \text { A }\end{array}$

Means that do not share a letter are significantly different.

Tukey Simultaneous Tests for Differences of Means

Difference 


$\begin{array}{lccccc}\text { of Time } & \text { Difference } & \text { SE of } & \text { Simultaneous } & \\ \text { Adjusted } & & 95 \% \text { CI } & \text { T-Value } & \text { P- } \\ \text { (s) Levels } & \text { of Means } & \text { Difference } & & & \\ \text { Value } & -0.0333 & 0.0979 & (-0.2333,0.1667) & -0.34 \\ 120-60 & & & \\ 0.736 & & & \end{array}$

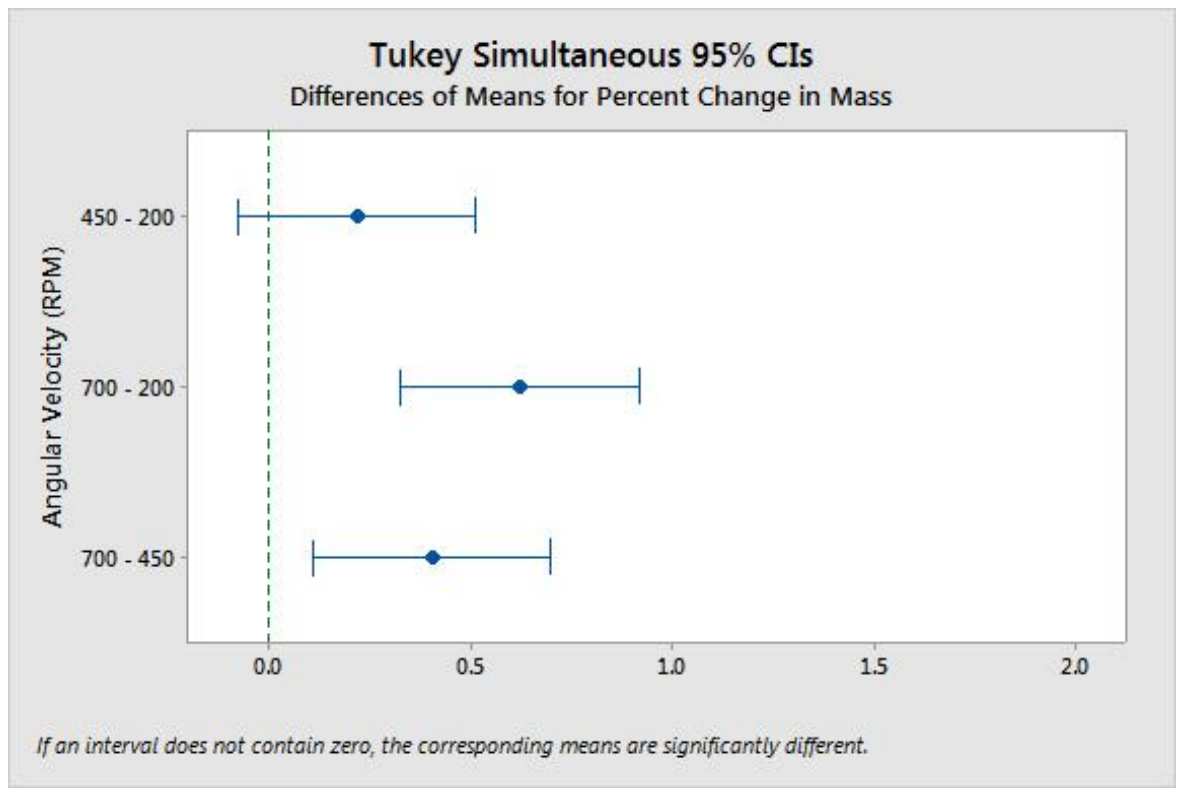

Figure 42 - Experimental Run \#2, Tukey Comparison for Angular Velocity 


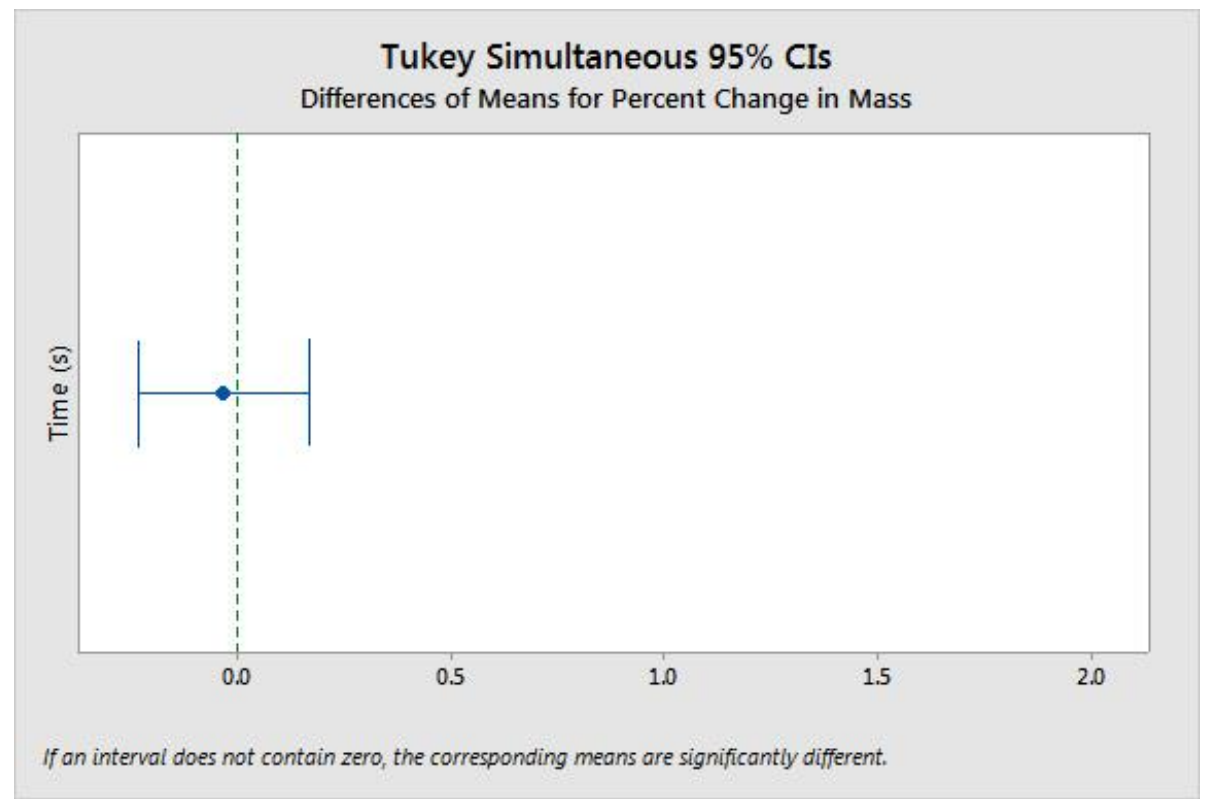

Figure 43 - Experimental Run \#2, Tukey Comparison for Time

\section{Appendix C4. Results for Experimental Run \#3}

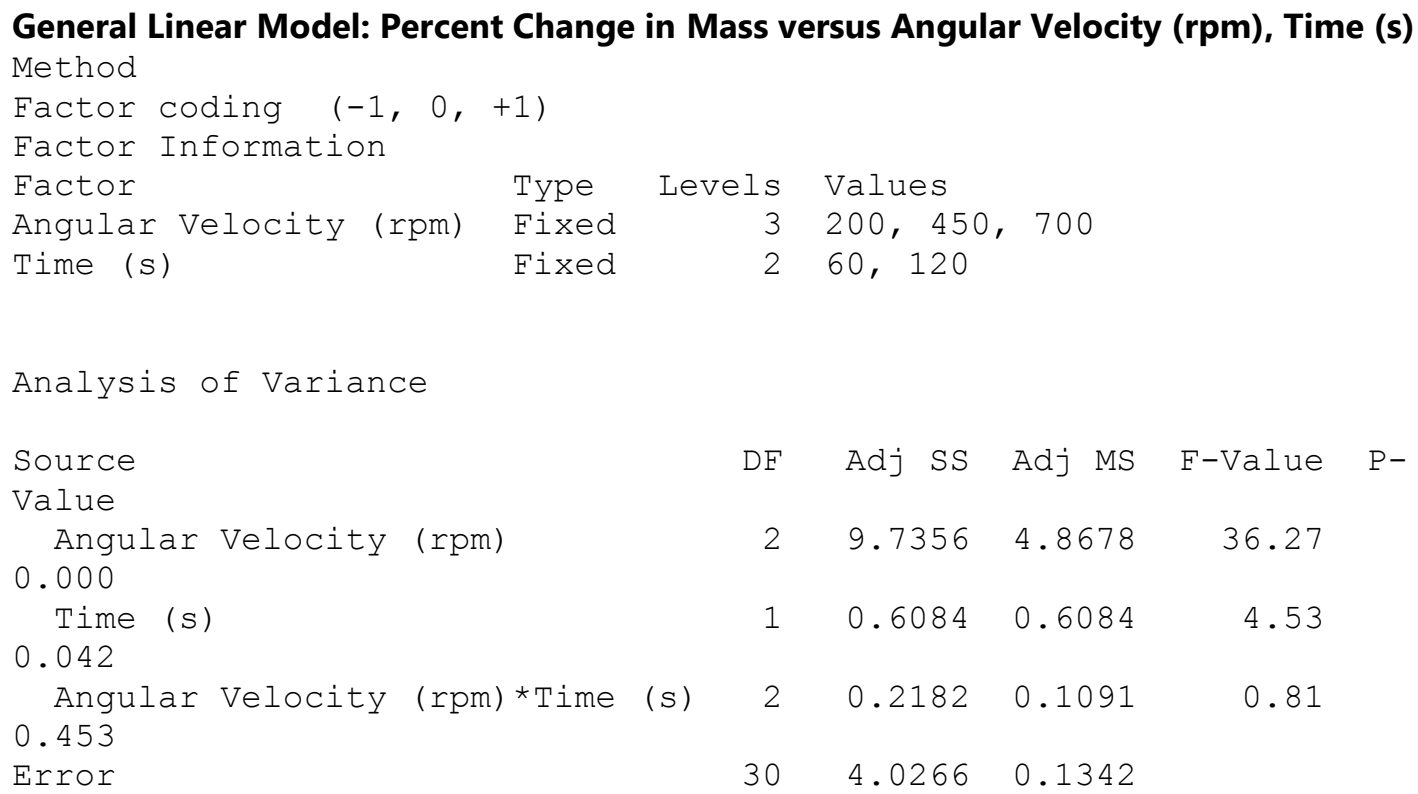


Model Summary
0.366359
S R-Sq
$\mathrm{R}-\mathrm{sq}(\mathrm{adj})$
$\mathrm{R}-\mathrm{sq}$ (pred)
$67.80 \%$
$60.26 \%$

$0.36635972 .40 \%$

\section{Comparisons for Percent Change in Mass}

Tukey Pairwise Comparisons: Response $=$ Percent Change in Mass, Term = Angular Velocity (rpm)

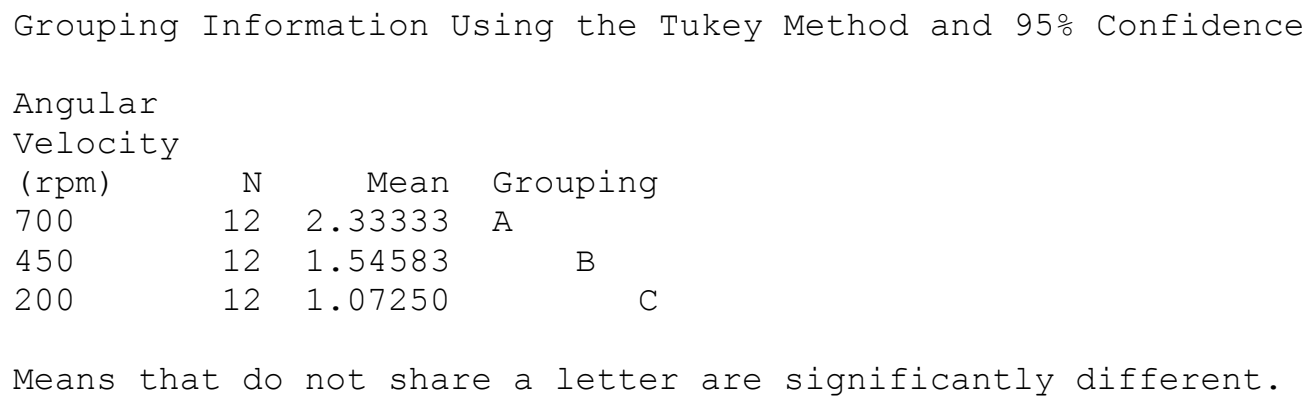

\section{Tukey Simultaneous 95\% CIs}

Tukey Pairwise Comparisons: Response $=$ Percent Change in Mass, Term $=$ Time $(s)$

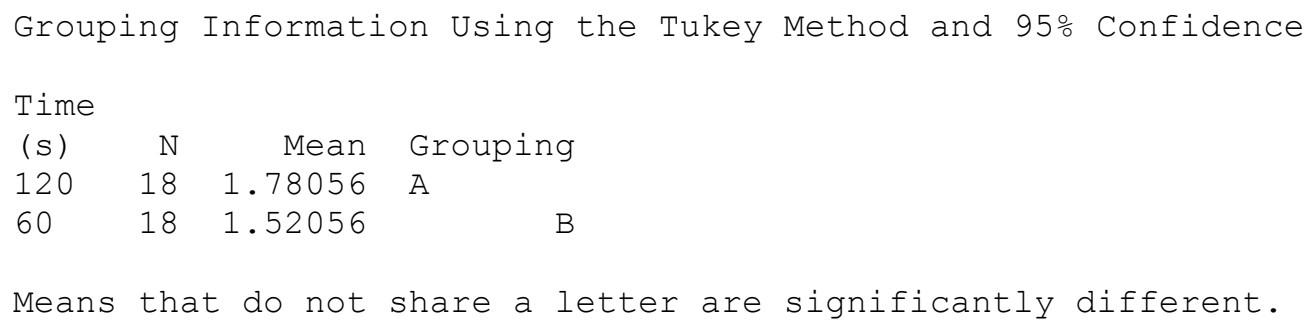




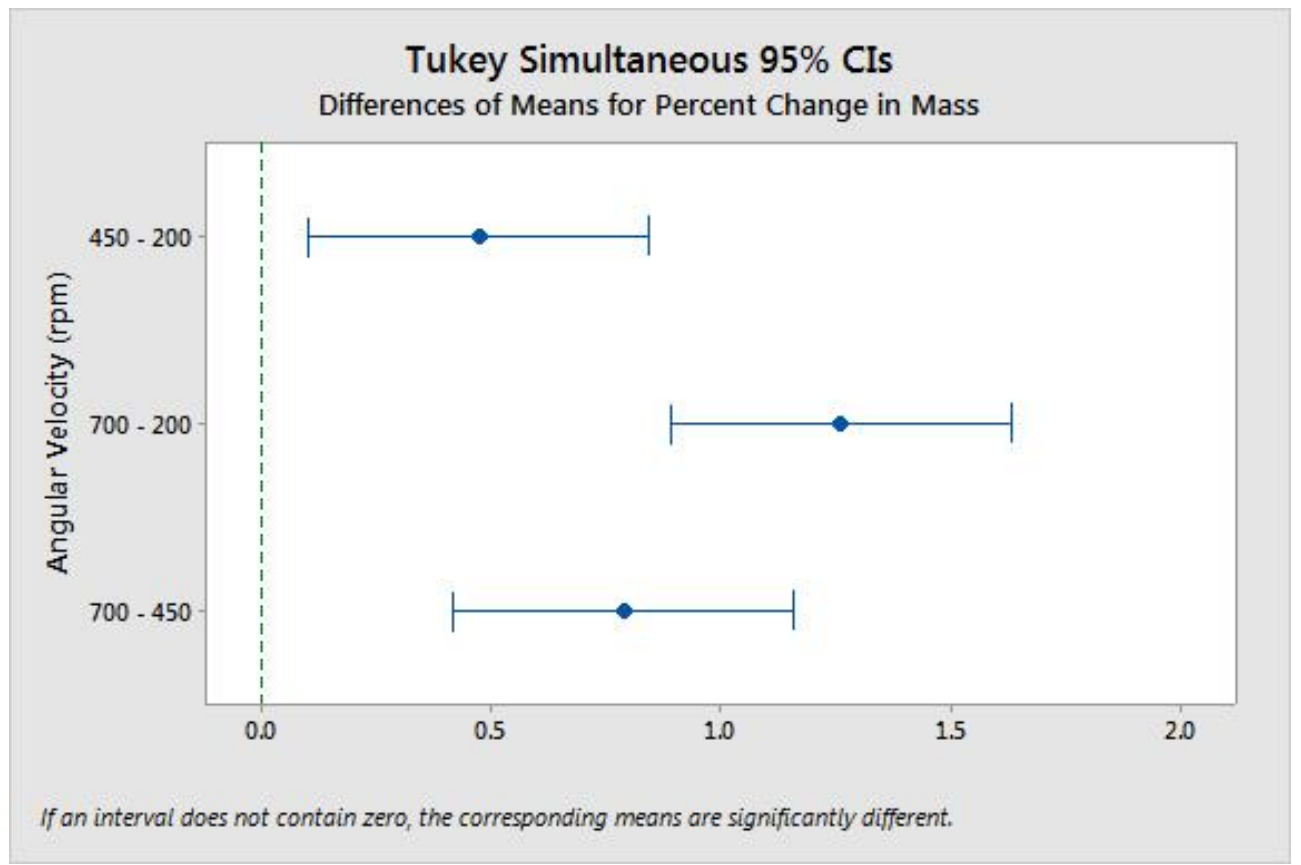

Figure 44 - Experimental Run \#3, Tukey Comparison for Angular Velocity

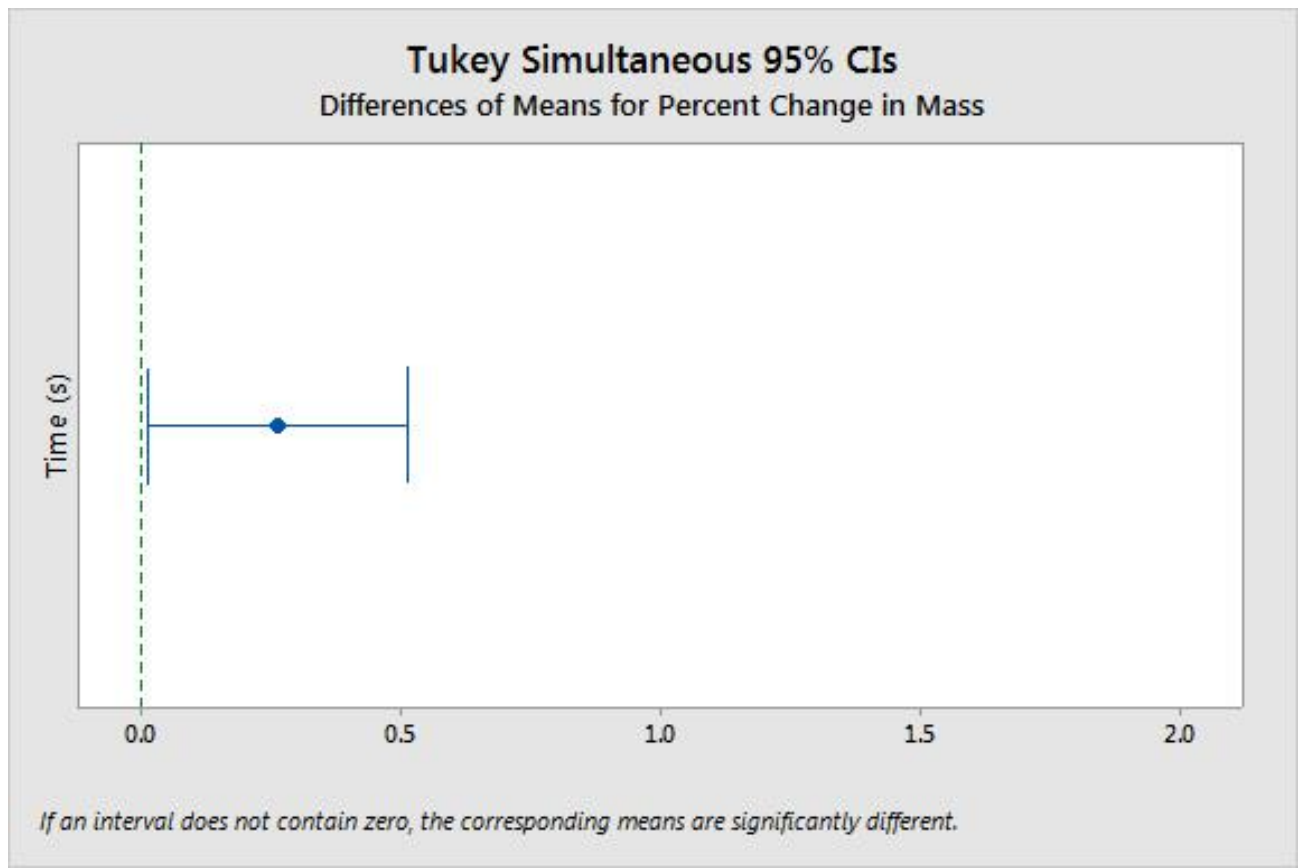

Figure 45 - Experimental Run \#3, Tukey Comparison for Time 


\section{Appendix C5. Results for Combined Experimental Runs}

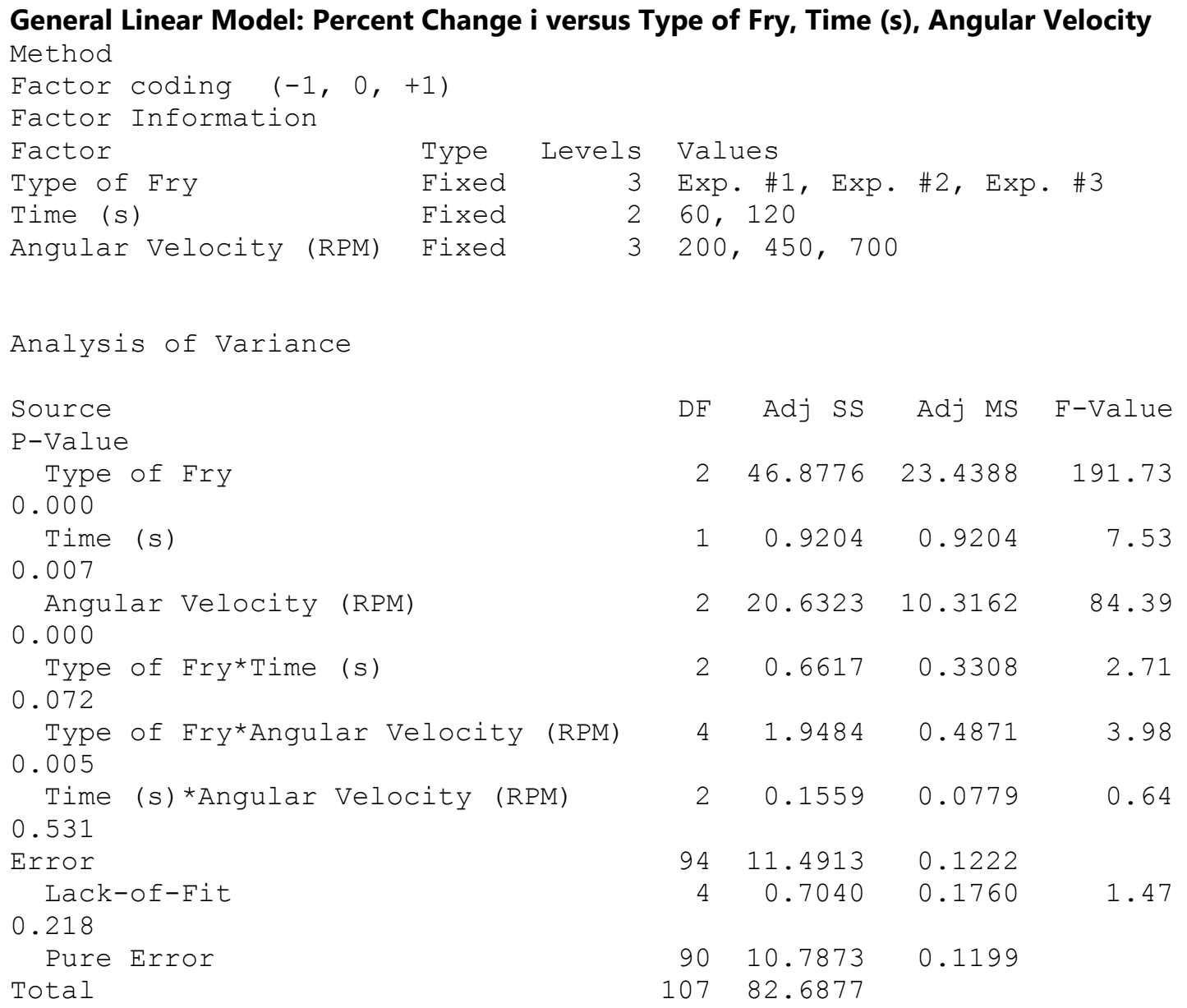

Model Summary
$\mathrm{S} \quad \mathrm{R}-\mathrm{Sq}$

\section{Comparisons for Percent Change in Mass}

Tukey Pairwise Comparisons: Response $=$ Percent Change in Mass, Term $=$ Type of Fry

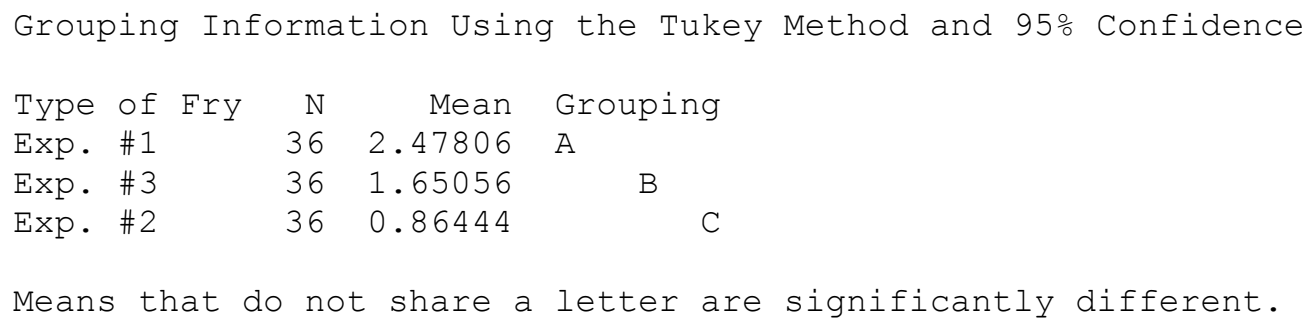




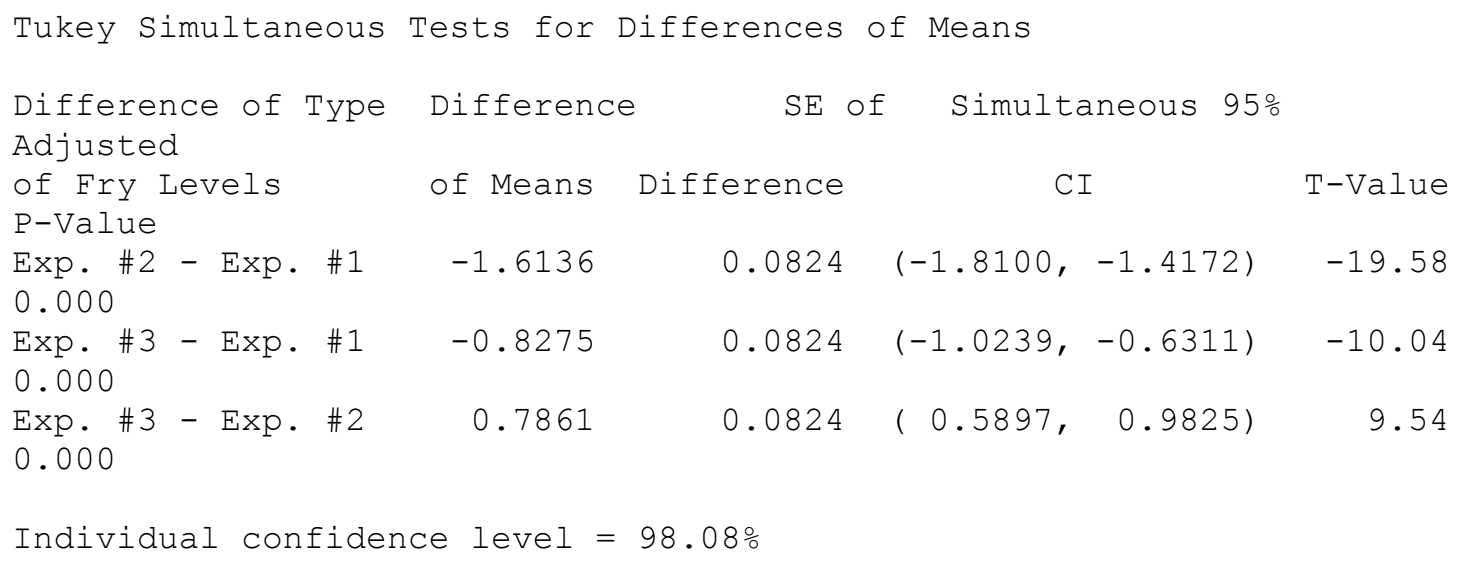

\section{Tukey Simultaneous 95\% CIs}

\section{Tukey Pairwise Comparisons: Response $=$ Percent Change in Mass, Term = Time (s)}

Grouping Information Using the Tukey Method and 95\% Confidence

Time

$\begin{array}{lrrlr}\text { (s) } & \mathrm{N} & \text { Mean } & \text { Grouping } \\ 120 & 54 & 1.75667 & \text { A } & \\ 60 & 54 & 1.57204 & & \text { B }\end{array}$

Means that do not share a letter are significantly different.

Tukey Simultaneous Tests for Differences of Means

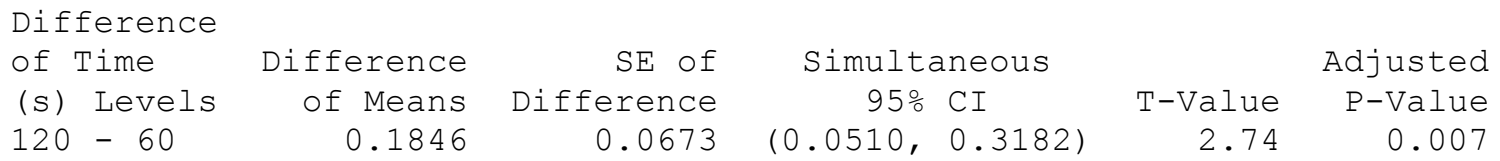

\section{Tukey Simultaneous 95\% CIs}

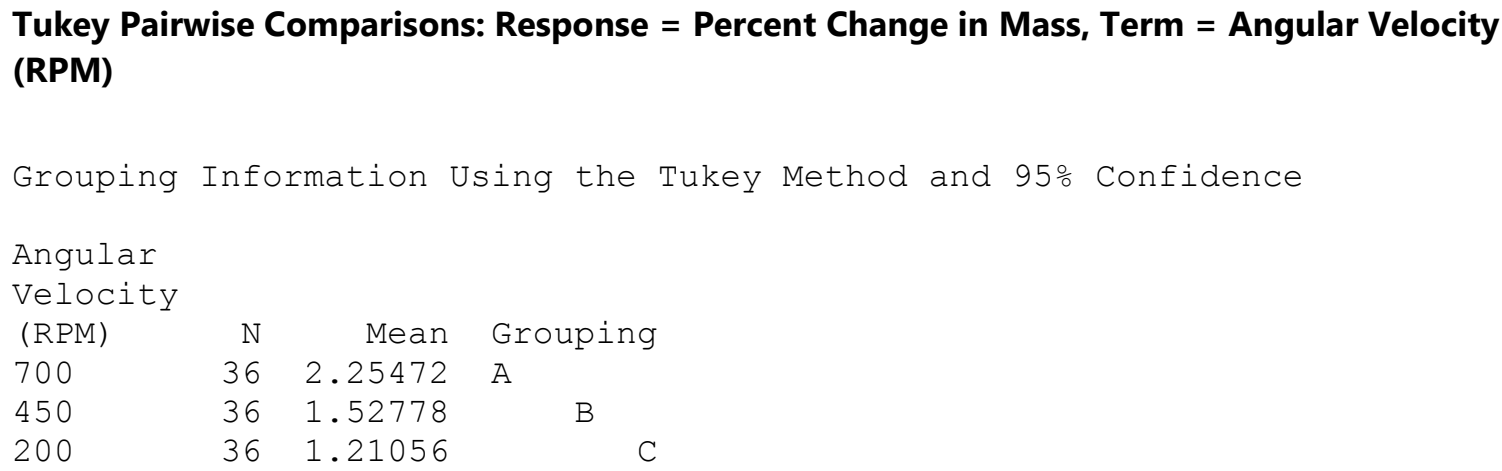
(RPM) 


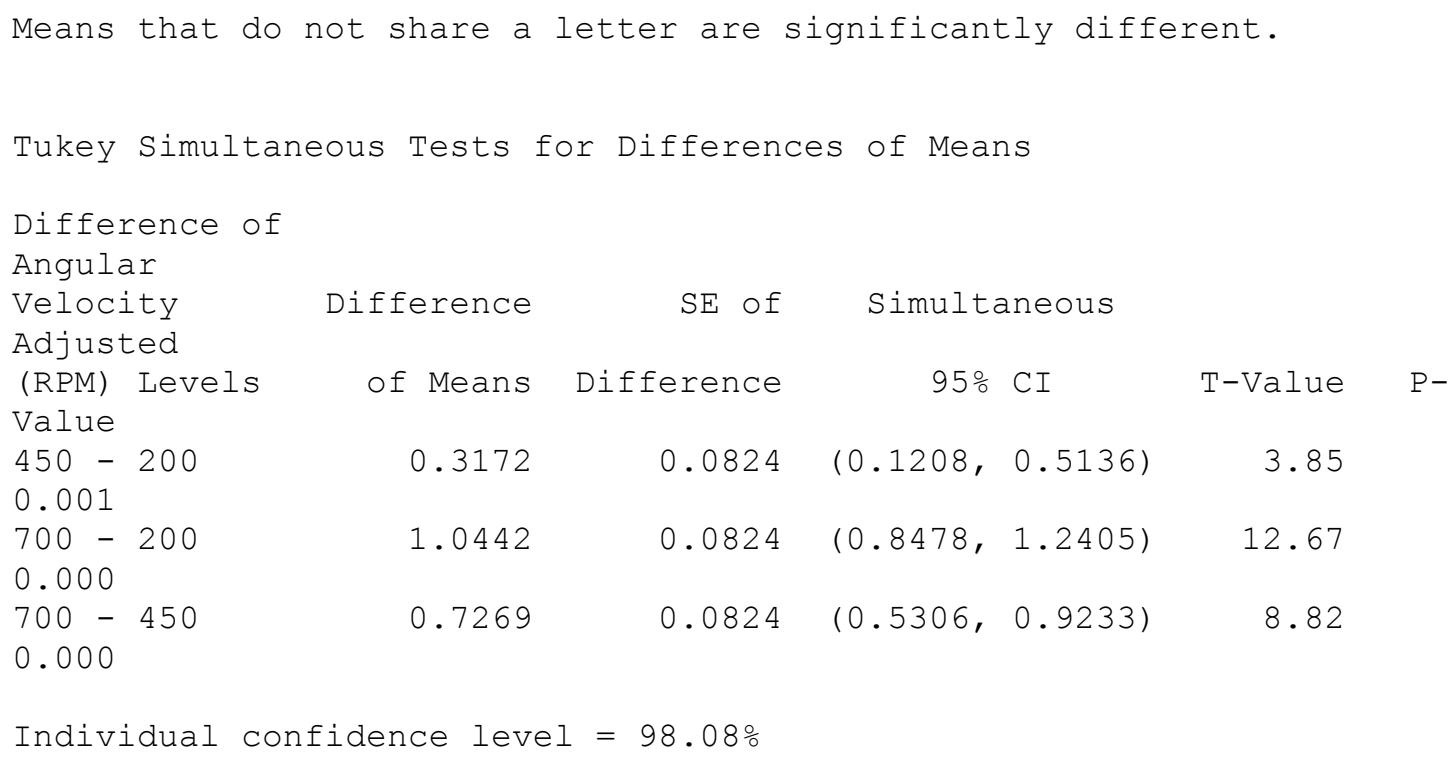

\section{Tukey Simultaneous 95\% CIs}

Tukey Pairwise Comparisons: Response $=$ Percent Change in Mass, Term $=$ Type of Fry*Angular Vel

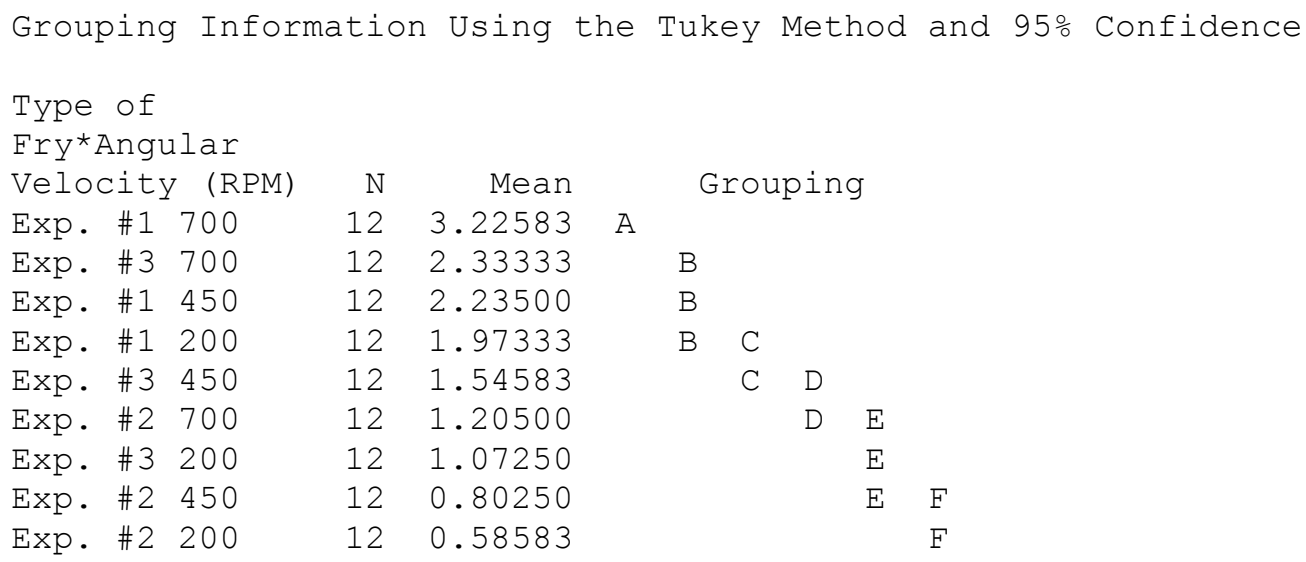




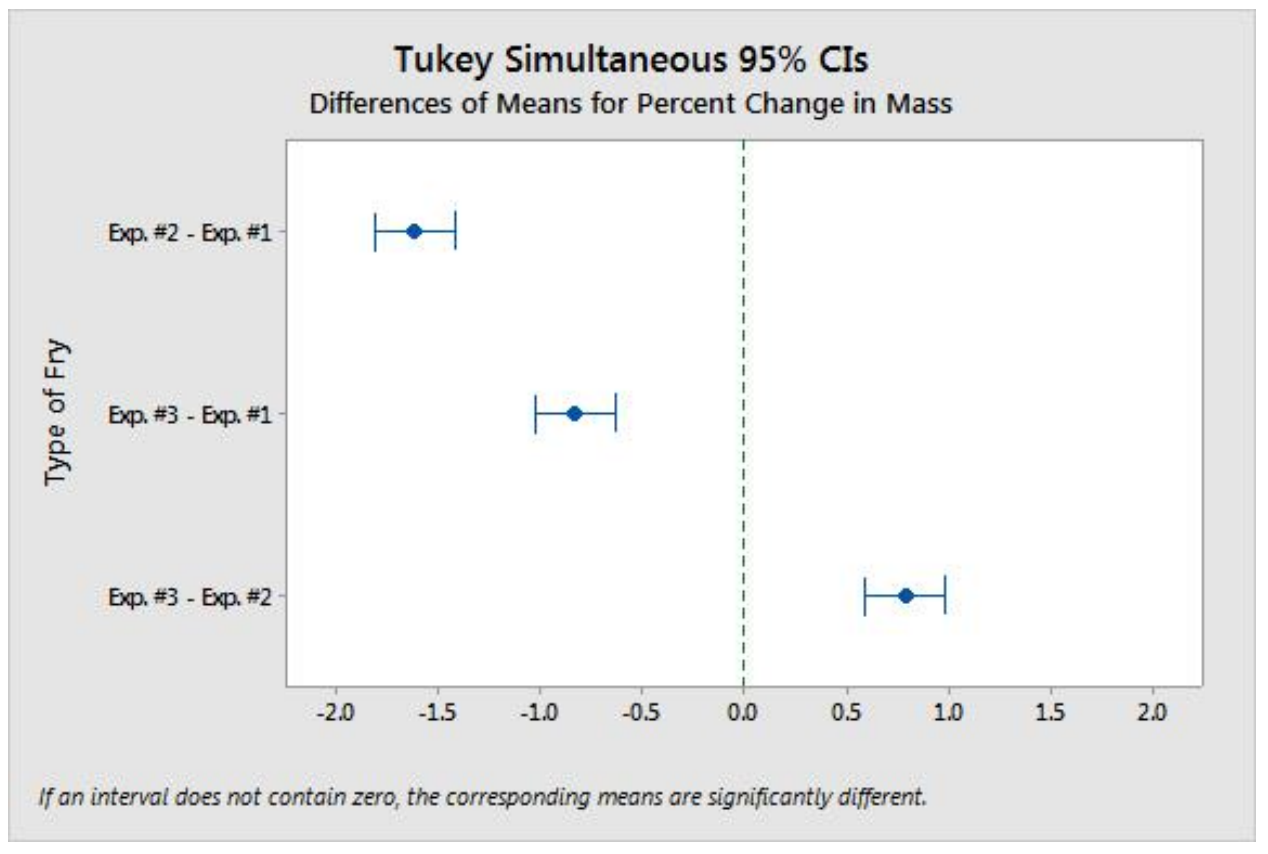

Figure 46 - Experimental Run \#1-3, Tukey Comparison for Type of Fry

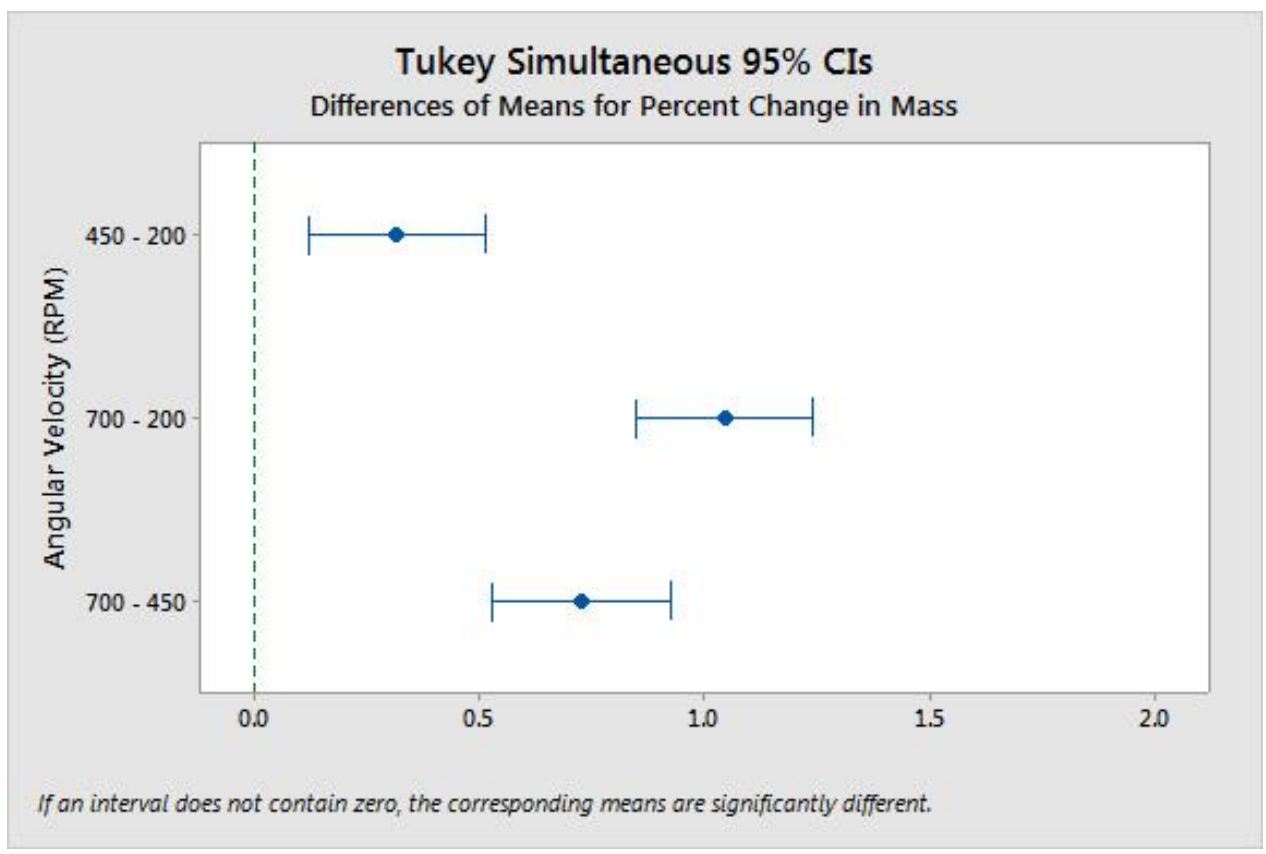

Figure 47 - Experimental Run \#1-3, Tukey Comparison for Angular Velocity 


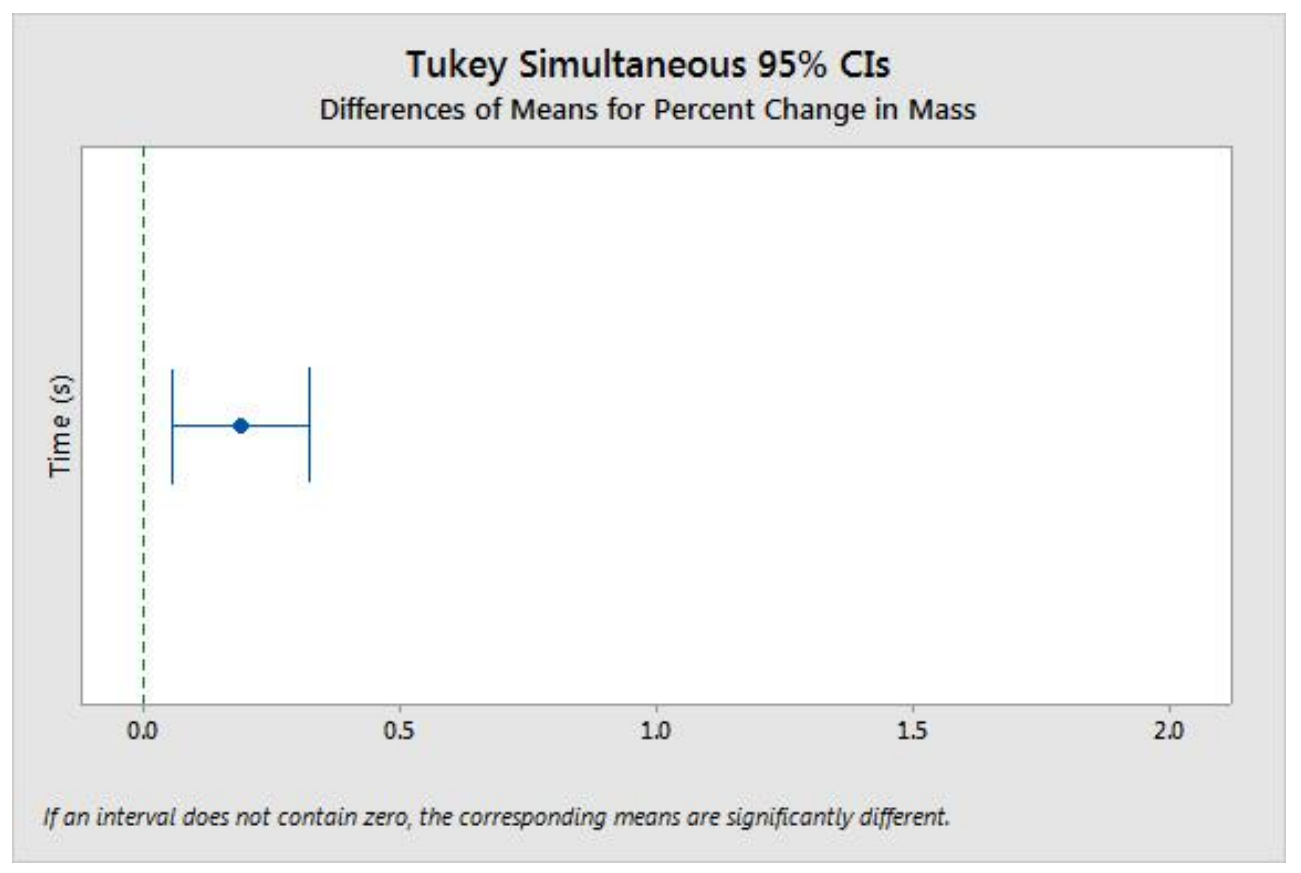

Figure 48 - Experimental Run \#1-3, Tukey Comparison for Time 


\section{Appendix D. Oxygen Bomb Calorimeter}

\section{Appendix D1. Oxygen Bomb Calorimeter Procedures and Equations}

The Bomb Calorimeter was used from the Thermal Science Lab in the Mechanical

Engineering building. Glen Thorncroft provided guidance and lab instructions for safe procedures during this experiment. The equipment needed for the bomb calorimeter is listed below:

- Digital thermometer

- Electrical fuse ignitor

- Bomb

- Motor with belt and pulley

- Insulated container with lid and stirrer

- Oval bucket

- Fuse

- Crucible

- Bomb carrying handle

The procedures for safely running the bomb calorimeter are as follows:

1. Weigh $2.000 \mathrm{~kg}$ of tap water into the oval bucket and place it into the insulated container

2. Cut $10 \mathrm{~cm}$ of fuse wire and bind it to the electrode on the bomb

3. Weigh the fuel, it should be near a gram but should not exceed $1.05 \mathrm{~g}$ of fuel

4. Place fuel in the crucible in the bomb

5. Screw the retaining ring onto the bomb to seal it up

6. Charge the bomb to $25 \mathrm{~atm}$. 
7. Place the bomb back in the calorimeter with the carrying handle. Be careful not to knock over any fuel in the crucible

8. Attach the ignition leads into the bomb and connect the wires to the $10 \mathrm{~cm}$ leads on the ignitor

9. Attach the belt onto the stirrer and motor. Start the stirrer for about five minutes to stabilize the temperature

10. Record the temperature for every minute for five minutes prior to igniting fuel

11. Wear safety glasses and ignite the fuel at the five minute mark

12. The temperature will begin to rise within 10-15 seconds. Record the temperature every minute until the temperature evens out, then record for another five minutes

13. Remove the bomb from the container and slowly remove the compressed air from the bomb

14. Measure the length of remaining fuel on the electrodes

15. Wash and dry equipment

The main equations used to determine the caloric content of the fuel is shown below:

$$
H H V=\left(\frac{W \Delta T-e L}{m_{f}}\right)
$$

$\mathrm{HHV}=$ higher heating value $(\mathrm{cal} / \mathrm{g})$

$\mathrm{W}=$ energy equivalent factor $(\mathrm{cal} / \mathrm{C})$ obtained from the calorimeter

$\mathrm{E}=$ heat released by the wire $(2.3 \mathrm{cal} / \mathrm{cm})$

$\mathrm{L}=$ length of fuse burned $(\mathrm{cm})$

$m_{f}=$ mass of the fuel $(\mathrm{g})$

$\Delta T=$ temperature rise of the system $(\mathrm{C}$ or $\mathrm{K})$ 


$$
E=H H V * m_{f}
$$

$\mathrm{E}=$ caloric value of the fuel (cal)

The last equation is for the temperature correction because the temperature five minutes before starting may not be at steady state. Similarly the last five minutes of the experiment after the peak temperature may not be at steady state. This equation corrects for the unsteady temperature before and after testing.

$$
\Delta T_{\text {corrected }}=T_{f}-T_{i}-m_{1}\left(t_{60}-t_{i}\right)-m_{2}\left(t_{f}-t_{60}\right)
$$

$T_{f}=$ final (or max) temperature $(\mathrm{C})$

$T_{i}=$ initial temperature $(\mathrm{C})$

$t_{f}=$ time at final temperature $(\mathrm{min})$

$T_{60}=$ temperature at $60 \%$ of the final temperature $(\mathrm{C})$

$t_{i}=$ time at initial temperature (min)

$t_{60}=$ time at $60 \%$ of the final temperature (min)

$m_{1}=$ initial rise/fall of temperature (slope)

$m_{2}=$ final rise/fall of temperature (slope) 


\section{Appendix D2. Oxygen Bomb Calorimeter Data}

Table 43 - Oxygen Bomb Calorimeter Temperature Data for Raw Fries

\begin{tabular}{|c|c|}
\hline Time (minutes) & Temperature $(\mathbf{C})$ \\
\hline 0 & 23.164 \\
\hline 1 & 23.164 \\
\hline 2 & 23.165 \\
\hline 3 & 23.165 \\
\hline 4 & 23.165 \\
\hline 5 & 23.165 \\
\hline 6 & 23.8 \\
\hline 7 & 24.175 \\
\hline 8 & 24.324 \\
\hline 9 & 24.386 \\
\hline 10 & 24.416 \\
\hline 11 & 24.43 \\
\hline 12 & 24.435 \\
\hline 13 & 24.436 \\
\hline 14 & 24.436 \\
\hline 15 & 24.435 \\
\hline 16 & 24.434 \\
\hline 17 & 24.432 \\
\hline
\end{tabular}

Table 44 - Caloric Value (E) Calculation for Raw Fries

\begin{tabular}{|l|c|}
\hline W [energy equivalent factor] $(\mathrm{cal} / \mathrm{C})=$ & 2421 \\
\hline $\mathrm{e}$ [heat released by wire] $(\mathrm{cal} / \mathrm{cm})=$ & 2.3 \\
\hline 1 [length of burned fuse] $(\mathrm{cm})=$ & 7.5 \\
\hline m_f [mass of fuel burned] $(\mathrm{g})=$ & 0.833 \\
\hline Delta $T$ [rise in temp.] $(\mathrm{C}$ or $\mathrm{K})=$ & 1.251 \\
\hline HHV [higher heating value] $(\mathrm{cal} / \mathrm{g})=$ & 3615.15 \\
\hline $\mathrm{E}$ [caloric value] $(\mathrm{cal})=$ & 3011.42 \\
\hline
\end{tabular}


Table 45 - Caloric Value (E) with Corrected Temperature for Raw Fries

\begin{tabular}{|l|c|}
\hline T_f [max or final temp.] (C) $=$ & 24.435 \\
\hline T_i [initial temp.] (C) $=$ & 23.165 \\
\hline T_60 [Temp 60\% up the curve] (C) $=$ & 23.927 \\
\hline t_60 [time 60\% up the curve] $(\mathrm{C})=$ & 6.5 \\
\hline t_i [initial time.] (min) $=$ & 5 \\
\hline t_f [final time.] (min) $=$ & 12 \\
\hline m_1 [initial slope] $(\mathrm{C} / \mathrm{min})=$ & 0.00020 \\
\hline m_2 [Final slope] $(\mathrm{C} / \mathrm{min})=$ & -0.00060 \\
\hline Delta T Corrected $(\mathrm{C})=$ & 1.281 \\
\hline New HHV $(\mathrm{cal} / \mathrm{g})=$ & 3701.76 \\
\hline New E (cal) $=$ & 3083.57 \\
\hline
\end{tabular}

Table 46 - Oxygen Bomb Calorimeter Temperature Data for Cooked Fries

\begin{tabular}{|c|c|}
\hline Time (minutes) & Temperature (C) \\
\hline 0 & 23.11 \\
\hline 1 & 23.111 \\
\hline 2 & 23.112 \\
\hline 3 & 23.113 \\
\hline 4 & 23.115 \\
\hline 5 & 23.116 \\
\hline 6 & 24.095 \\
\hline 7 & 24.731 \\
\hline 8 & 24.948 \\
\hline 9 & 25.046 \\
\hline 10 & 25.093 \\
\hline 11 & 25.106 \\
\hline 12 & 25.114 \\
\hline 13 & 25.117 \\
\hline 14 & 25.116 \\
\hline 15 & 25.115 \\
\hline 16 & 25.113 \\
\hline 17 & 25.11 \\
\hline
\end{tabular}


Table 47 - Caloric Value (E) Calculation for Cooked Fries

\begin{tabular}{|l|c|}
\hline W [energy equivalent factor] $(\mathrm{cal} / \mathrm{C})=$ & 2421 \\
\hline e [heat released by wire] $(\mathrm{cal} / \mathrm{cm})=$ & 2.3 \\
\hline 1 [length of burned fuse] $(\mathrm{cm})=$ & 8 \\
\hline m_f [mass of fuel burned] $(\mathrm{g})=$ & 1.006 \\
\hline Delta T [rise in temp.] $(\mathrm{C}$ or $\mathrm{K})=$ & 1.977 \\
\hline HHV [higher heating value] $(\mathrm{cal} / \mathrm{g})=$ & 4739.48 \\
\hline E [caloric value] $(\mathrm{cal})=$ & 4767.92 \\
\hline
\end{tabular}

Table 48 - Caloric Value (E) with Corrected Temperature for Cooked Fries

\begin{tabular}{|l|c|}
\hline T_f [max or final temp.] $(\mathrm{C})=$ & 25.114 \\
\hline T_i [initial temp.] $(\mathrm{C})=$ & 23.116 \\
\hline T_60 [Temp 60\% up the curve] $(\mathrm{C})=$ & 24.315 \\
\hline t_60 [time 60\% up the curve] $(\mathrm{C})=$ & 6.5 \\
\hline t_i [initial time.] $(\mathrm{min})=$ & 5 \\
\hline t_f [final time.] $(\mathrm{min})=$ & 12 \\
\hline m_1 [initial slope] $(\mathrm{C} / \mathrm{min})=$ & 0.00120 \\
\hline m_2 [Final slope] $(\mathrm{C} / \mathrm{min})=$ & -0.00080 \\
\hline Delta T Corrected $(\mathrm{C})=$ & 2.011 \\
\hline New HHV $($ cal/g) $=$ & 4821.30 \\
\hline New E $($ cal $)=$ & 4850.23 \\
\hline
\end{tabular}




\section{Appendix E. Additional Calculations}

\section{Appendix E1. Steady State Heat Transfer Calculations Using EES}

"Simplified model for heat transfer for french fries in a centrifuge until SS"

"Known Variables"

$\mathrm{h} \_$inside $=25\left\{\mathrm{~W} / \mathrm{m} 2^{\wedge} \mathrm{K}\right\}$

A_fry $=4 * 3 * 0.25 * 20 *(0.0254 * 0.0254)\left\{\mathrm{m}^{\wedge} 2\right\}$

T_fry $=200+273\{\mathrm{~K}\}$

A_inside $=\left(\left(2 * \mathrm{pi}^{*} 4 * 4\right)+(\mathrm{pi} * 8 * 5)\right) * 0.0254 * 0.0254\left\{\mathrm{~m}^{\wedge} 2\right\}$

A_side $=\left(\mathrm{pi}^{*} 8 * 5\right) * 0.0254 * 0.0254\left\{\mathrm{~m}^{\wedge} 2\right\}$

sigma $=0.0000000567\left\{\mathrm{~W} / \mathrm{m} 2^{\wedge} \mathrm{K}^{\wedge} 2\right\}$

Epsilon_fry $=0.5$

Epsilon_pc $=0.9$

r_carriage $=3.5 * 0.0254$

r_pc $=4 * 0.0254$

A_bottom $=2 *\left(\mathrm{pi}^{*} 4 * 4\right) * 0.0254 * 0.0254\left\{\mathrm{~m}^{\wedge} 2\right\}$

L_pc $=(1 / 5) * 0.0254\{\mathrm{~m}\}$

$\mathrm{K} \_\mathrm{pc}=0.2\left\{\mathrm{~W} / \mathrm{m}^{*} \mathrm{~K}\right\}$

L_foam $=0.0254\{\mathrm{~m}\}$

$\mathrm{K} \_$foam $=0.03\{\mathrm{~W} / \mathrm{m} * \mathrm{~K}\}$

h_atm $=5\left\{\mathrm{~W} / \mathrm{m} 2^{\wedge} \mathrm{K}\right\}$

A_foam $=\left(\left(\mathrm{pi}^{*} 5 * 5\right)+\left(\mathrm{pi}^{*} 10 * 7\right)\right) * 0.0254 * 0.0254\left\{\mathrm{~m}^{\wedge} 2\right\}$

T_atm $=20+273\{\mathrm{~K}\}$ 
"Driving Equations"

\{Convection inside the Centrifuge\}

q_conv1 = h_inside*A_fry*(T_fry-T_air)

q_conv2 = h_inside*A_inside*(-T_pc+T_air)

\{Radiation heating the side walls

q_rad1 $=\left(\right.$ A_side $*$ sigma* $\left.\left(T \_f r y \wedge 4-T \_p c^{\wedge} 4\right)\right) /((1 /$ Epsilon_fry $)+((1-$

Epsilon_pc)/Epsilon_pc)*(r_carriage/r_pc))

q_rad2 $=\left(\right.$ A_bottom*sigma* $\left.\left(T \_f r y \wedge 4-T \_p c^{\wedge} 4\right)\right) /((1 /$ Epsilon_fry $)+(1 /$ Epsilon_pc $)-1)$

\{Conduction through the centrifuge walls \}

q_cond $=\left(T \_p c-T \_f o a m\right) /\left(\left(L \_p c /\left(A \_i n s i d e * K \_p c\right)\right)+\left(L \_\right.\right.$foam $\left.\left./\left(A \_i n s i d e * K \_f o a m\right)\right)\right)$

\{Convection outside\}

q_conv.out $=$ h_atm*A_foam* $\left(T \_\right.$foam $-T \_$atm $)$

\{Energy Balance Equations $\}$

q_conv1 = q_conv2

q_rad1+q_rad2+q_conv1 $=$ q_cond

q_conv.out $=$ q_cond

Appendix E2. Transient Heat Transfer Calculations Using Matlab

응ransient Heat Transfer Calculations using the Lumped Capacitance Method 


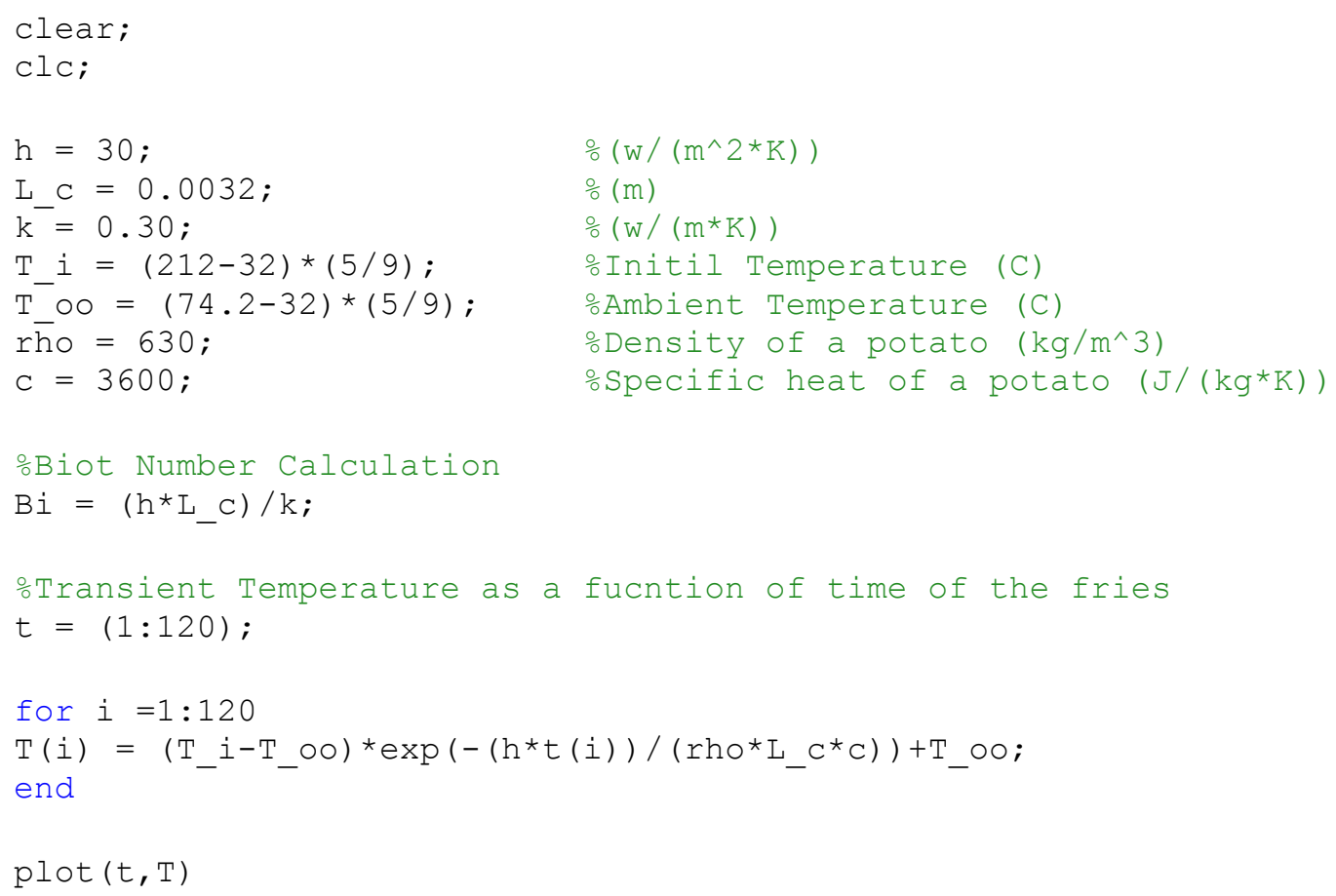


Appendix E3. Experimental Raw Data for Transient Heat Transfer

Table 49 - Experimental Temperature Profile of French Fry

\begin{tabular}{|c|c|c|}
\hline Time (sec) & Temperature (F) & Temperature ( C ) \\
\hline 0 & 212 & 100.0 \\
\hline 15 & 209 & 98.3 \\
\hline 30 & 205.2 & 96.2 \\
\hline 45 & 203.2 & 95.1 \\
\hline 60 & 199 & 92.8 \\
\hline 75 & 194.8 & 90.4 \\
\hline 90 & 190 & 87.8 \\
\hline 105 & 187 & 86.1 \\
\hline 120 & 184.6 & 84.8 \\
\hline 135 & 181 & 82.8 \\
\hline 150 & 176.6 & 80.3 \\
\hline 165 & 172.6 & 78.1 \\
\hline 180 & 170.6 & 77.0 \\
\hline 195 & 166 & 74.4 \\
\hline 210 & 162.4 & 72.4 \\
\hline 225 & 161 & 71.7 \\
\hline 240 & 158.4 & 70.2 \\
\hline
\end{tabular}

